Original Research Paper

\title{
Advanced Manufacturing for Novel Materials in Industrial Design Applications
}

\author{
${ }^{1}$ Francesco Tamburrino, ${ }^{1}$ Antonio Apicella, \\ ${ }^{1}$ Raffaella Aversa and ${ }^{2}$ Florian Ion Tiberiu Petrescu \\ ${ }^{I}$ Advanced Material Lab, Department of Architecture and Industrial Design, \\ Second University of Naples, 81031 Aversa (CE), Italy \\ ${ }^{2}$ ARoTMM-IFToMM, Bucharest Polytechnic University, Bucharest, (CE), Romania
}

\section{Article history}

Received: 12-05-2018

Revised: 19-05-2018

Accepted: 28-05-2018

Corresponding Author: Florian Ion Tiberiu Petrescu ARoTMM-IFToMM, Bucharest Polytechnic University, Bucharest, (CE), Romania Email: scipub02@gmail.com
Abstract: The research presented starts with a focus on Smart Materials, or rather materials with properties that react to external stimuli (temperature, electric or magnetic field, $\mathrm{pH}$ or mechanical stress, for example) related to the environmental changes, modifying one or some of their own properties (mechanical, electrical, appearance, etc.). Afterward, one category of Smart Materials, Shape Memory Alloys (SMAs), has been investigated with the aim to develop an industrial application. In particular, a smart and active shadow system for thermal comfort of urban or indoor environments, based on the valorization of the unique property of SMAs to change their shape depending on the temperature (SME, Shape Memory Effect). Without the need to use expensive and complex mechanical system composed of many parts to assemble and characterized by higher cost of energy required for its functioning and its manufacturing. In order to develop the system, SMAs like Nitinol (Ni-Ti) wires with a diameter of $0,75 \mathrm{~mm}$ (Austenite finish $85^{\circ} \mathrm{C}$ ) have been studied. Particularly, DSC (Differential Scanning Calorimetry) thermal analysis, aimed to investigate a characteristic range of temperature for martensitic and austenitic transformations and get data to plan more suitable and optimized procedures, conditions and parameters for heat treatments needed for Nitinol training have been carried out. In parallel, CAD models have been developed to simulate and better understand forces needed for a proper functioning of the smart shadow system, to predict its behavior, to have a support for a correct choice of SMA wires (selecting wires with a diameter suitable to produce a force high enough to produce strains), to decide wires positioning and quantity. Finally, for "as-drawn" Nitinol wires, using the data experimentally collected with DSC thermal analysis, SME training procedures have experimented. With the wires, programmed to have a two-way memory effect, using milling and additive technologies, prototypes where the wires are embedded in casted polymers (rubber silicone or polyurethane) or assembled to parts manufactured with additive technologies have been built, in order to test and enhance product functioning and manufacturability. The results obtained for the application, although the Smart Shadow System is not completely engineered and other evolutionary steps for it are possible, show that the use of SMAs gives the possibility to have an active system able to be weather responsive, ensuring a significant shape memory effect depending on the temperature. This advanced property, in fact, gives the possibility, optimizing functioning parameters (temperatures, thicknesses, geometry, structure), to have a sensitive, adaptive and smart system that can ensure the best thermal condition for any meteorological situation.

Keywords: Biomechanics, Biomaterials, Shape Memory Alloy, Biomechanically Inspired Machine 


\section{Introduction}

The research presented starts with a focus on Smart Materials, or rather materials with properties that react to external stimuli (temperature, electric or magnetic field, $\mathrm{pH}$ or mechanical stress, for example) related to the environmental changes, modifying one or some of their own properties (mechanical, electrical, appearance, etc.).

Afterward, one category of Smart Materials, SMAs (Shape Memory Alloys), has been investigated with the aim to develop an industrial application.

In particular, a smart and active shadow system for thermal comfort of urban or indoor environments, based on the valorization of the unique property of SMAs to change their shape depending on the temperature (SME, Shape Memory Effect). Without the need to use expensive and complex mechanical system composed of many parts to assemble and characterized by higher cost of energy required for its functioning and its manufacturing.

In order to develop the system, SMAs like Nitinol (Ni-Ti) wires with a diameter of $0,75 \mathrm{~mm}$ (Austenite finish $85^{\circ} \mathrm{C}$ ) have been studied. Particularly, DSC (Differential Scanning Calorimetry) thermal analysis, aimed to investigate a characteristic range of temperature for martensitic and austenitic transformations and get data to plan more suitable and optimized procedures, conditions and parameters for heat treatments needed for Nitinol training have been carried out.

In parallel, CAD models have been developed to simulate and better understand forces needed for a proper functioning of the smart shadow system, to predict its behavior, to have a support for a correct choice of SMA wires (selecting wires with a diameter suitable to produce a force high enough to produce strains), to decide wires positioning and quantity.

Finally, for "as-drawn" Nitinol wires, using the data experimentally collected with DSC thermal analysis, SME training procedures have experimented. With the wires, programmed to have a two-way memory effect, using milling and additive technologies, prototypes where the wires are embedded in casted polymers (rubber silicone or polyurethane) or assembled to parts manufactured with additive technologies have been built, in order to test and enhance product functioning and manufacturability (Pittaccio et al., 2015; Viscuso and Pittaccio, 2012; Priadko et al., 2017; Nikolaev et al., 2008; Yang et al., 2013; Yang and Wayman, 1992; Van Humbeeck, 2010; Otsuka and Ren, 1999; Otsuka et al., 1971; Velázquez and Pissaloux, 2012; Melton and Mercier, 1980; Knowles and Smith, 1981; Miyazaki et al., 1984; Lahoz and Puértolas, 2004; Matsumoto et al., 1987; Šittner et al., 2014; Duerig, 1990; Naresh et al., 2016; Ziólkowski, 2012; Shaw et al., 2008; Aversa et al., 2018; 2017a; 2017b; 2017c; 2016a; 2016b; 2016c; 2016d; 2016e; 2016f; 2016g; 2016h; 2016i; Mirsayar et al.,
2017; Petrescu et al., 2015, 2016a; 2016b; 2016c; Petrescu and Calautit, 2016a; 2016b; Kus and Breczko, 2010; Otsuka et al. 1976; Yang and Wayman, 1992; Harrison, 1975; Hanlon, 1967; Huang et al., 2003; Sofla et al., 2008; Biewener and Roberts, 2000; Kauffman and Mayo, 1993; Lindstedt, 2016; Meisel et al., 2014; Xiangyang et al., 2003).

Moreover, the experience of Smart Shadow System development suggests future outlooks for SMA use in Industrial Design applications that will be discussed further (Tamburrino, 2016).

The research discussed for the presented paper starts with a focus on Smart Materials, that is defined as advanced materials with properties that react to changes in their environment (temperature, electric or magnetic field, $\mathrm{pH}$ or mechanical stress, for example). This means that one or some of their properties (mechanical, electrical, appearance, etc.) can be changed by external stimuli related to the environmental changes. The effect of Smart Materials are often reversible and can be repeated many times. Many have been the materials studied and experimented during the research activities, some of these are Piezoelectrics, ElectroActive Polymers (EAPs), Organic Light Emitting Diode (OLED), Phase Change Materials (PCMs), Amorphous Metals and Shape Memory Alloys (SMAs). The study of SMAs, aimed to develop an industrial application, represents the main focus of the paper.

These alloys are characterized by two different temperature-dependent crystal structures (phases) called Martensite (lower temperature) and Austenite (higher temperature or parent phase) and therefore by different properties for every phase. This aspect is responsible for their most identifying characteristic: Shape Memory Effect (SME). They can exhibit two kinds of SME, defined as one-way and two-way effects. In the first case, they remember the shape associated with austenitic phase and in the second case both shape associated with austenitic phase and the shape associated with the martensitic phase. Nowadays the use of SMAs is widespread for advanced fields of application, basically aeronautics and biomedical. In the first case especially for high stability in cyclic applications and Shape Memory Effect, in the second mainly for biocompatibility (Nitinol in particular) and superelasticity. On the other hand applications of SMAs for industrial or product design is still so poorly spread and their potentialities are only rarely and weakly exploited.

The paper starts with an overview of Smart Materials in the first chapter, then there is a specific focus on SMAs, their thermal behavior by Differential Scanning Calorimetry (DSC) technique, their experimental programming for one-way and two-way effect, the development of an industrial application and final considerations on future perspectives based on materials and technologies for more customized and advanced applications. 
According to the aim to develop an industrial application, a smart and adaptive shadow system that uses the advanced properties of SMAs has been developed.

The specific goal has been to design an active system to use for thermal comfort of urban or indoor environments, able to valorize the unique property of SMAs to change their shape depending on the temperature (SME). Without the need to use expensive and complex mechanical system composed of many parts to assemble and characterized by higher cost of energy required for its functioning and manufacturing.

In particular the challenge for the application has been to develop a living and weather-responsive system, able to ensure the best thermal condition for any meteorological situation, working as a shield for the sun rays when the weather is hot, increasing its size and providing bigger shadows, not shielding the sun rays when the weather is cold, keeping its smallest size configuration.

Basically, the use of SMAs gives the possibility to have and remember preset shapes for different temperatures and obtain smart modules that don't need human input or external devices control to react to weather changes.

The method used for research presented, in order to reach the expected results has been an integrated approach, where a study of SMAs, data collected by DSC thermal analysis, SolidWorks simulations of system behavior and prototyping experience gave a concurrent contribution to application development.

It is necessary to underline that simulations tools, in particular, have been very important to virtually test the system behavior and predict the interaction between SMA and the other parts of systems.

Finally the design options developed for application are in one case a solution, where SMAs wires are embedded in a rubber that gives the possibility to the module to strain and bend according to the programmed shapes of SMA used and in another case a solution wherein one part there is a hinge joint and a lever system that is assembled to SMA wires that changing their shapes allow to the Smart Shadow System to take opened and closed configurations, shielding or not shielding sun rays (depending on wheater conditions).

\section{Materials and Methods. Smart Materials}

Material technology over the years had a great impact on the evolution of human civilization, characterizing and giving the name to different historical periods with terms as Stone Age, Bronze Age and Iron Age.

Nowadays in response to the growing need to have intelligent, adaptive and active products or systems with advanced performances of functionality, sustainability and market, we can argue that our century is the "Smart Materials Age".

Smart Materials can be defined as advanced materials with properties that react to changes in their environment (temperature, electric or magnetic field, $\mathrm{pH}$ or mechanical stress, for example). This means that one of their properties (mechanical, electrical, appearance, etc.) can be changed by external stimuli related to the environmental changes. The effect of Smart Materials are often reversible and can be repeated many times.

There is a wide range of Smart Materials. Among the main categories there are Piezoelectric materials, that are Smart Materials able to produce a voltage when a stress is applied or to produce a deformation when a voltage is applied, for this characteristic they are used as sensors or actuators; Shape Memory Alloys, that are characterized by Shape Memory Effect and pseudoelasticity, they can "remember" different shapes for different temperatures, Magnetostrictive materials, that exhibit change in shape under the influence of magnetic field; temperatureresponsive materials, that undergo under change upon temperature; Halochromic materials that change their color upon acidity changes; Photomechanical materials, that change shape under exposure to light (Fig. 1).

During the Ph.D., research activities on some categories of Smart Materials and in some cases of Advanced Materials have been developed. In particular, the materials studied and experienced have been Piezoelectrics, ElectroActive Polymers (EAPs), Organic Light Emitting Diode (OLED), Phase Change Materials (PCMs), Amorphous Metals and Shape Memory Alloys (SMAs).

Piezoelectrics, in more detail, are materials able to produce an electrical current when a pressure or stress is applied. For these materials, the crystal raster is not symmetrically structured, but it is electronically neutral. When a force is applied, the crystals move slightly towards and from each other, causing the electrical stability to change, thereby generating electrical current. This process is reversible when a voltage is applied to the material, crystals bend towards each other, the material deforms (Fig. 2).

Piezoelectric materials can be natural or man-made. The most common natural piezoelectric material is quartz, but non-natural piezoelectric materials are more efficient and mostly ceramics. Due to their complex crystalline structure, the process with which they are made is very precise and follows very specific steps. Fine powders of the component metal oxides are mixed in specific proportions, then heated to form a uniform powder. The piezo powder is mixed with an organic binder and is formed into structural elements having the desired shape (discs, rods, plates, etc.). The obtained shape is fired according to specific conditions of time and temperature, during this process the piezo powder particles sinter and the material attains a dense crystalline structure. The part is cooled, then shaped or trimmed. Finally, in order to polarize the material, it is exposed to a strong and direct current electric field aimed to align all dipoles in the material (Fig. 3). 


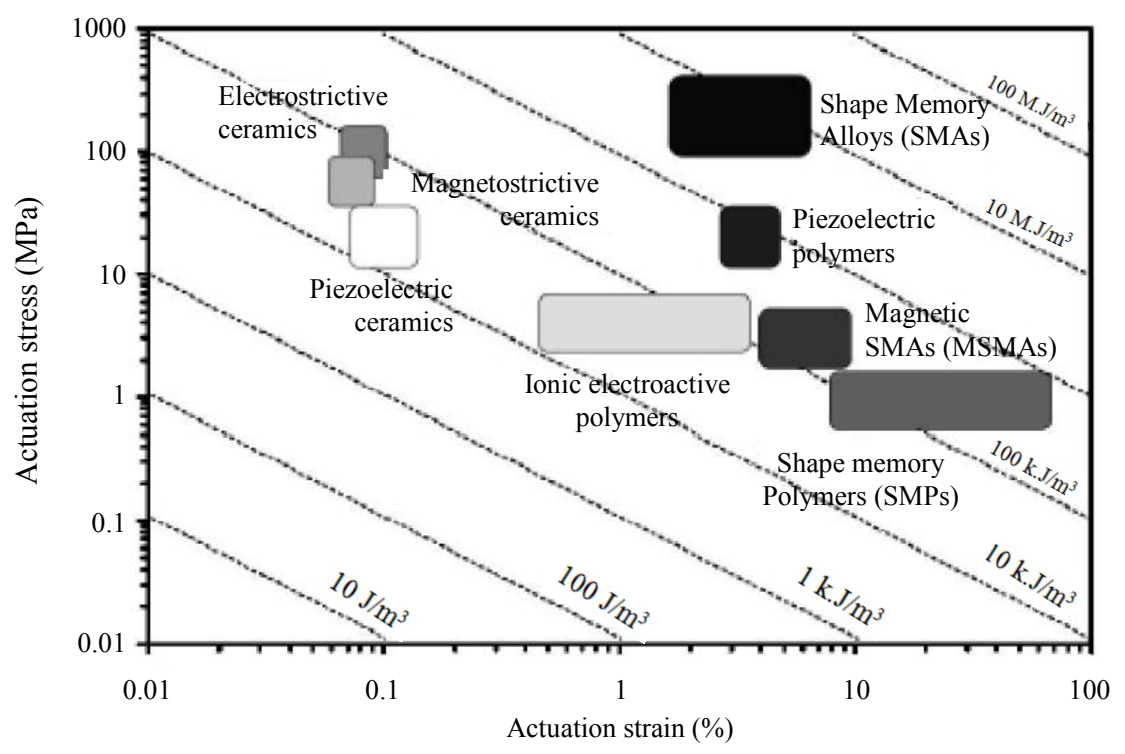

Fig. 1: Actuation energy density diagram for different Smart Materials

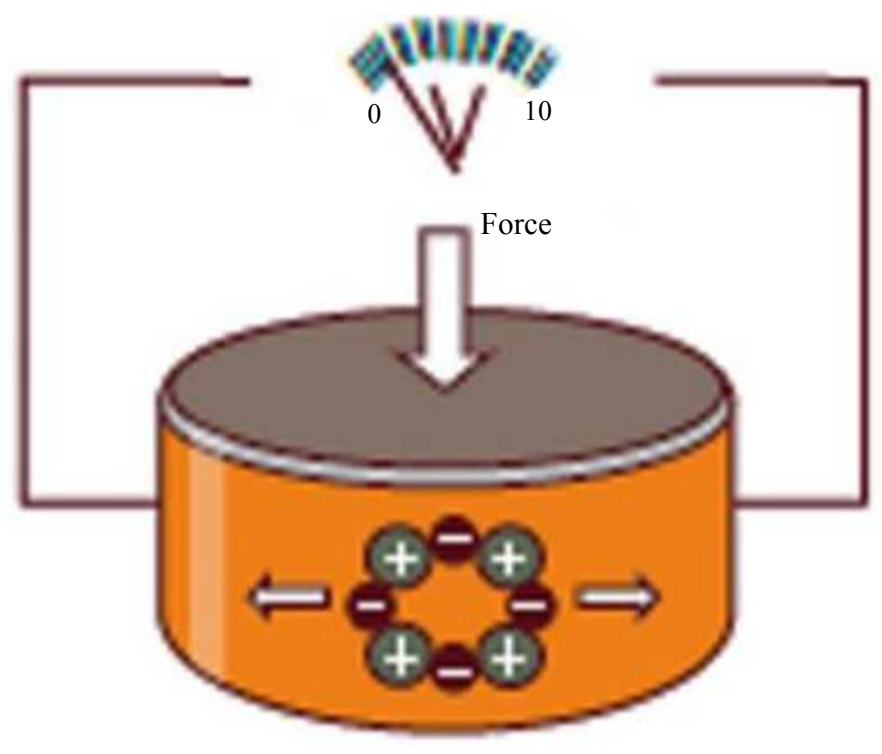

Fig. 2: Piezoelectric working principle

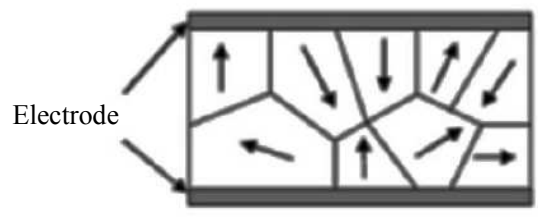

Random dipole

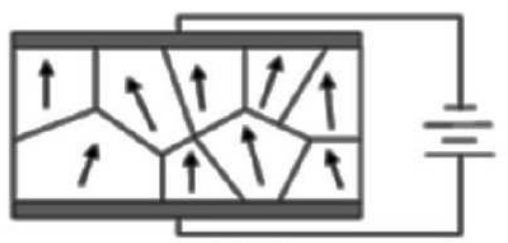

Polarization

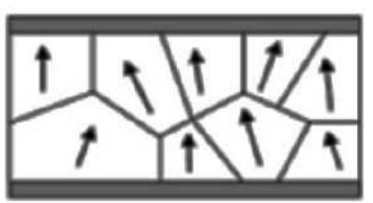

Surviving polarity

Fig. 3: Polarization of ceramic materials to generate Piezoelectric Effect

The main applications field for Piezoelectric are:

- Automotive
- Computers

- Consumer goods

- Medical 


\section{- Military}

They are used in automotive for airbag sensors, airflow sensors, audible alarms, fuel atomiser, keyless door entry, seat belts buzzers, knock sensors; in computer applications for disc drives, inkjet printers; in consumer goods for cigarettes lighters, depth finders, fish finders, humidifiers, jewelry cleaners, musical instruments, speakers, telephones; in medical applications for disposable patient monitors, foetal heart monitors, ultrasonic imaging; in military for depth sounders, guidance system, hydrophones, sonar.

EAPs, instead, are materials able to change shape when an electric field is applied. The effect is similar to Piezoelectric but fundamentally different. EAPs are quite wide and many different types exist. Fundamentally there are two types of EAPs, electronic and ionic. Coulomb forces drive the electronic EAP, which include dielectric, electrostrictive, electrostatic, piezoelectric and ferroelectric.

This type of EAP materials can be made to hold the induced displacement while activated under a DC voltage, allowing them to be considered for robotic applications, for example.

The most common type of electronic EAP is made up of a film of an elastomer dielectric material that is coated on both sides with another expandable film of a conducting electrode. When a voltage is applied to the two electrodes a pressure is created upon the dielectric layer. The elastic dielectric polymer acts as an incompressible fluid which means that as the electrode pressure causes the dielectric film to become thinner, it expands in the planar directions. The electrical force is converted to mechanical actuation and motion. These EAP materials have a greater mechanical energy density and they can be operated in air with no major constraints. However, the electronic EAP require a high activation field $(>100-\mathrm{V} / \mu \mathrm{m})$.

In contrast to the electronic EAP, ionic EAPs are materials that involve mobility of ions and they consist of two electrodes and electrolyte. Electrostatic forces and mobile cations are responsible for the bending. The activation of the ionic EAP can be made by as low as 1-2 Volts to induce a bending displacement. Examples of ionic EAP include gels, polymer-metal composites, conductive polymers and carbon nanotubes. Their disadvantages are the need to maintain wetness and there are also difficulties to sustain constant displacement under activation of a DC voltage (except for conductive polymers), (Fig. 4).

The main field of EAPs are:

- Mechanisms

- Robotics, toys and animatronics

- Human-machine interfaces

- Medical applications

- Liquid and gases flow control (Fig. 5)

- Control weaving

- Micro electro mechanical system (mems)

- Polymer sensor and transducers

OLEDs (Fig. 6-7) are another class of materials that could be defined as "smart composites" more than "smart materials", since they are constructed by mixing different layers of materials together. A typical OLED consists of two organic layers (electron and hole transport layers), embedded between two electrodes. The top electrode is usually a metallic mirror with high reflectivity and the bottom electrode a transparent ITO layer on top of the glass substrate. When a voltage is applied to the electrodes the charges start moving in the device under the influence of the electric field.

\section{DIELCTRIC EAP}
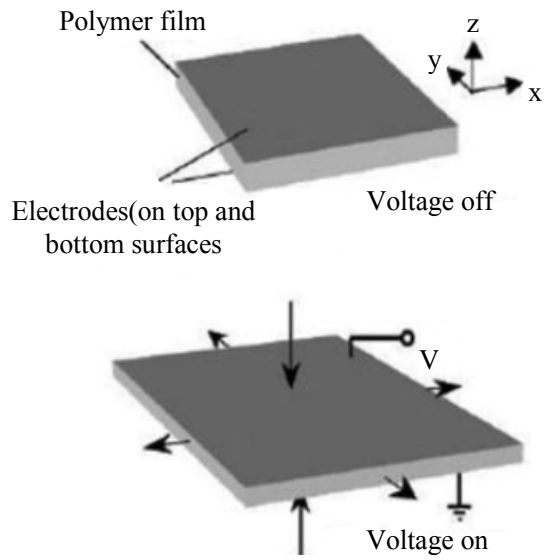

IONIC EAP

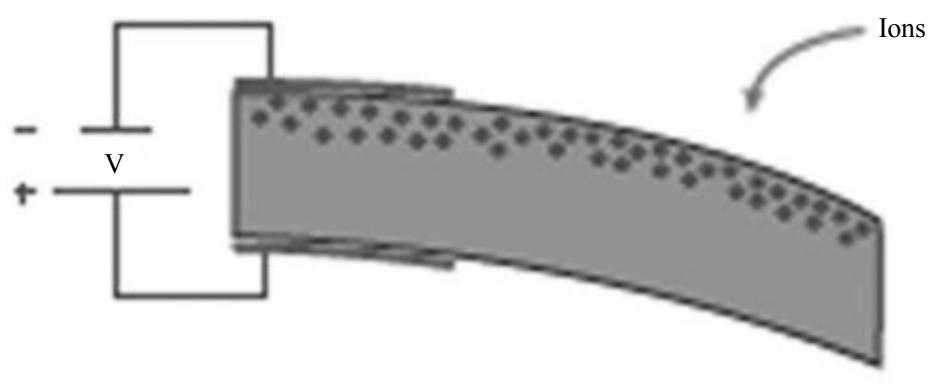

Fig. 4: Dielectric and Ionic EAP working principles 


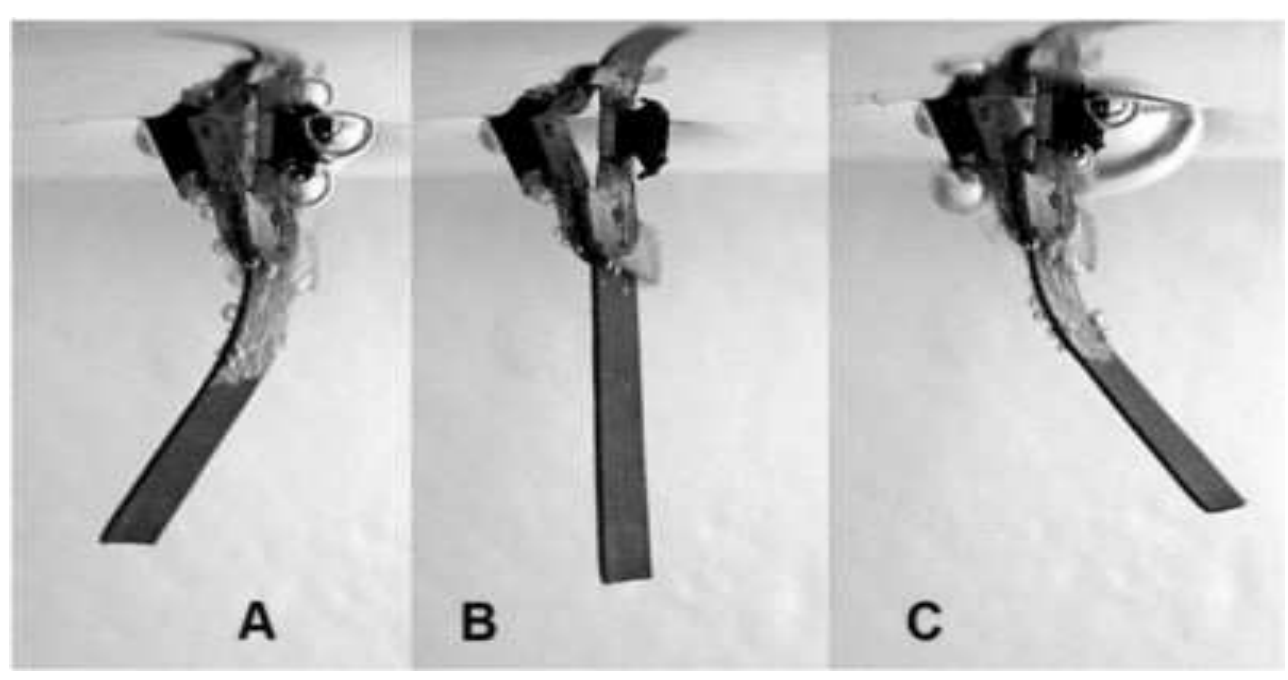

Fig. 5: Ionic EAP working in water
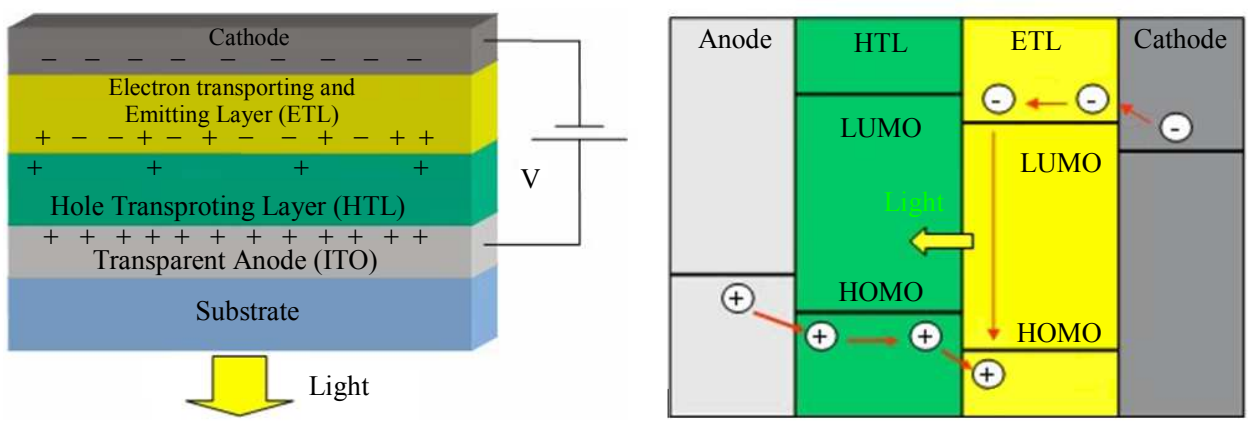

Fig. 6: Typical OLED construction, charge transport and light generation

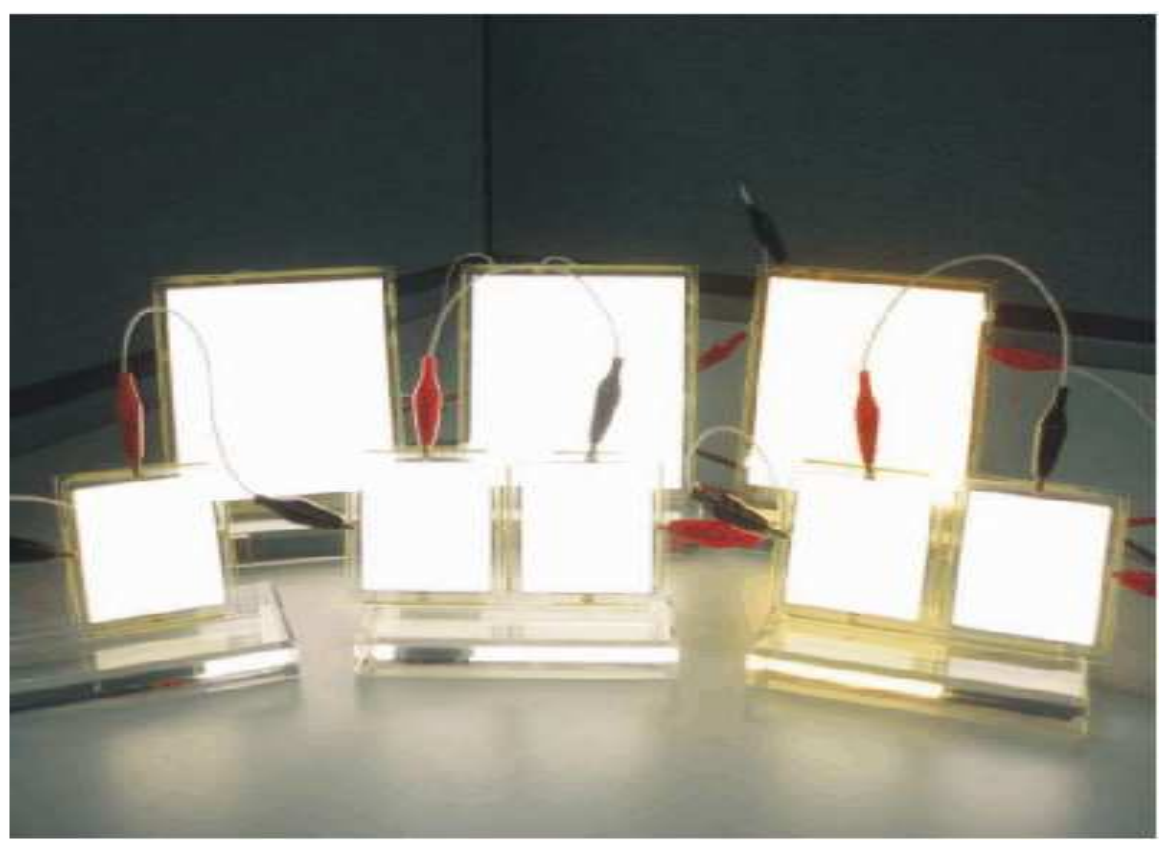

Fig. 7: OLED lighting panels. (Courtesy of LG Chem) 
Electrons leave the cathode and holes move from the anode in opposite direction. The recombination of this charges leads to the creation of a photon with a frequency given by the energy gap $(E=h v)$ between the LUMO and HOMO levels of the emitting molecules. Therefore, the electrical power applied to the electrodes is transformed into light. In order to observe light emission, a minimum voltage needs to be applied and this is called as the turn- ON voltage of the OLED. This voltage needs to be large enough for the electrons and holes transport layers to overcome the barriers to LUMO and HUMO energy levels.

OLED's the thickness of every layer is in the order of the wavelength of the generated light, providing an angular distribution very different from isotropic. Interference effects like Wide-Angle or Multiple Beam interferences are presents in the actual OLED. Therefore, the thickness of every layer and the location of the emitter play an important role on the angular distribution of the generated photons.

OLED devices are used for general lighting as well as for displays, backlight sources in LCD displays, signaling (emergency lighting, traffic signals) or automotive applications (dashboard). In particular, their use gives the following advantages:

- Large area sources

- High brightness and wide viewing angle

- Thin, flat and lightweight

- Low voltage and fast switching technology

- Form freedom and tunable emission

- Flexible displays

- Low-cost production

Phase Change Materials (PCMs), instead, are substances that absorb and release thermal energy during the process of melting and solidifying. When the material solidifies, it releases a large amount of energy in the form of latent heat at a relatively constant temperature. Conversely, when such material melts, it absorbs a large amount of heat from the environment. In particular, PCMs have a significant capability to store or release energy as latent heat and therefore a high storage or release density in a relatively small volume. In fact, because the amount of latent heat absorbed or released is much larger than the sensible heat, applications of PCMs, aimed to reduce energy consumption in buildings, are widespread. Anyhow, because each PCM has its own phase change temperature, which is the temperature at which latent heat is absorbed or released, it is important to choose the most suitable kind of PCM for the different applications.
The main fields of application for PCMs are where a temperature control is needed and they are:

- Air condition

- Shelter devices

- Food, chemical and pharmaceutical transportation

- Automotive

- House heating

- Catering

- Construction materials

One example of PCMs use is a latent heat battery by BMW (optional equipment in BMW 5 series)where the storage material is connected to the radiator and stores excess heat when the motor runs at operating temperature. This heat is then available at the next cold start to heat up the motor quickly and for the interior comfort. Due to the latent heat battery's insulation, it can maintain the energy for 2 days at an outside temperature of $-20^{\circ} \mathrm{C}$.

Many other examples of application for PCMs are common for food and beverage storage, for electronic devices in order to avoid overheating and for house applications, where not very thick walls are available and an alternative way to have a good thermal comfort is got using PCMs (Fig. 8).

Amorphous Metals belong to advanced materials category, that can be defined as all materials that exhibit completely novel properties or that have properties superior to conventional materials, in term of toughness, hardness, durability, elasticity, corrosion resistance, for example.

They are metal alloys characterized by an amorphous atomic structure. In contrast to traditional metals, where there is a crystalline arrangement for the atoms. This unique characteristic gives to amorphous metals advanced properties.

The atomic arrangement of amorphous metals is strategically designed to give the metal its advanced properties (Fig. 9). Strength and almost nonexistent solidification shrinkage are two of many advantageous properties of amorphous metals. Others benefits include:

- High Hardness

- Superior Strength/Weight Ratio

- Superior Elastic Limit

- High Corrosion Resistance

- High Wear-Resistance

- Unique Acoustical Properties

- High Yield Strength

All the above-mentioned properties can be achieved, basically, because there are no grains or slip planes to cause regional weaknesses. 


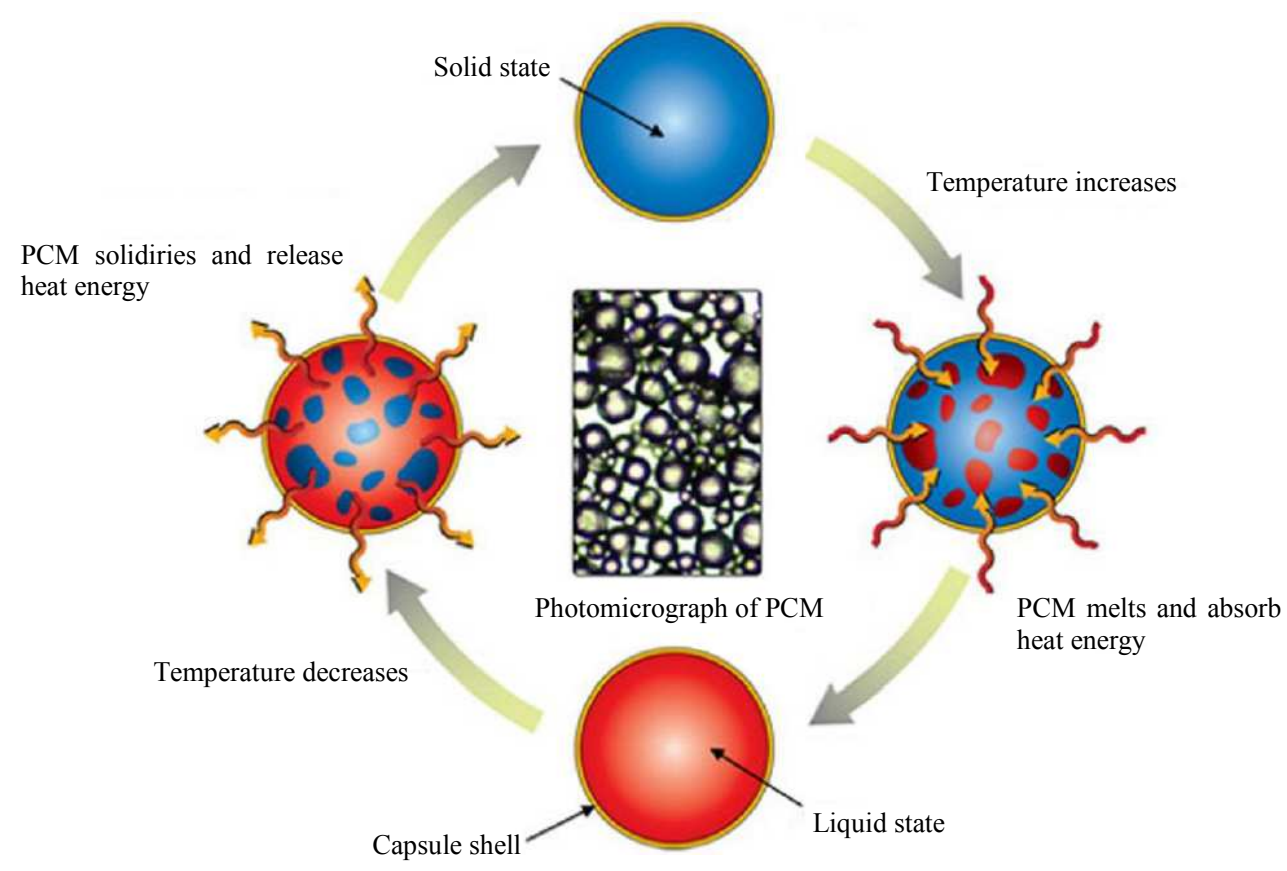

Fig. 8: PCMs working principle
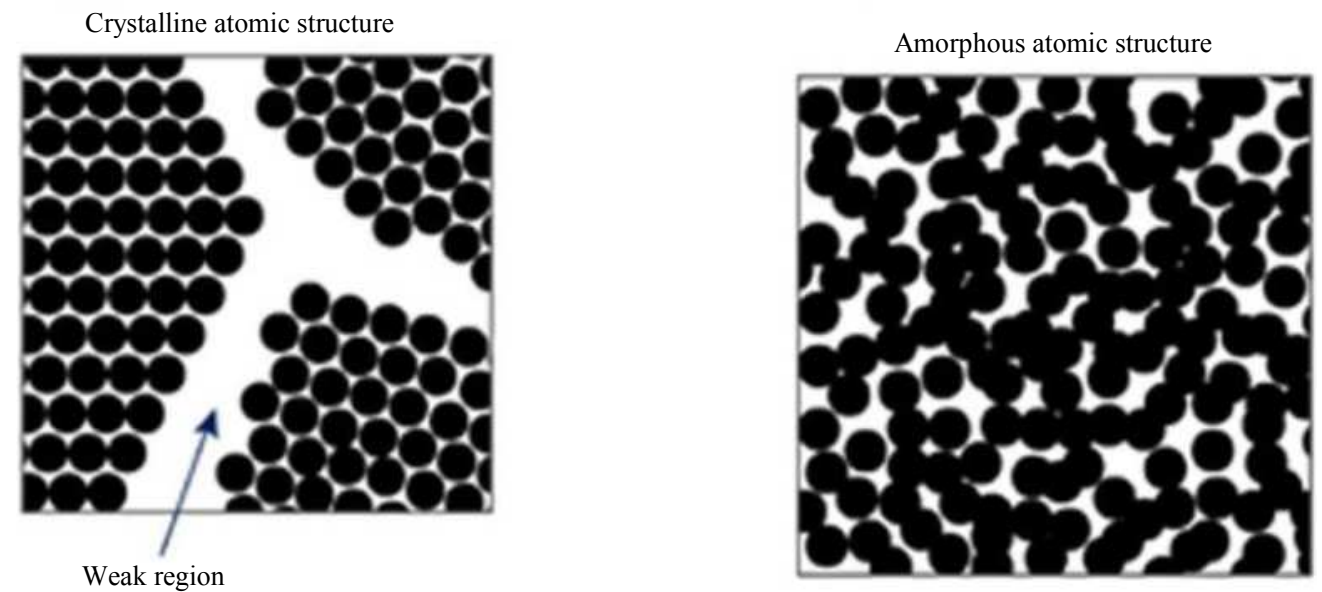

Fig. 9: Crystalline atomic structure of conventional metals and amorphous atomic structure of Amorphous Metals

\section{Results}

Low solidification shrinkage, when an injection molding manufacturing process is used, gives the possibility to produce precision parts within very close tolerances directly from a mold.

Shrinkage rate for some amorphous metals is around $0.4 \%$. When compared to conventional Metal Injection Molding (MIM) processes, the MIM sintering step typically shrinks for a value of around $15-20 \%$, which can cause warping and requires secondary machining to meet precision tolerances.

In addition to low solidification rate, amorphous metals have a surface roughness of fewer than $0.05 \mu \mathrm{m}$.
This is a significant benefit compared with other processes that require post-processing to meet a good quality surface, while MIM components, instead, typically have surface roughness values included between 0.8-1.6 $\mu \mathrm{m}$. This characteristic gives the possibility to obtain very fine details and create textures or highly polished surfaces to be imparted in a single step during high rate production.

Amorphous metal alloys are stronger than highstrength titanium, with yield strength of $1524 \mathrm{MPa}$, since titanium has yield strength of $830 \mathrm{Mpa}$. Like most amorphous materials, the yield strength of liquid metal alloys are nearly identical to its ultimate tensile strength, meaning that when the material is stressed to its yield 
limit, rather than plastically deforming, it will break and is therefore technically considered brittle (in contrast with traditional metals mechanical behavior), even though it is highly elastic.

The yield strength is more remarkable when compared with other metal molding or casting processes. The ultimate tensile strength of die-cast materials like zinc, aluminum and magnesium does not exceed, for example, $425 \mathrm{Mpa}$.

Some amorphous metals can undergo $1.8 \%$ of elongation before reaching its yield point. This depends on the material's Elastic Modulus, which is $93 \mathrm{GPa}$ and its unique amorphous atomic structure, in fact, other high strength materials tend to be much stiffer, reflecting their higher modulus of elasticity. Amorphous metals, in general, have some characteristics similar to or higher than traditional metals and other (like elasticity, solidification shrinkage) close to polymers (Fig. 10).

Amorphous metals also have a very high hardness, which can prove beneficial for parts that require a durable scratch and wear resistant surface. The hardness value (around 563 Vickers) is significantly harder than conventional metal alloys. Die-cast alloys have hardness roughly between 130 Vickers and 340 Vickers maximum.

In addition to the chemical composition, one of the reasons that give to Amorphous Metal its unique atomic structure is the cooling ratio. The material is cooled quickly enough, the alloy solidifies in an amorphous state, precluding crystallization. The high quality of alloy depends on a precise balance of constituent elements with very low levels of impurities. Impurities such as oxygen, nitrogen, hydrogen and carbon can act as initiation sites for crystallization during cooling and can result in inferior crystalline parts. When the composition varies too far from specifications, crystallization can occur much more quickly, compromising the characteristic properties of the alloy.

Nowadays the main fields of application for Amorphous Metals are military, sporting goods, medical, sporting arms, automotive and optics.

For military the Amorphous metals are used especially for parts where a high control and quality of surfaces is needed. The amorphous metal and its processability give the possibility to match or exceed the necessary precision and cut the cost with a one-step molding process.

For sporting goods field Amorphous Metals are used, for example, for innovative golf clubs with the characteristic (because of high elasticity) to transfer all the energy that a golf player uses to hit the ball.

For sporting arms to produce hard, strong, corrosion resistant, elastic parts with high precision and mirror-like surface roughness.

For medical to produce, for example, miniature clamps manufactured with the capability to apply forces that do not decrease over time, despite numerous cycles.

In the automotive field they are used because of lightweight, high strength to weight ratio, durability, dimensional precision, superior corrosion resistance and unique shape forming ability.

In optics, Amorphous Metal mirrors are able to deliver optical surfaces without distortion or reflective interference from crystalline grains. These mirrors have also the capability to be subsequently hot-formed into more complex shapes and surfaces (Fig. 11).

SMAs, instead, have been the main subject of study and they will be discussed further.

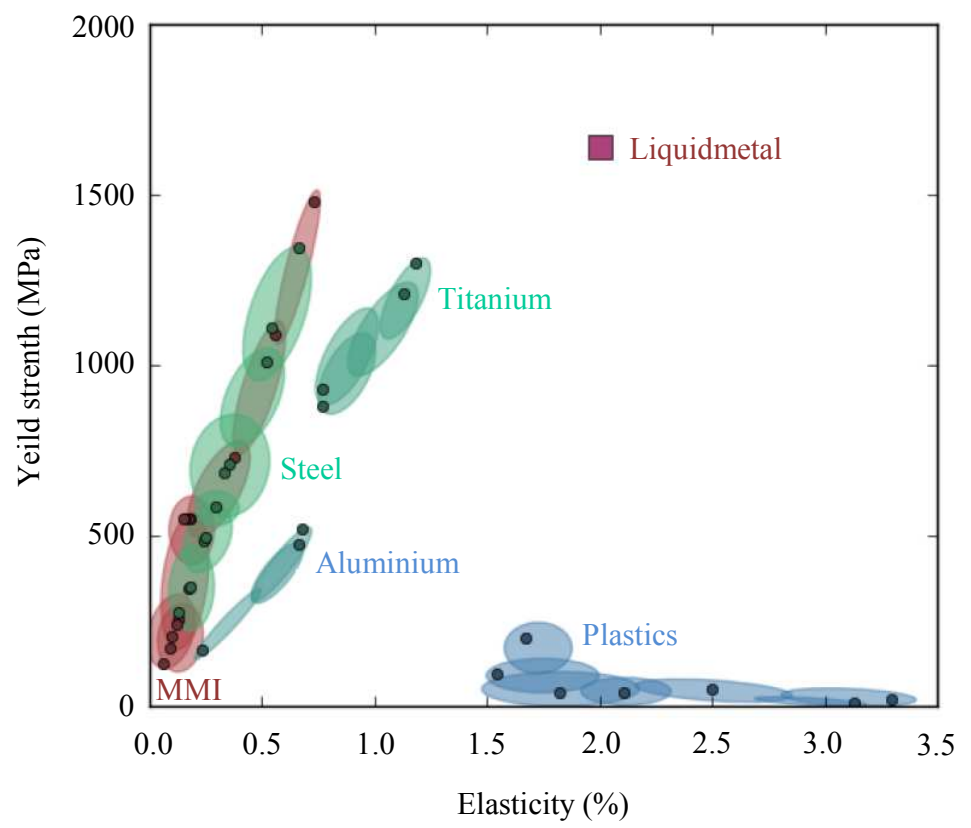

Fig. 10: Strength and elasticity values for common materials and Amorphous Metals 


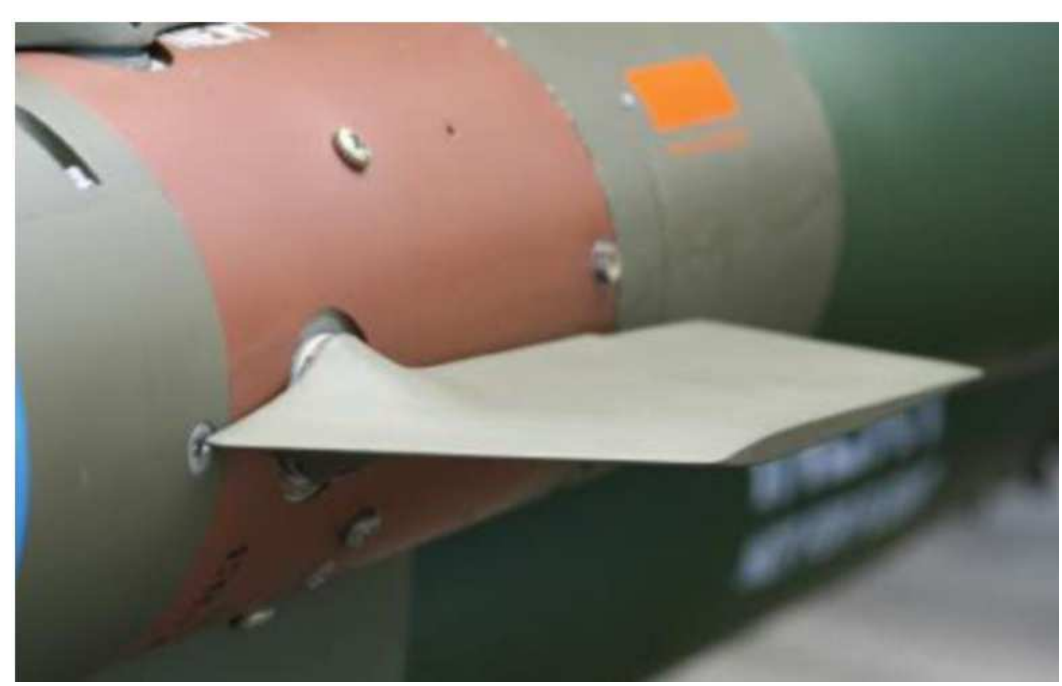

Fig. 11: Amorphous Metals are widespread in applications where high precision parts/surfaces and volume production are requested. Example of application in Military sector

\section{SMAs, Shape Memory Alloys}

Shape Memory Effect was discovered for the first time during the 1960 s at U.S. Naval Ordnance Laboratory. The researcher of the Laboratory found this effect in an equiatomic alloy of Nickel and Titanium, this alloy because of the discovery was named Nitinol (Nickel-Titanium Naval Ordance Laboratory).

Before of this moment, there were some significant steps towards the discovery of Shape Memory Alloys (SMAs), like the discovery of pseudoelastic behavior for $\mathrm{Au}-\mathrm{Cd}$ alloy in 1932 and formation and disappearance of martensitic phase observed by decreasing and increasing the temperature for a $\mathrm{Cu}-\mathrm{Zn}$ alloy.

In term of applications for these advanced metal alloys, over the years, we find in the 1970s first reported medical applications, in 1980s first experimental orthodontic and orthopedic applications, 1990s first commercial spread of stent applications, in 2000s and nowadays, instead, we have also the use of SMAs for actuators, couplings, surgical instruments and, in general, a higher spread for biomedical field. On the other hand applications of SMAs for industrial or product design are still so poorly spread and SMAs potentialities are only rarely and weakly exploited (Fig. 12).

SMAs are characterized by two different temperature-dependent crystal structures (phases) called Martensite (lower temperature) and Austenite(higher temperature or parent phase) and therefore by different properties for every phase.

Martensite phase has an Face Centered Cubic (FCC) crystal structure and Austenite, instead, has a BCC (Body-Centered Cubic) crystal structure.

Where there is the reversible transition between the two temperature-dependent phases of the SMAs, obviously change their properties, but plastic strains do not occur, the material is always inside the elastic range of deformations (Fig. 13).

The four characteristic temperatures of SMAs are Martensite finish (Mf), Martensite start (Ms), Austenite start (As), Austenite finish (Af). When SMA is heated, it starts to change into Austenite phase and completes the transition at Af temperature; similarly when it iscooled, it starts the transformation to Martensite at Ms temperature and completes the transition at Mf temperature.

Martensitic crystal can have different orientation direction, called variants. There are two ways for these variants to assemble: Twinned martensite (Mt) and detwinned martensite (Md). Mt is characterized by a combination of self-accommodated variants (macroscopic shape change is negligible), Md, instead, is characterized by a dominant specific variant (process results in a macroscopic shape change, where a strained configuration is kept when the load is released). When for SMAs occur martensitic transformations there is a shear without a volume change. Likewise, we have characteristic transition temperatures between Martensite and Austenite phases, there are also specific load levels for the transition between twinned and detwinned Martensite, called " $\sigma s "$ (detwinning start stress) and " $\sigma \mathrm{f}$ " (detwinning finish stress), (Fig. 14).

Moreover, in addition to thermally induced phase transformation, transitions can be generated by applying a sufficiently high mechanical load to the SMA in the austenitic phase, in this way a transition from Austenite to fully detwinned Martensite occurs. If the temperature is above Af, a complete shape recovery to Austenite is observed upon unloading. This SMA characteristic is known as a pseudoelastic effect. 


\section{SMAs Thermoelastic Transformations}

The martensitic transformation from Austenite to Martensite and its reverse transformation are the result of the need of crystal lattice structure to accommodate to the minimum energy state for a given temperature, in particular, lattice transformations involve a shearing deformation that results from cooperative atomic movements (Fig. 15).
The transformations are highly ordered and the displacement of individual atoms can be predicted. Basically, they are caused by the difference in free energy between Martensite phase and Austenite phase. Consequently, in order to induce the Austenite to Martensite transformation and vice versa, the chemical free energy must be lower for the final state (Austenite to Martensite, free energy lower for Martensite. Martensite to Austenite, free energy lower for Austenite).

\begin{tabular}{|c|c|c|c|}
\hline Alloy & Composition & $\begin{array}{c}\text { Range of transformation } \\
\text { temperatures } \\
\left(A_{s}\right)^{\circ} \mathrm{C}\end{array}$ & $\begin{array}{c}\text { Transformation } \\
\text { hysteresis, }{ }^{\circ} \mathrm{C}\end{array}$ \\
\hline$\overline{\mathrm{AgCd}}$ & $44 \sim 49$ at $\% \mathrm{Cd}$ & $.190 \sim 50$ & $\sim 15$ \\
\hline $\mathrm{AuCd}$ & $46.5 \sim 50$ at $\% \mathrm{Cd}$ & $30 \sim 100$ & $\sim 15$ \\
\hline CuAlNi & $\begin{array}{l}14 \sim 14.5 \text { wt \%Al } \\
3 \sim 4.5 \text { wt } \% \mathrm{Ni}\end{array}$ & $-140 \sim 100$ & $\sim 35$ \\
\hline $\mathrm{CuSn}$ & $\sim 15$ at $\% \mathrm{X}$ & $.120 \sim 30$ & \\
\hline $\mathrm{CuZn}$ & $38.5 \sim 41.5$ wt $\% \mathrm{Zn}$ & $-180 \sim 10$ & $\sim 10$ \\
\hline $\begin{array}{l}\mathrm{CuZn} X \\
(\mathrm{X}=\mathrm{Si}, \mathrm{Sn}, \mathrm{Al})\end{array}$ & small wt \% X & $-180 \sim 200$ & $\sim 10$ \\
\hline InTI & $18 \sim 23$ at \% Tl & $60 \sim 100$ & $\sim 4$ \\
\hline $\mathrm{NiAl}$ & $36 \sim 38$ at \% Al & $-180 \sim 100$ & $\sim 10$ \\
\hline TiNi & $46.2 \sim 51$ at $\% \mathrm{Ti}$ & $-50 \sim 110$ & $\sim 30$ \\
\hline $\begin{array}{l}\text { TiNi X } \\
(\mathrm{X}=\mathrm{Pd}, \mathrm{Pt})\end{array}$ & $\begin{array}{l}50 \text { at } \% \mathrm{Ni}+\mathrm{X} \\
5 \sim 50 \text { at } \% \mathrm{X}\end{array}$ & $-200 \sim 700$ & $\sim 100$ \\
\hline $\mathrm{TiNiCu}$ & $\sim 15$ at $\% \mathrm{Cu}$ & $-150 \sim 100$ & $\sim 50$ \\
\hline TiNiNb & $\sim 15$ at $\% \mathrm{Nb}$ & $-200 \sim 50$ & $\sim 125$ \\
\hline TiNiAu & 50 at $\% \mathrm{Ni}+\mathrm{Au}$ & $20 \sim 610$ & \\
\hline $\begin{array}{l}\text { TiPd X } \\
(\mathrm{X}=\mathrm{Cr}, \mathrm{Fe})\end{array}$ & $\begin{array}{c}50 \text { at \% } \mathrm{Pd}+\mathrm{X} \\
\sim 15 \text { at } \% \mathrm{X}\end{array}$ & $0 \sim 600$ & $\sim 50$ \\
\hline $\mathrm{MnCu}$ & $5 \sim 35$ at \% Cu & $-250 \sim 180$ & $\sim 25$ \\
\hline FeMnSi & 32 wt\%Mn, 6wt\%Si & $-200 \sim 150$ & $\sim 100$ \\
\hline $\mathrm{FePt}$ & $\sim 25$ at $\% \mathrm{Pt}$ & $\sim 130$ & $\sim 4$ \\
\hline $\mathrm{FePd}$ & $\sim 30$ at $\% \mathrm{Pd}$ & $\sim 50$ & \\
\hline $\begin{array}{l}\text { FeNi X } \\
(\mathrm{X}=\mathrm{C}, \mathrm{Co}, \mathrm{Cr})\end{array}$ & small wt\% X & & \\
\hline
\end{tabular}

Fig. 12: Main kinds of SMAs

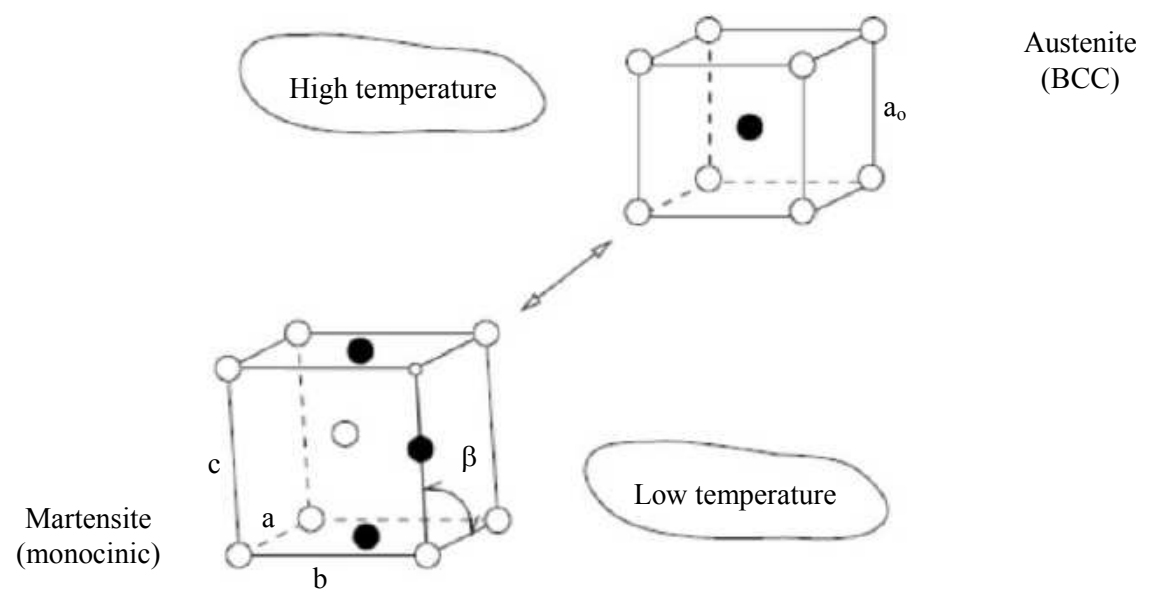

Fig. 13: Phase transformations in SMAs 


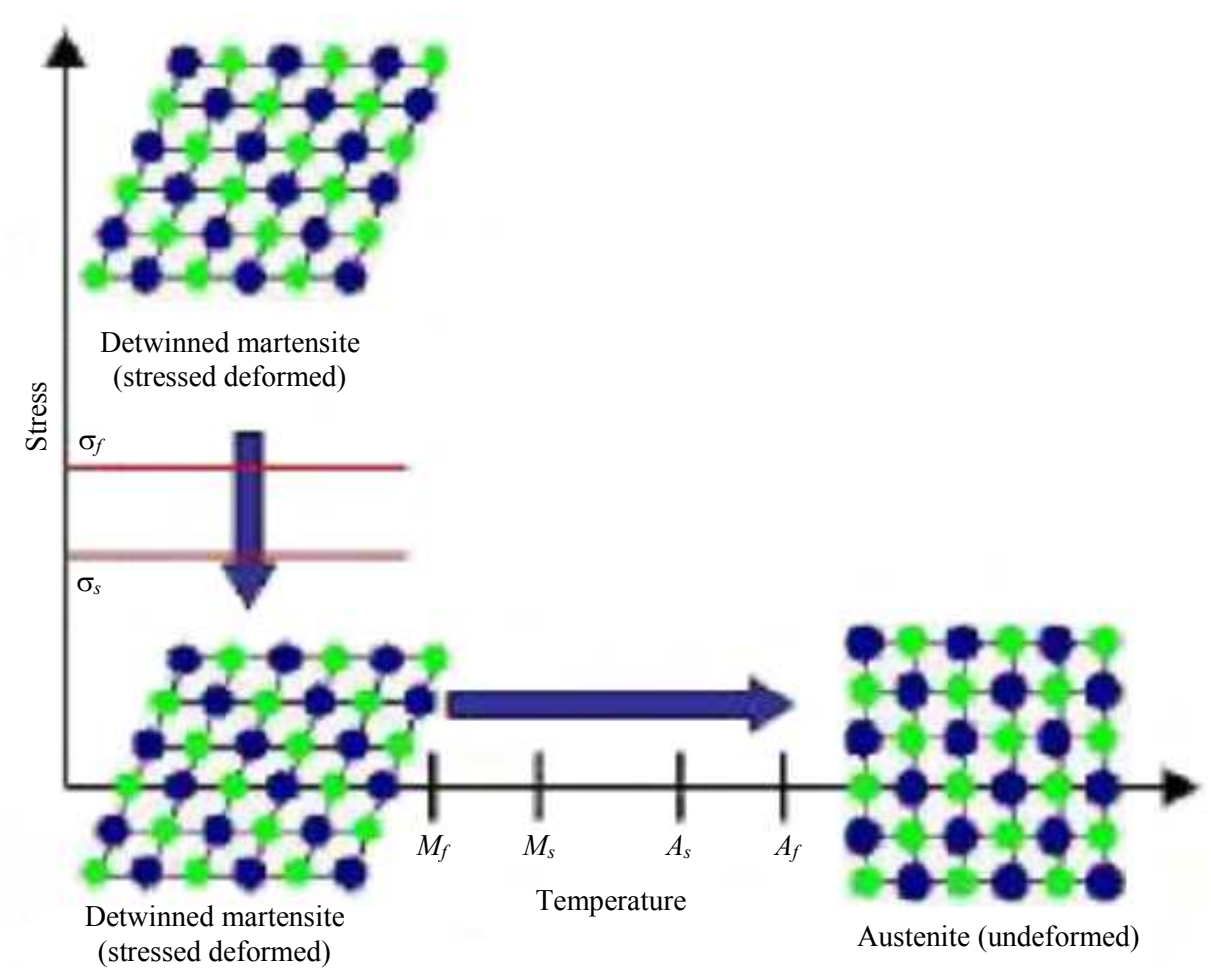

Fig. 14: Thermo-mechanical behavior of SMAs

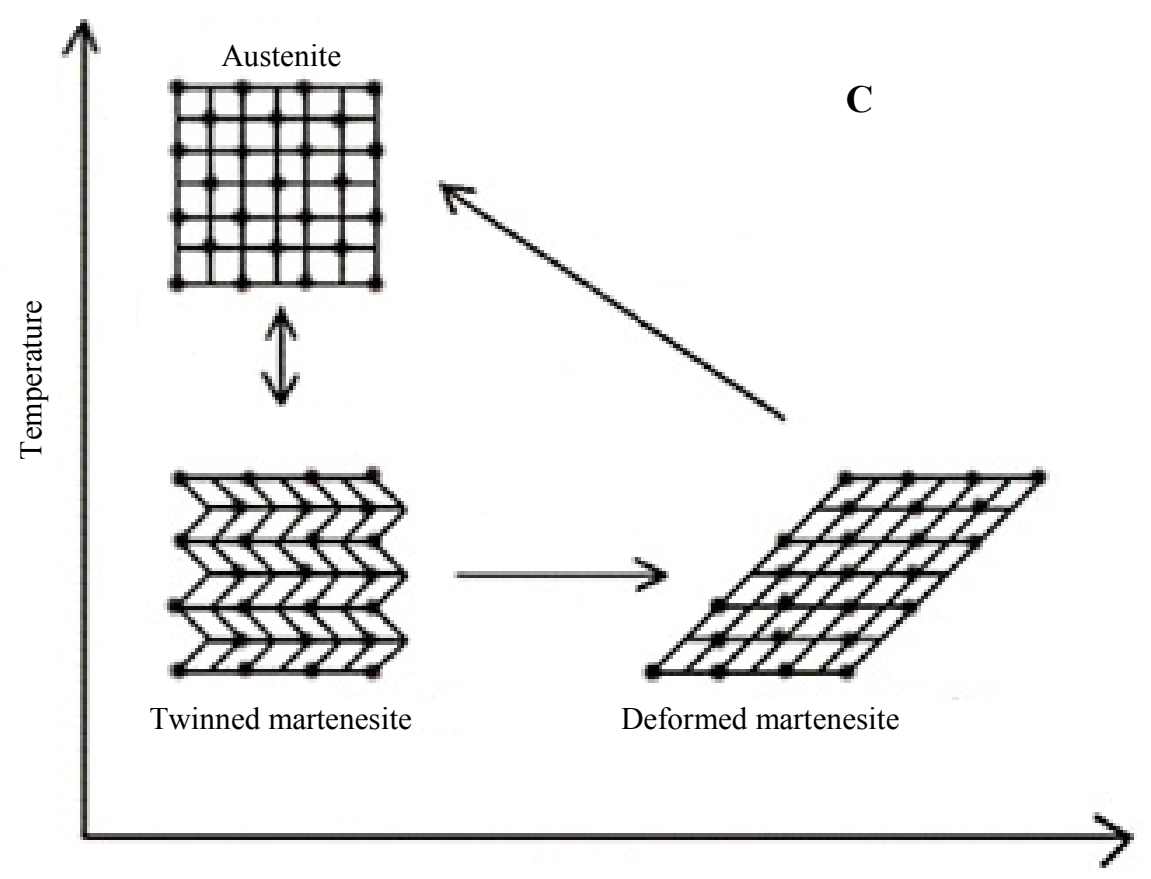

Fig. 15: Austenite-Martensite transformations and Shape Memory Effect

A distinguishing characteristic for SMAs is the hysteresis, that is defined as the difference between the temperatures at which the material is $50 \%$ transformed to Austenite upon heating and $50 \%$ to
Martensite upon cooling, therefore hysteresis represents the difference of temperatures between middle point included between $\mathrm{Mf}$ and Ms and middle point included between As and Af (Fig. 16). 


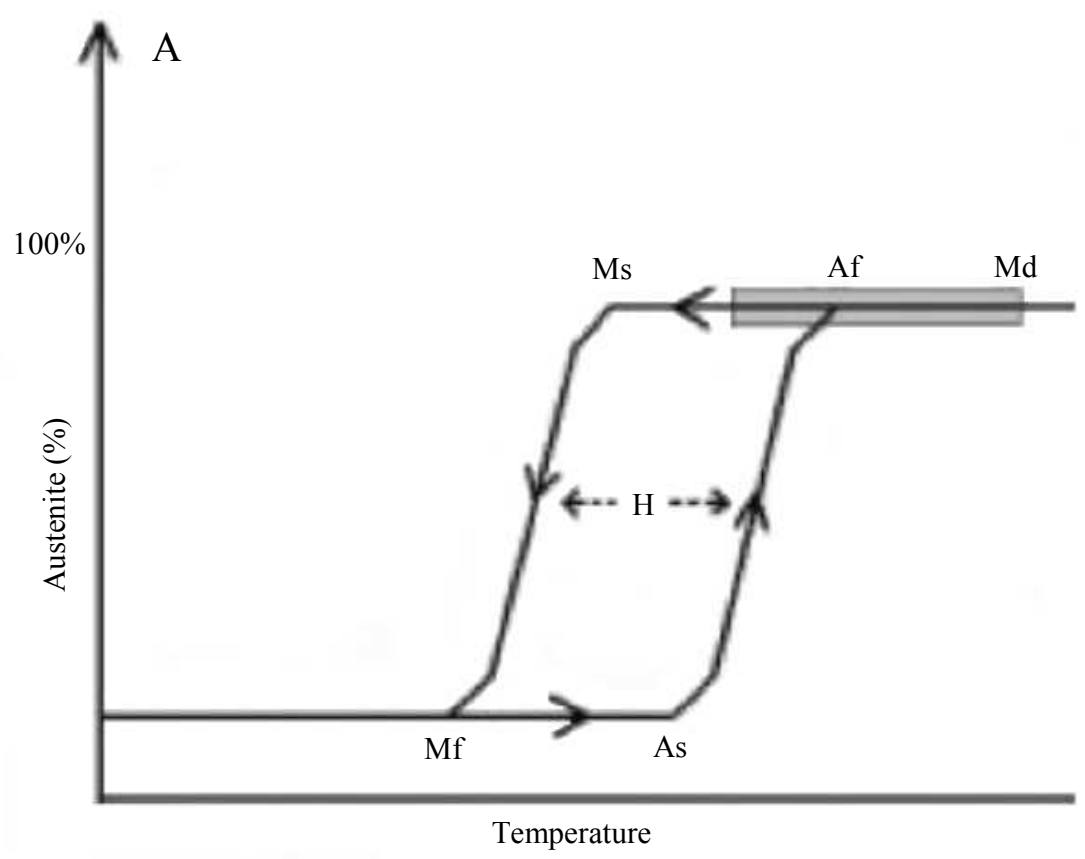

Fig. 16: Phase transition and Hysteresis in SMAs

The thermoelastic transformations can be induced by a temperature change, but also applying a mechanical stress, in both cases, there is a change for the free energy of the material. The volume change related to the above-described transformations is very small $(0,34 \%$ for Ni-Ti from Austenite to Martensite, for example). For martensitic phase we can have up 24 variants for a grain, that are self-accommodated int twinning groups (no macroscopic shape change) or specific dominant variants induced by external stress (with macroscopic shape change).

\section{Shape Memory Effect}

The most identifying characteristic of SMAs, as deductible by the name, is the Shape Memory Effect. The SMAs can exhibit two kinds of Shape Memory Effect, defined as oneway and two-way effects.

For one-way effect, we mean the SMAs ability to remember and resume the macroscopic shape associated with austenitic phase when heated up to Af temperature; for two-way the effect, instead, we mean the first ability described added to the capability to recover also the macroscopic shape associated with martensitic phase when cooled up to Mf temperature.

To get one or two-way memory effect, in order to program preset shapes for martensitic and austenitic phases, thermo-mechanical treatments are required (Fig. 17).

\section{Superelasticity}

Superelasticity or pseudoelasticity represents the SMAs capability to return to the original shape upon unloading after a strain.
This behavior is observed only over a specific range of temperature included between $\mathrm{Af}$ and $\mathrm{Md}$, where for Md we mean the highest temperature at which Martensite can no longer stress-induced.

Inside the above-described temperature range, the macroscopic deformation is accommodated by the formation of Martensite (detwinned Martensite), when the stress is released the SMAs transforms back to Austenite and takes the macroscopic shape associated with this phase. Above the Md temperature, the deforms like ordinary metals and therefore by slipping.

Below As, instead, the SMA is in its Martensite phase and, as easily deducible, doesn't recover the macroscopic shape associated with Austenite phase upon unloading (Fig. 18).

\section{Mechanical Properties}

The mechanical properties of SMAs depend on crystal phase arrangement and consequently on temperature.

For martensitic phase, for example, modulus of elasticity, tensile yield strength and ultimate tensile strength are lower than for austenitic phase. This is the reason because SMAs are easier to deform and ductile at low temperature (martensitic range of temperature) than at hight temperature (austenitic range of temperature).

For these characteristics, if we drop a Ni-Ti ball, with a temperature below As, from a constant height, it bounces only slightly over half the height reached by a similar ball dropped above Af temperature. 


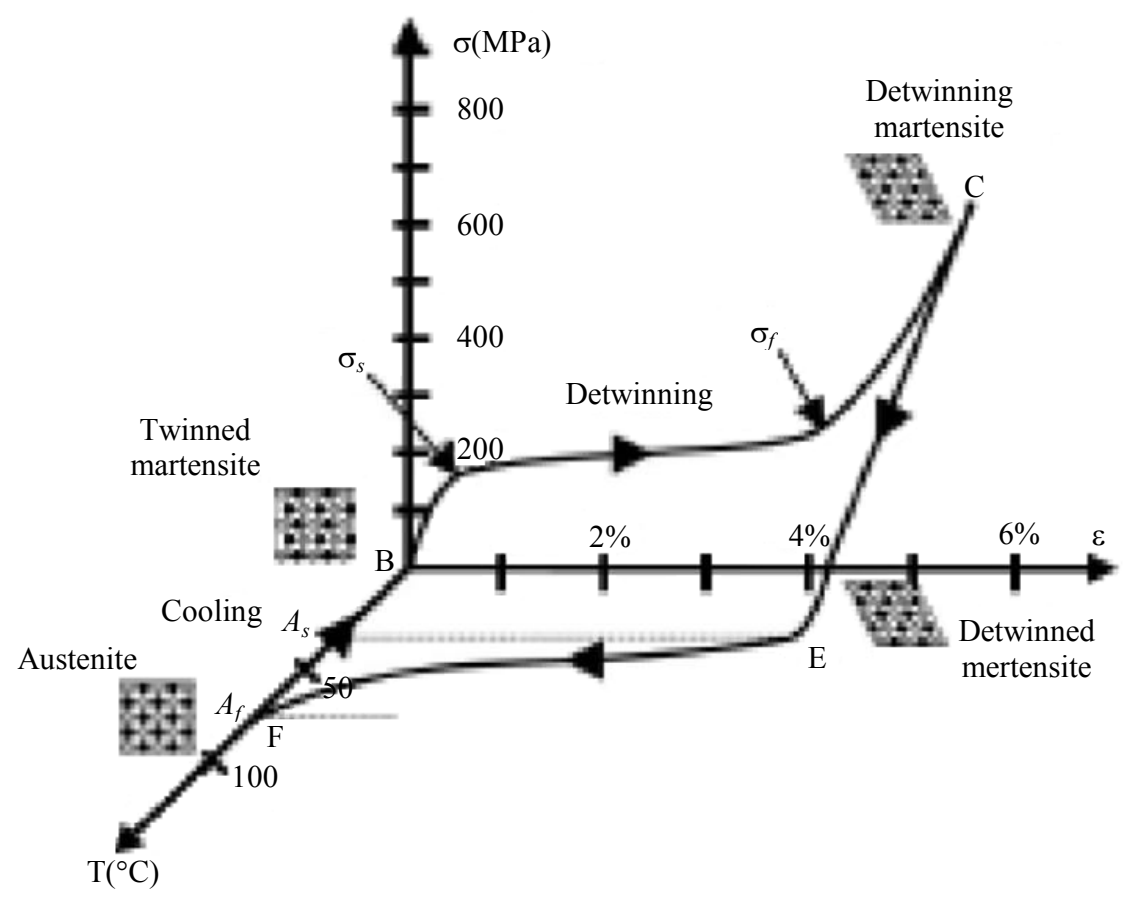

Fig. 17: Stress-strain-temperature data exhibiting shape memory effect for SMAs
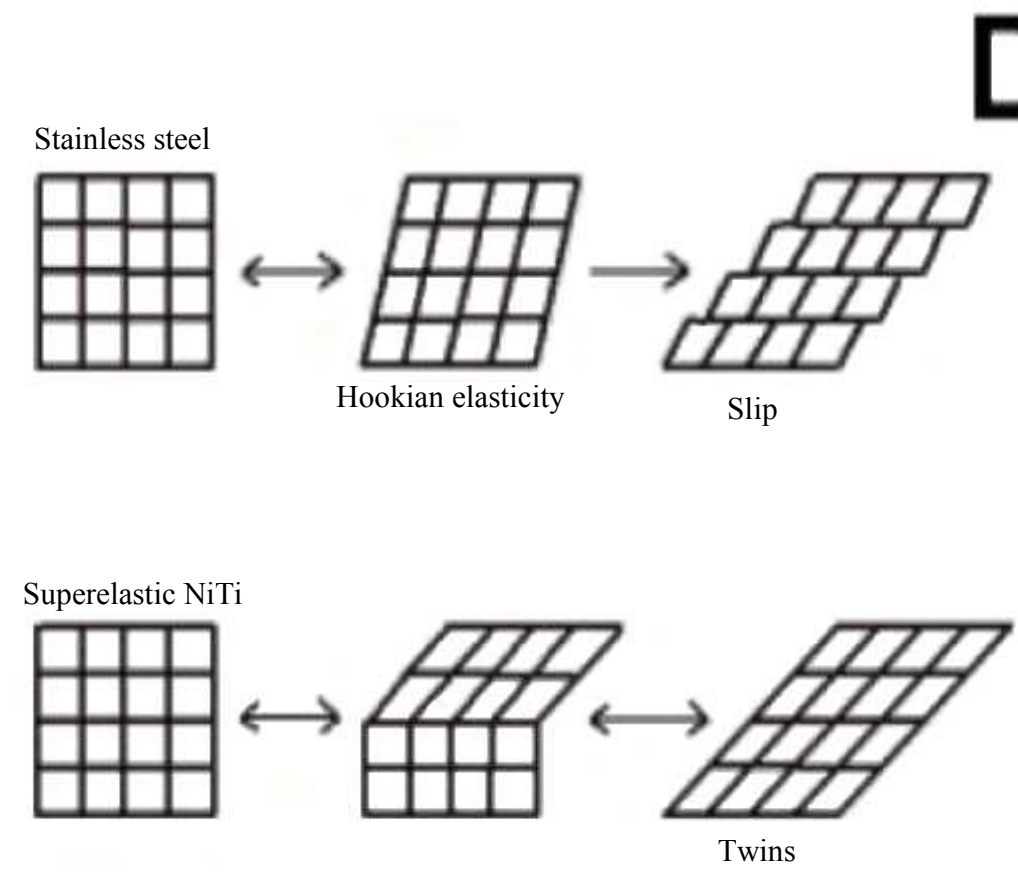

Deformation

Fig. 18: Lattice structure behavior upon loading for a traditional metal and a SMA 


\begin{tabular}{lccccc}
\hline & \multicolumn{2}{c}{ NiTi } & Stainless Steel & Titanium & T1-6Al-4V \\
\cline { 2 - 5 } & Austenitic & Martensitic & & & \\
\hline Ultimate tensile strength (Mpa) & $800-1500$ & $103-1100$ & $483-1850$ & $540-740$ & $920-1140$ \\
Tensile yield strength (Mpa) & $100-800$ & $50-300$ & $190-1213$ & 390 & $830-1070$ \\
Modulus of elasticity (GPa) & $70-110$ & $21-69$ & $190-200$ & $105-110$ & $100-110$ \\
Elongation at failure (\%) & $1-20$ & up to 60 & $12-40$ & 16 & 8 \\
\hline
\end{tabular}

* Lowest and highest values have been compiled from picked references (Buehler et al. 1967, Funakubo 1987, Breme et al. 1998, Van Humbeeck et al. 1998).

Fig. 19: Mechanical properties depending on crystal phases of Ni-Ti alloy

The above-described mechanical behavior gives the possibility to use an SMA in its martensitic phase for systems where there is a need of a dampening effect or, conversely, in its austenitic phase for systems where an elastic effect is requested.

The dampening effect of martensitic phase is exploited, for example, to attenuate the peak stress between bone and articular prosthesis.

For an SMA the Young's Modulus of austenitic phase can be several times higher than that of martensitic phase. In particular, this characteristic depends on phase composition, orientation and extent of martensitic variants (The Table of the Fig. 19).

\section{Alloy Composition, Precipitates and Microstructure}

As already discussed, the biggest part of SMAs has as main constituents Nickel and Titanium. The composition and the amount of Nickel and Titanium are responsible for variability in the number of electrons available for bonding and have a significant impact on transformations temperatures of SMAs.

A very small excess nickel, in fact, can reduce Temperature of Transformation (TTR) and increase the permanent yield strength of the austenite phase by roughly threefold. Moreover, the amount of nickel present in the alloy may be controlled even during the ingot melting and casting process. Meanwhile, titaniumrich alloys contain have higher transformation temperatures than those of the nickel less-rich or equiatomic NiTi alloys.

The transition temperature of a 50Ni-50Ti (at \%) alloy is from -50 to $+100^{\circ} \mathrm{C}$. Reduction in TTR can be achieved during the manufacturing process due to changes in nickel-titanium ratio or by cold working and thermal treatment. $\mathrm{Ni} \mathrm{Ti}$ alloy contains more nickel and when this approaches 60 at \% Ni an alloy presents a lower shape memory effect through its ability to be heat-treated increases. This kind of composition provides an alloy more resilient, tougher and with a lower modulus of elasticity than other alloys such as stainless steel, for example.
Regarding precipitates and microstructure of SMAs and, in particular, those with Nickel and Titanium as main constituents.

The method of manufacturing and the heat treatments applied to $\mathrm{Ni} \mathrm{Ti}$ wires during manufacturing process leads to breakage of the small crystal and a recrystallization is necessary to develop a predictable average grain size and orientation.

As a result of composition and thermal treatment, uniform grains may be formed or precipitates of some chemical constituents can be acquired. These particles with different characteristics of the matrix are constituents not thermodynamically stable under heat treatment temperature and they can be combined with other constituents uniformly dispersed throughout the matrix. Ni2Ti and Ni3Ti precipitates allow the excess nickel to get off the crystal matrix, reduce the Ni content and increase the temperature of transformation. Other precipitates, instead, as Ti3Ni4 can affect the mechanical behavior as the strength of matrix austenite phase, improving the recoverability of the shape memory effect.

\section{Effects With Contents of Copper, Oxygen or Carbon}

Copper-based SMA with a content from 5 to 15 at $\%$ of copper as a substitute for $\mathrm{Ni}$, transforms in two steps under a sequence from cubic to orthorhombic and then to monoclinic. With an increase of $\mathrm{Cu}$ content, the transformation starts temperature of the austenite (BCC) to orthorhombic martensite does not change while the second step from orthorhombic to monoclinic decreases and only occurs in alloys of copper contents below 15 at \%.

Changes in $\mathrm{Cu}$-based alloys composition resulting from $\mathrm{Cu}$ addiction affect the mechanical behavior once hysteresis reduction, embrittlement, formability and the Ms temperature and precipitations are also affected.

The solid solubility of oxygen in NiTi alloy is very small and the addiction beyond this limit may contribute to increasing of the contents of a primary phase of NiTi and a eutectic mixture of a solid solution of NiTi and oxides. The oxygen combines with the nickel and titanium forming a complex oxide (Ti4Ni2O) which is 
present in NiTi as small oxide particles scattered throughout the structure. The oxygen atoms consume two atoms of titanium for each atom of nickel twice as much $\mathrm{Ti}$ than $\mathrm{Ni}$, resulting in the increasing of the nickel content in the remaining NiTi matrix and they have an effect on the TTR. The effects of nickel increase, as already discussed, give as result lower temperatures of transformation.

Regarding some Ni-Ti-C ternary alloys, the carbon exists as carbides which show an increased hardness coupled with an inherent brittleness. TiC precipitates have the same effect of oxygen that causes an alteration in the nickel balance with its increase.

\section{Main Fields of Application}

Many metal alloys show shape memory effect, but few of them have been developed on a commercial scale.

The biggest part of SMA applications is based on Ni$\mathrm{Ti}$ or ternary NiTi-Cu or NiTi-Nb alloys. Although Ni-Ti SMAs are characterized by high costs and by a more difficult processability than $\mathrm{Cu}$-based SMAs, there are many reasons to prefer Ni-Ti alloys to other SMAs. NiTi alloys are, for example, much stronger, more ductile with high stability in cyclic applications and with a higher electrical resistivity that electrical activation easier to obtain and manage.

The main categories of application for SMAs are:

- Free recovery applications

- Clamping devices

- Actuation applications

- Superelastic applications

- Damping applications
Basically nowadays SMAs are used for advanced fields of applications like aeronautics and biomedical, for example.

In fact, in 1971 there was the first large-scale application of SMA with a coupling to connect titanium hydraulic tubes in the Grumman F-14 aircraft. The alloy used was a Ni-Ti-Fe, Fe was allowed to obtain a low transformation temperature (around $-55^{\circ} \mathrm{C}$ ), with the aim to keep the alloy inside the austenitic phase and avoid the martensitic phase, softer and more ductile. Anyhow, in general, coupling or fastener based on SMAs, used for aeronautics or other fields are heatsensitive elements with the function to lock or unlock different parts within a short time and at a critical temperature. Many applications with this function have spread in space technology for safety.

SMA actuators, instead, can be classified as thermal actuators able to convert thermal energy into mechanical energy, where the heat can be used to perform work.

The largest commercial success of SMAs is linked to biomedical applications. The combination of a good biocompatibility, ductility, shape memory effect and superelasticity provides a unique material for medical applications. In particular, the temperature-dependent character of superelastic effect is easy to manage and absolutely suitable for biomedical applications since the temperature of human body is quite stable (Fig. 20).

The advantage of pseudoelastic archwires is the capability to have near-zero stress change over a large strain increment. This behavior provides a nearly constant, moderate force to actively move the teeth over a larger period than stainless steel (Fig. 21).

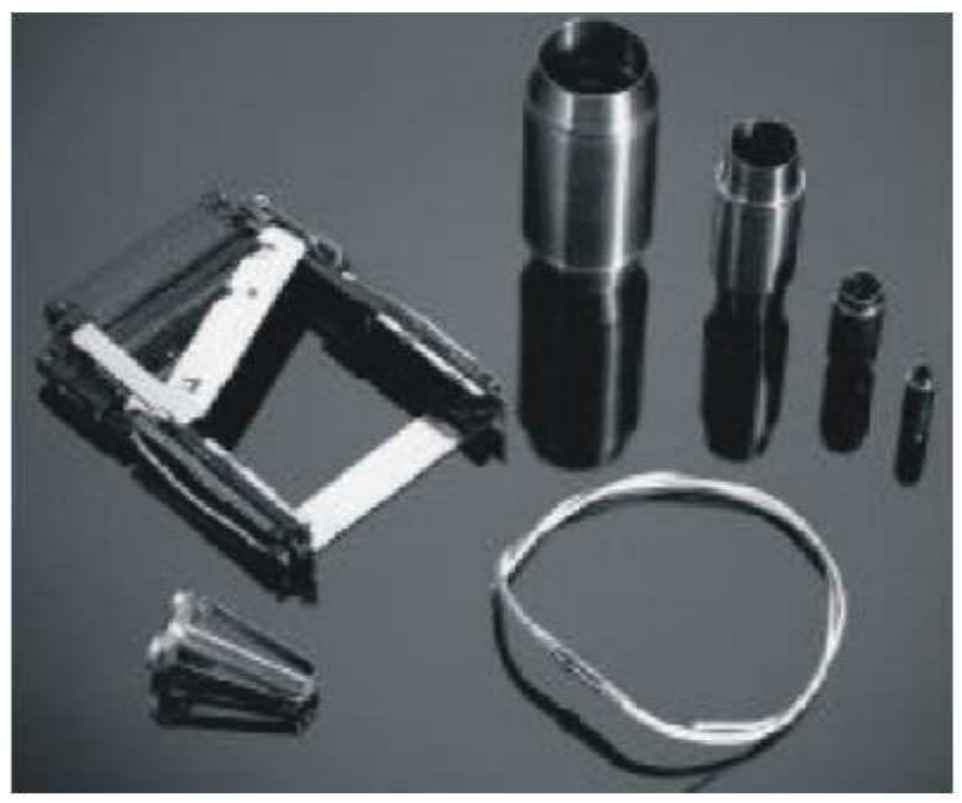

Fig. 20: Couplings and connectors using SMA behavior 


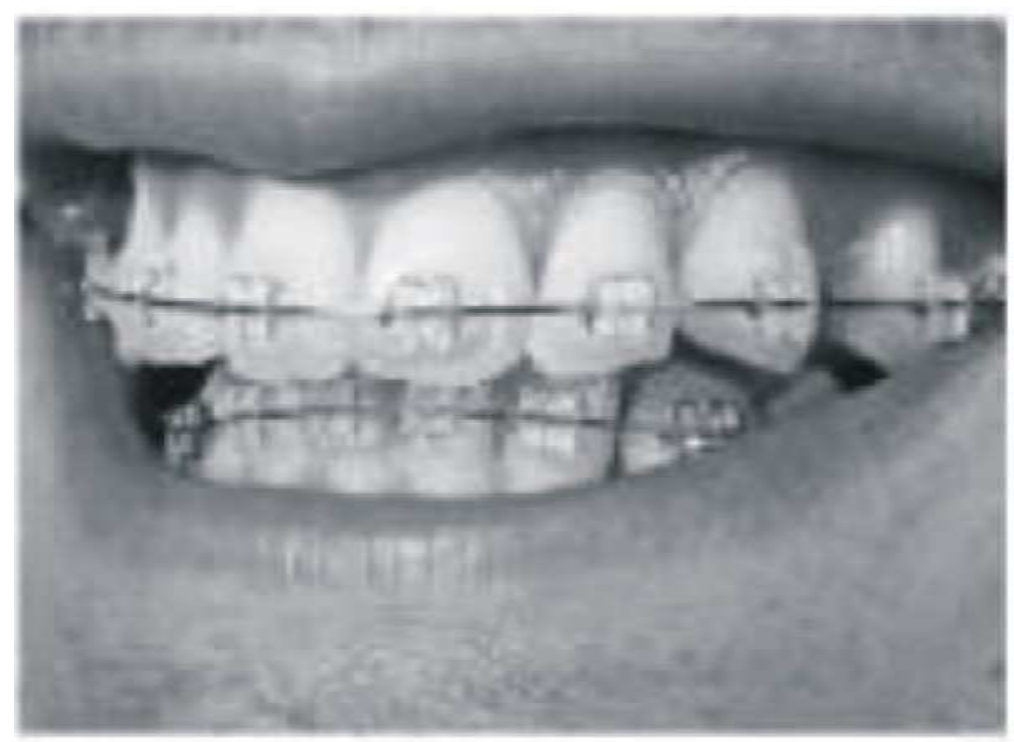

Fig. 21: Orthodontic application of SMAs with pseudoelastic archwires
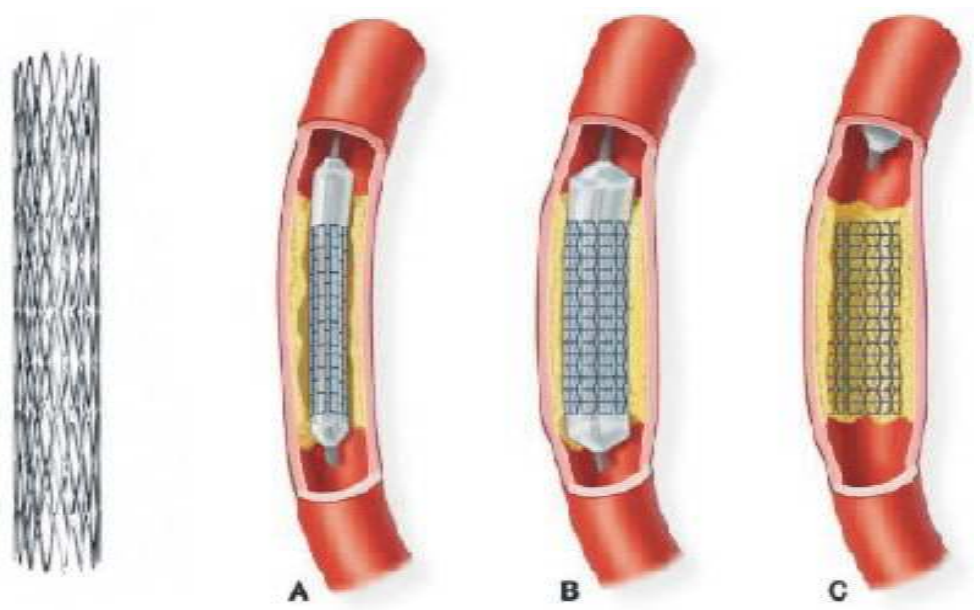

Fig. 22: Ni-Ti stent and process of placing

The most common use of SMAs in the biomedical field is with self-expanding $\mathrm{Ni}-\mathrm{Ti}$ stent for cardiovascular applications. Ni-Ti stents are generally laser cut from sheets or tubing and then are shape-set to define the diameter.

After being constrained, the stent is introduced into the body when the temperature is higher than As of SMA and after being released, it can expand to its original larger the diameter and slowly push outward on the walls of the blood vessel (Fig. 22).

Another common use of SMAs is for staples in orthopedic applications to facilitate healing of broken or fractured bones. In particular, the staple is installed in its open configuration, then upon heating with an external source, it returns to its original shape, providing a compressive force at the interface of the separated bones.
Moreover, SMAs are also used for biomedical or surgical instruments. There are, for example, Nitinol drills for root canal surgery of tooth with the advantage to give the possibility to bend to rather large angles or SMA baskets used to remove stones in the bile duct or other instruments exploiting Shape Memory Effect for grippers, scissors and tongs used for laparoscopy procedures.

\section{Focus on Industrial Design Applications}

In this paragraph, a specific focus on industrial design applications of SMAs has been made. As already discussed in the previous paragraph, during the years after the discovery of SMA the use of the material became widespread for advanced fields of application, basically aeronautics and biomedical. In the first case especially for high stability in cyclic applications and 
Shape Memory Effect, in the second mainly for biocompatibility (Ni-Ti in particular) and superelasticity.

Only during the $80 \mathrm{~s}$, there was the first trace of industrial applications, where we mean all products or applications that do not belong to advanced fields like the two above-mentioned and, conversely, we include sectors as automotive, interiors, fashion, jewelry, consumer goods, etc.

In particular, during 80s SMAs were used for underwear (basically brassieres), eyeglasses and mobile phone antennas. All these applications have the characteristic to exploit the superelastic behavior for simple devices. Some examples are the eyeglasses that can be strained, folded and stored in a pocket and then, upon unloading, take another time the original shape being ready for the use. Another example is women's brassieres, where the use of SMA has both esthetic as well as structural functions.

The application of superelastic NiTi alloy to the wire re-enforcement, called the underwire, offers improved comfort due to the much lower elastic modulus than the conventional steel wires. An additional advantage is the fact that the superelastic NiTi wires are resistance to permanent deformation which can be the result of washing and drying cycles.

During the $90 \mathrm{~s}$ and $00 \mathrm{~s}$, instead, there is a significant spread of SMAs for applications like thermal or electrical actuators, many times used for air conditioning flaps to have a smart and heat-responsive behavior for opening and closing when the system turns on and off and in many cases for car windows opening and closing, too.

Important reasons to select SMA as an actuation mechanism are:

- Simplicity of mechanism

- Creation of clean, silent, spark-free and zero gravity working conditions

- High power/weight (or power/volume) ratios

In general, SMAs are considered in this period and not only, for systems with repeated actions such as grippers, positioners, etc. The low energy mechanism is compensated by mechanisms which include a high gain on weight, high work/volume density and almost zero gravity accelerations (Fig. 23).

Nowadays, for the first time, there is the first high volume production for automotive. In fact, a kind of pneumatic valve to inflate and deflate cushions in car's seats is manufactured in about 10 million per year and it is installed in all main vehicle's platform of Daimler, BMW, GM, Hyundai, Ford, Porsche and Volkswagen. The SMA, in this case, is applied as a wire with the geometry of a spring (Fig. 24).

Moreover, experimentations, where SMAs are used to implement and develop smart textiles and breathable fabrics that, in accordance with needs, respond to thermal stimuli, are increasingly frequent (Fig. 25).

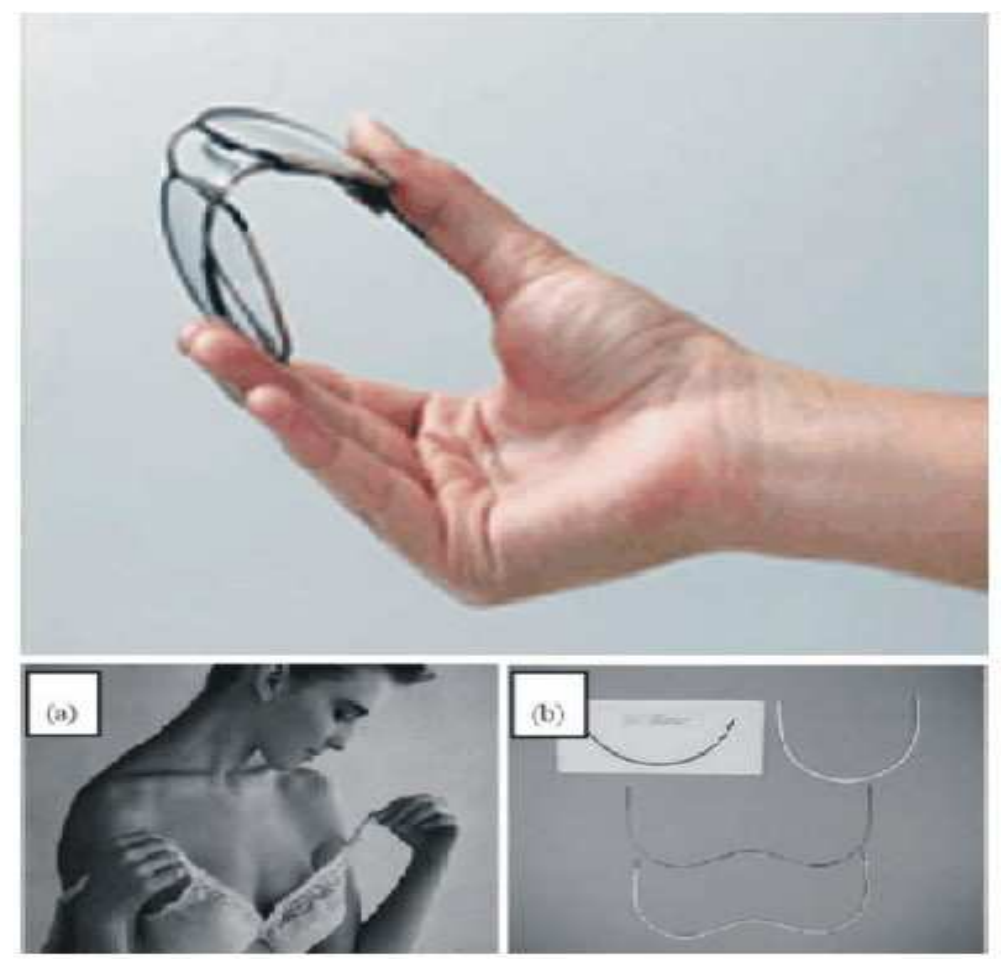

Fig. 23: Foldable eyeglasses and brassieres made with SMAs. (a) brassiere, (b) various shapes of superelastic NiTi underwires 


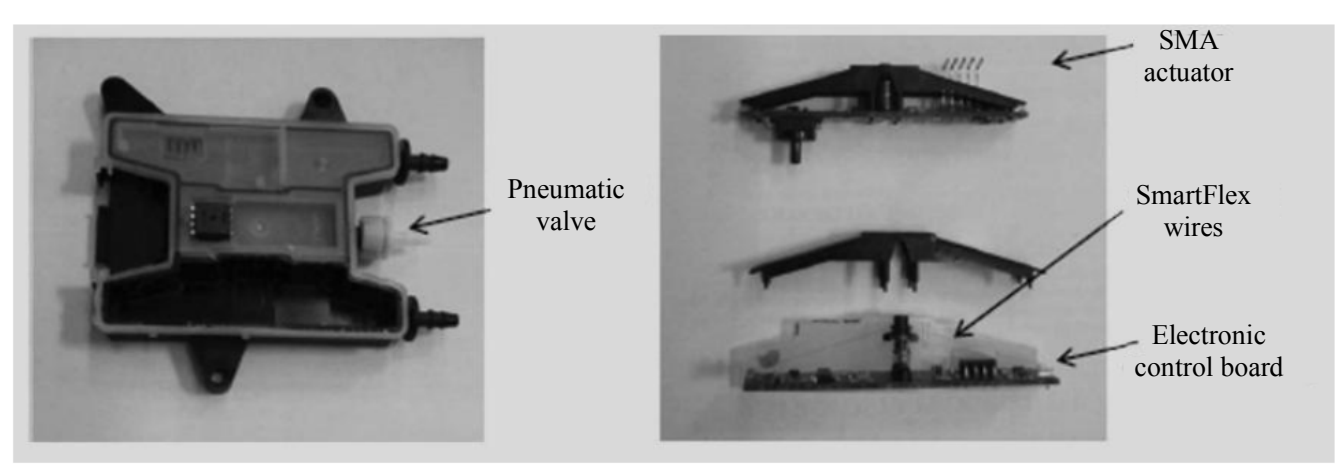

Fig. 24: Pneumatic valve to inflate and deflate cushions in car seats

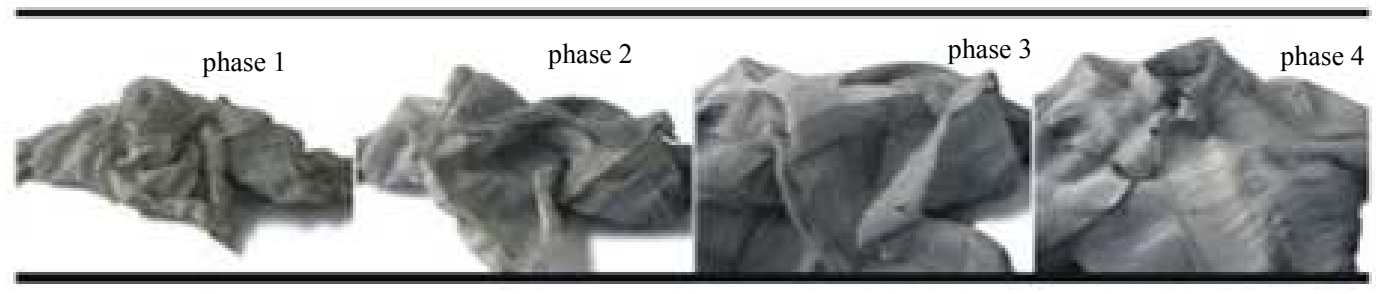

Fig. 25: Thermal Shape Memory Shirt by Oricalco Fabric

\section{Experimental Characterization of SMAs}

In order to better understand phase transformation behavior for SMAs, their sensitivity to heat treatments required for SME programming and temperature range of phase transitions, Differential Scanning Calorimetry (DSC) analysis have been carried out on two types of SMAs. Nitinol and Flexinol wires have been used.

The DSC analysis has been aimed to have experimental data to reach a deeper control on SMAs programming and working parameters. In order to develop knowledge and awareness on thermal behavior of SMAs and design solutions where a correct SMA programming and application are ensured.

The DSC technique determines the temperature and heat flow associated with material transitions as a function of time and temperature. It also provides quantitative and qualitative data on endothermic (heat absorption) and exothermic (heat evolution) processes of materials during physical transitions that are caused by phase changes, melting, glass transitions, crystallization, oxidation and other heat-related changes. The DSC instrument works in conjunction with a controller and associated software to allow data acquisition and analysis.

DSC technique can be used to characterize melting, crystallization, resin curing, loss of solvents and other processes involving an energy change, such as, for example, martensitic and austenitic transitions for SMAs. Similar to thermomechanical analysis, one test can generally be used to measure most or all of these properties. In DSC analysis, the sample is placed in an aluminum pan and the sample pan and an empty reference pan are placed on small platforms within the DSC chamber. Thermocouple sensors are positioned below the pans. DSC measurements can be made in two ways: by measuring the electrical energy provided to heaters below the pans necessary to maintain the two pans at the same temperature (power compensation), or by measuring the heat flow (differential temperature) as a function of sample temperature (heat flux), (Fig. 26).

The functional properties that distinguish SMAs from other materials are: Pseudoelasticity and SME. The most significant functional property of SMAs, the shape memory effect (SME), is characterized by the thermoelastic reversible crystallographic phase transformation from a high-temperature phase (BCC structure) to a low-temperature phase (monoclinic structure). In addition to these two phases, an intermediate phase can appear and it is known as the intermediate Rphase (rhombohedral crystal structure). Thus the alloy when is cooled down, transforms to the intermediate Rphase and then to the low temperature phase (martensite). In some cases, the presence of a pre-martensitic transition is very useful in the engineering fields, mainly owing to the fact that SME with its participation exhibits excellent fatigue properties. However, the appearance of different transformation behaviors and changes in critical transformation temperatures depend on many factors, like for example thermo-mechanical processing. Thus, a systematic investigation of material response to thermal heat-treatment with various process conditions, plays an important role in controlling the transformation properties. 


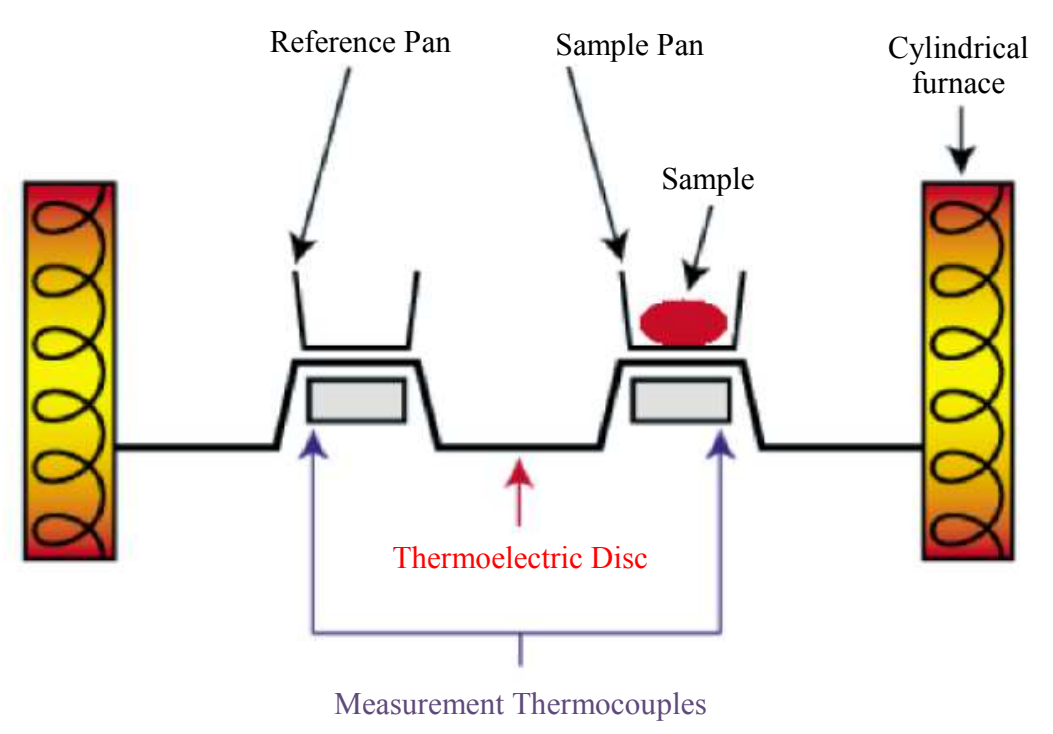

Fig. 26: Principle of working of differential scanning calorimetry

\section{Description of Method}

Considering the background, analysis of Nitinol and Flexinol wire samples have been performed. In particular, dynamic test composed by one heating segment from " -30 " to " $120^{\circ} \mathrm{C}$ " and one cooling segment from " 120 " to " $-30^{\circ} \mathrm{C}$ " and with a rate for a temperature change of $10^{\circ} \mathrm{C}$ per minute have been planned and carried out. The tool used for thermal analysis has been the "DSC 1, STARe System by Mettler Toledo". The samples used have a weight not higher than $10,0 \mathrm{mg}$ and for each of the three scanning steps have been considered:

- Dynamic, “- 30 to $120^{\circ} \mathrm{C} ; 120$ to $-30^{\circ} \mathrm{C}$ " - rate $10^{\circ} \mathrm{C} /$ minute

- Isothermal " $500^{\circ} \mathrm{C}$ ", with a duration of minutes chosen according to the heat treatments to simulate

- Dynamic, “- 30 to $120^{\circ} \mathrm{C} ; 120$ to $-30^{\circ} \mathrm{C}$ " - rate $10^{\circ} \mathrm{C} /$ minute

The choice to perform the isothermal scan depends just on the need to create controlled annealing conditions for wires, in order to simulate the heat treatment needed for SMA training (to set austenitic shape) and then analyze, with the second dynamic scan, the effects of heat treatment on temperatures of a transformation of the alloy. Thus the isothermal has no analytical purposes. After the isothermal, the sample cooling occurs by free air-cooling to room temperature.

\section{Our Results}

Considering background, method and thermal technique used, some significant thermograms are reported and discussed in this paragraph. In particular, the thermograms shown are aimed to compare the dynamic scan performed before isothermal and the dynamic scan carried out after it.

The thermogram reported below shows the results of the Nitinol sample studied with the dynamic scan described in the previous paragraph and an intermediate isothermal scan performed at $500^{\circ} \mathrm{C}$ for a duration of 10 minutes. The thermogram shows an endothermic reaction (heat absorbing) for martensite to austenite transformation, while exothermic reaction (heat emitting) for the austenite to martensite transformation. The area under peaks, instead, indicates the energy of transformation $(\Delta \mathrm{H})$. Using these peaks, the critical transition temperatures can be also determined (Fig. 27).

In accordance with the commonly accepted notation, the characteristic temperatures of SMA are expressed as Rs, Rf, Ms, Mf, As, Af (R-phase, martensite and austenite starting and finishing temperatures, respectively). Symbols such as $\mathrm{Rp}, \mathrm{Mp}$ and $\mathrm{Ap}$ are referred to as the peak of each characteristic crystal phase of SMA. Basically, each characteristic peak represents "excess" heating or cooling needed to maintain the temperature rate and it is caused by the extra energy addition or subtraction needed to transform the crystal structure.

Looking at the thermogram below, where the results of the dynamic scan performed as first and of the dynamic scan performed as third (after isothermal) on the same Nitinol sample are compared, it is possible to observe that a change for the characteristic temperatures of SMA crystal phases occurs. In particular Mp and Ap slightly increase for post-isothermal and energy adsorbed and emitted during the transitions $(\Delta \mathrm{H})$, as well (Fig. 28). 


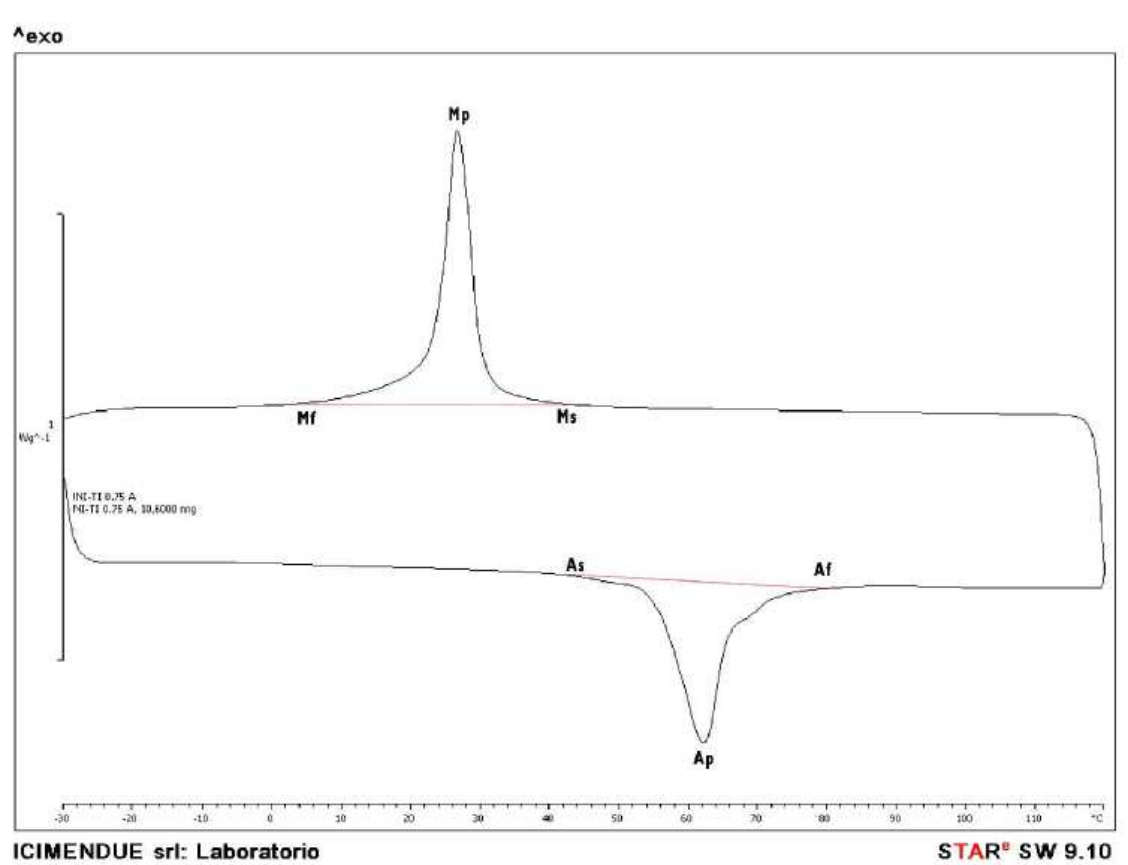

Fig. 27: DSC scan of Nitinol sample performed before Isothermal treatment

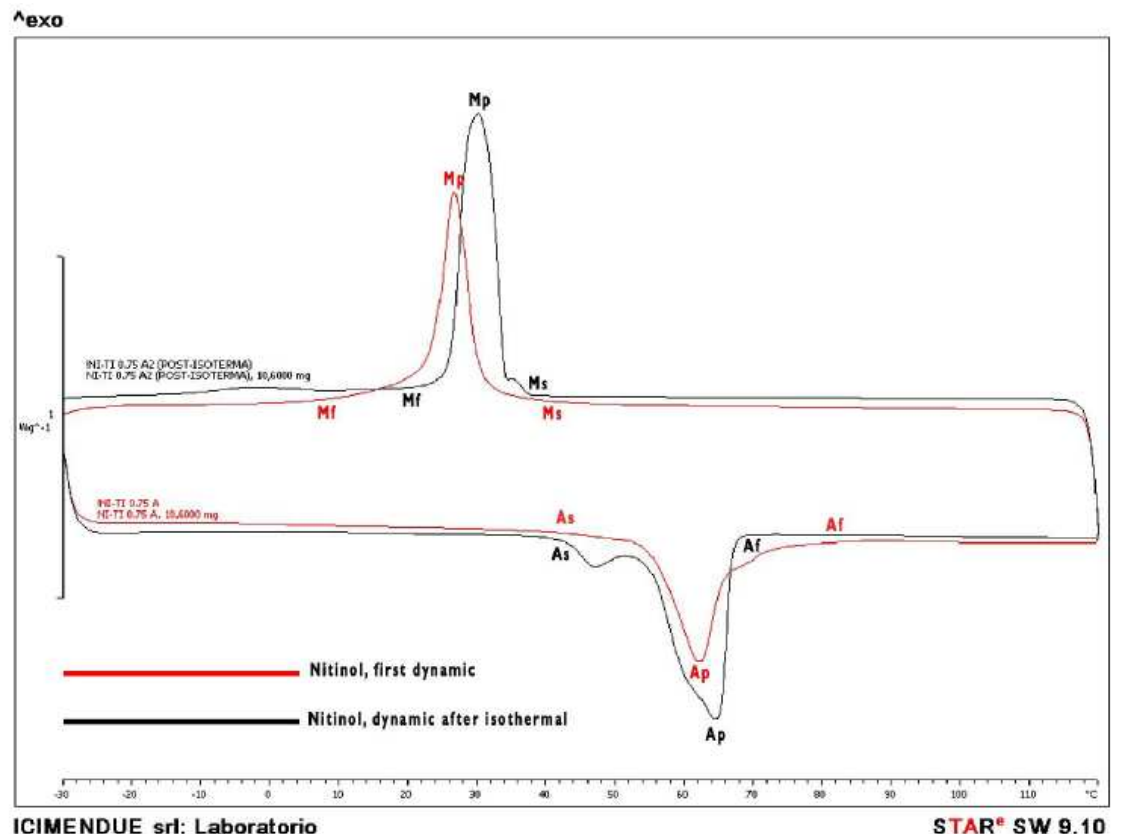

Fig. 28: DSC scan of Nitinol sample, results compared before and after Isothermal treatment

For thermal analysis of Flexinol, the method was the same used for Nitinol and also the scanning sequence for each sample, but the results are different. In particular, the thermogram below shows that the intermediate phase, called R-phase, with rhombohedral structure, appears. In general, the formation of the R-phase has been linked to the existence of large energy barriers that oppose the completion of the normal martensitic transformation. In particular, instead, this phase forms under the following conditions:

- In Ni-rich binary NiTi alloys - through aging in the temperature range between $350^{\circ}$ and $500^{\circ} \mathrm{C}$

- Through cold-working and a subsequent annealing procedure at temperatures between $300^{\circ}$ and $550^{\circ} \mathrm{C}$ 
- In ternary NiTi-based alloys - through the addition of a third element like $\mathrm{Fe}$, $\mathrm{Co}$ or $\mathrm{Al}$, for example

Moreover, the compared results show a significant change for the characteristic temperatures of SMA crystal phases occurs. In fact, $\mathrm{Mp}, \mathrm{Rp}$ and Ap for a postisothermal scan of Flexinol considerably decrease for post-isothermal. More than 10 degrees for $\mathrm{Rp}$ and $\mathrm{Ap}$ and almost 9 degrees for Mp (Fig. 29-30).

Finally, the DSC characterization of SMA thermal behavior provides valuable data not only to use for material training associated with SME programming but also to better understand and define the functioning parameters for the final industrial application.

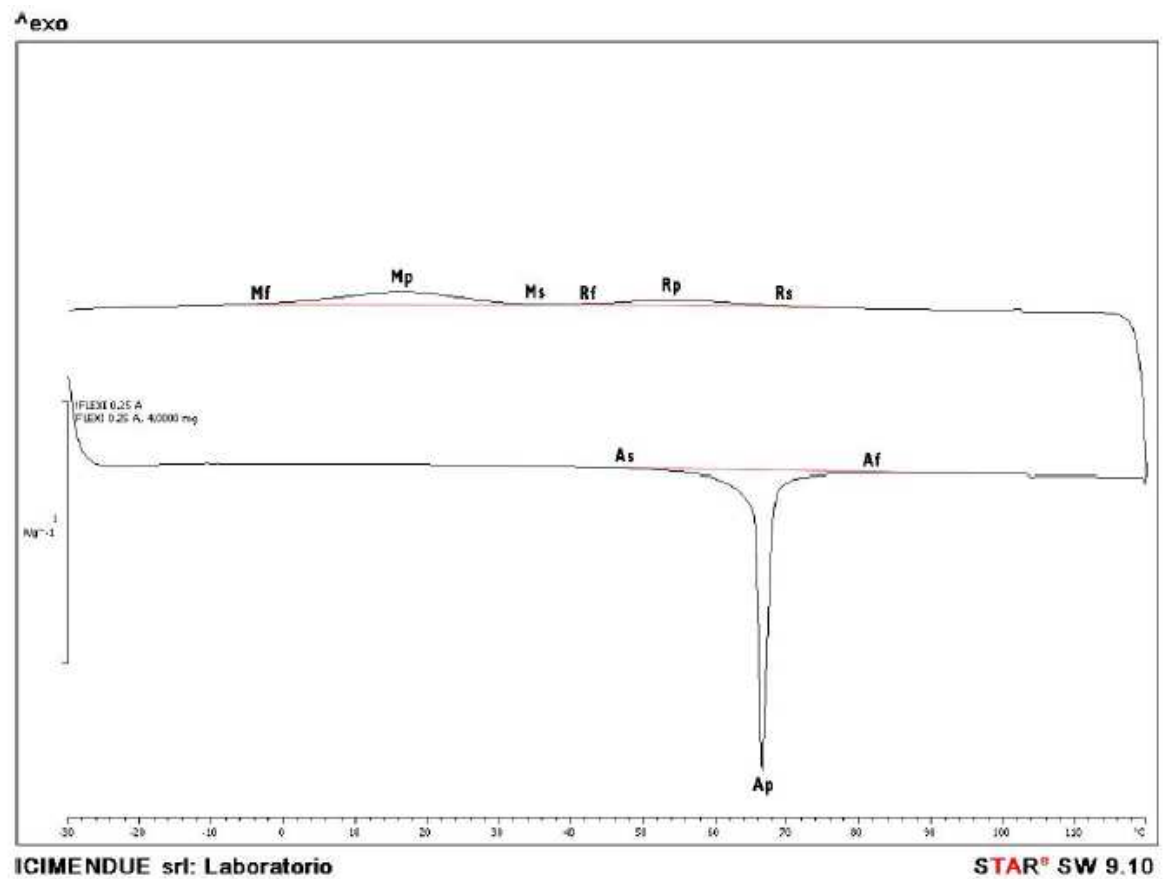

Fig. 29: DSC scan of Flexinol sample performed before Isothermal treatment

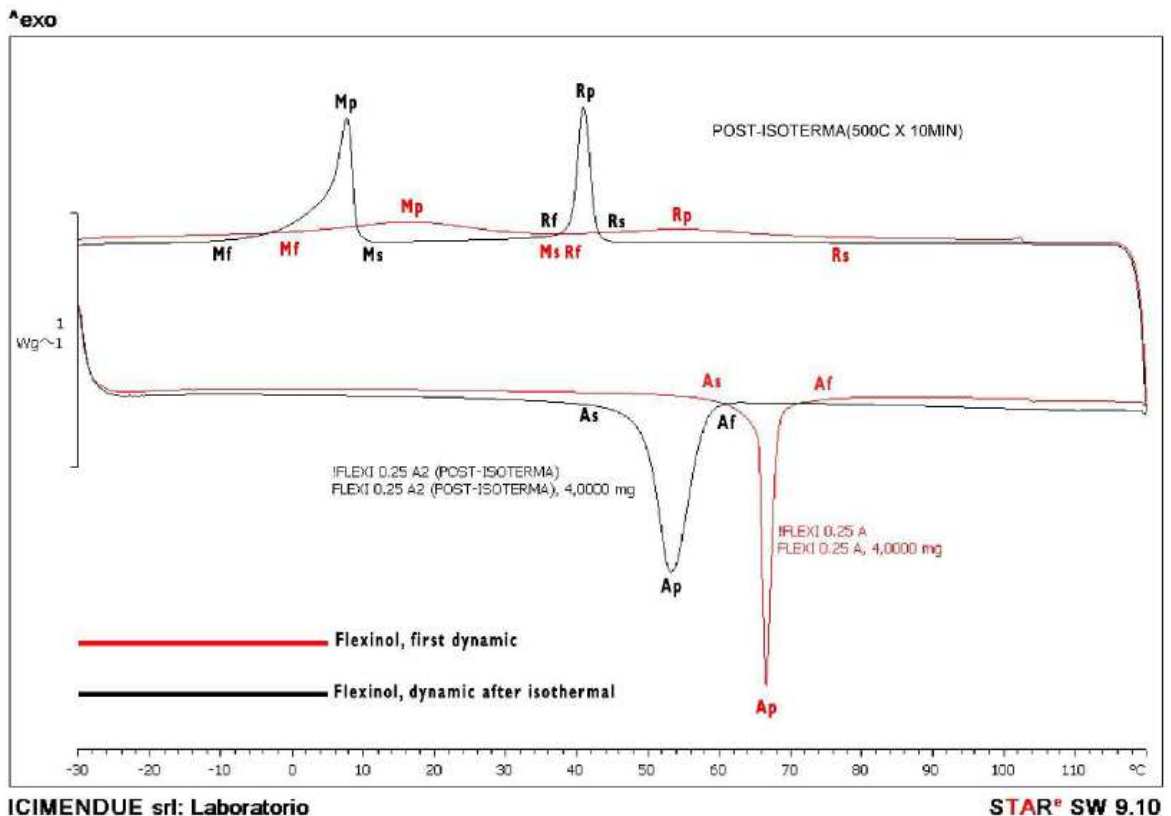

Fig. 30: DSC scan of Flexinol sample, results compared before and after Isothermal treatment 


\section{Discussion}

\section{SMA Programming One-Way Training}

Shape Memory Alloy can be characterized by two types of Shape Memory Effect (SME). One named oneway and another named two-way.

The type of SME obtained depends by the thermomechanical treatments performed for a specimen of SMA used.

For one-way effect, the SMA needs to be molded into the desired shape when it is in its martensitic range of temperature. Once the shape has been molded, a specific heat treatment to set the shape is required. In particular adequate parameters (temperature and time) for the heat treatment are needed to set the macroscopic shape associated with the austenitic phase of SMA.

In general, one-way training is easier and faster than two-way training and the steps needed are:

- To mold the SMA in its martensitic range of temperature

- To heat the alloy up to its temperature of annealing (roughly between 500 and $600^{\circ} \mathrm{C}$ for $\mathrm{Ni}-\mathrm{Ti}$ alloys)

- To quench it with cold water or rapid air cooling

One-way effect means that if the SMA is strained when it has a temperature below As and after is heated up to As, it remembers and takes the austenitic shape programmed with the above-described procedure (Fig. 31).

\section{Two-Way Training}

The two-way shape memory programming procedure can be made by SME training or SIM training. In both cases, the macroscopic shape associated with the austenitic phase of SMA is programmed with a previous procedure of one-way training (as described in the preceding paragraph).

With the SME training, the alloy is cooled below Mf and molded to the desired shape. It is then heated to a temperature above Af and left free to take its austenitic shape (programmed during the previous one-way training). To complete the training the thermomechanical procedure needs to be repeated 20-30 times.

With SIM training, instead, the SMA is bent and molded just above Ms and then cooled below Mf. Upon a subsequent heating above Af, it takes temperature the alloy takes its austenitic shape. Also, in this case, the procedure needs to be repeated 20-30 times.

The two-way effect essentially means that the SMA remembers two temperature-dependent macroscopic shapes, one associated with martensitic phase and one with austenitic phase. Basically, the thermo-mechanical cycles of two-way training procedures are necessary in order to set and remember the lower temperature shape (martensitic phase), (Fig. 32).

\section{Heat Treatments}

SMA is often supplied as raw materials and then heat treatments to memorize the macroscopic shapes associated with the two characteristic crystal phases are needed (Fig. 33).

The behavior of SMA is very sensitive to temperature and duration of heat treatments (in particular to the treatment performed to memorize austenitic shape), because the chemical composition could change and especially because the grain size could be different under different heat treatments conditions.

In general, heat treatments are a kind of aging process that can reduce the grain size, therefore increasing the aging time the Ms temperature of SMA decreases. Conversely decreasing aging time (the grain is bigger in this case) the Ms temperature increases.

The grain size has a significant effect also on the superelastic behavior of SMAs. In fact, with a bigger grain size, a strain after unloading is observed (3\% for a single crystal sample), instead of with a finer grain size we observe a full recovery and therefore a superelastic behavior after unloading Fig. 34).

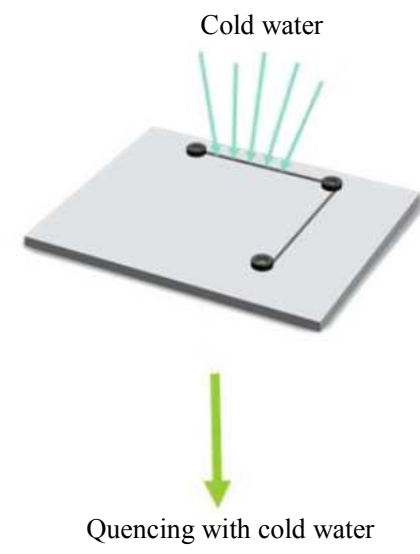

Molding in martensite phase annealing with oven at $550^{\circ} \mathrm{C}$

Fig. 31: Schematic representation of the one-way training 

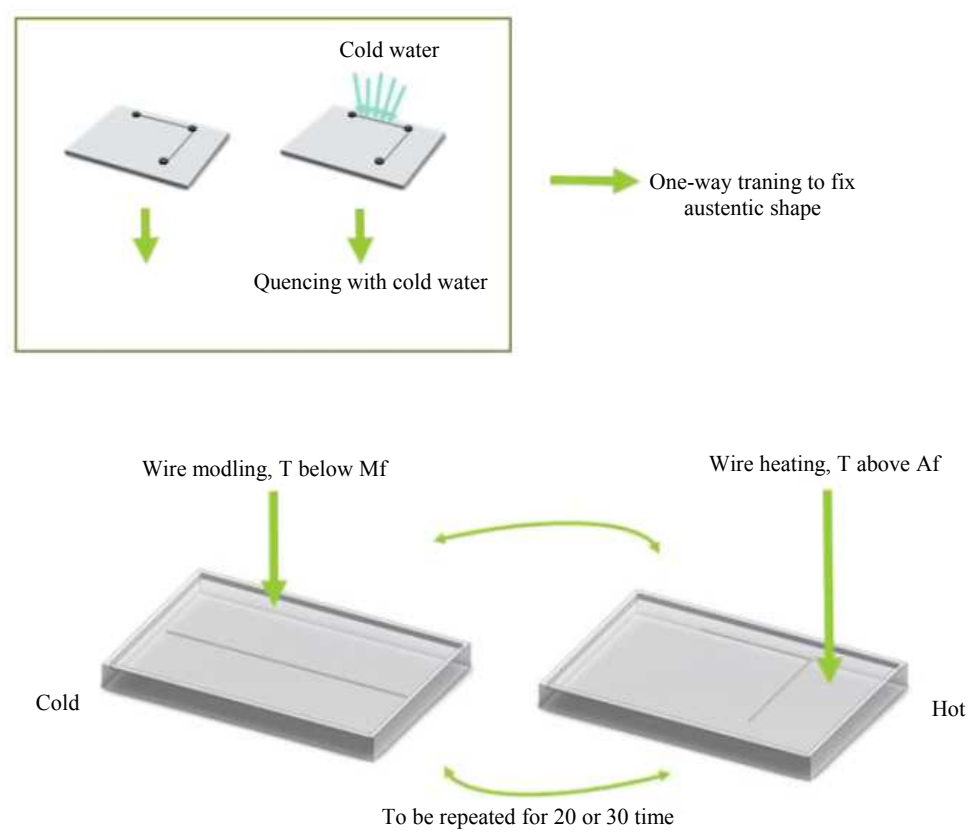

Fig. 32: Schematic representation of two-way training
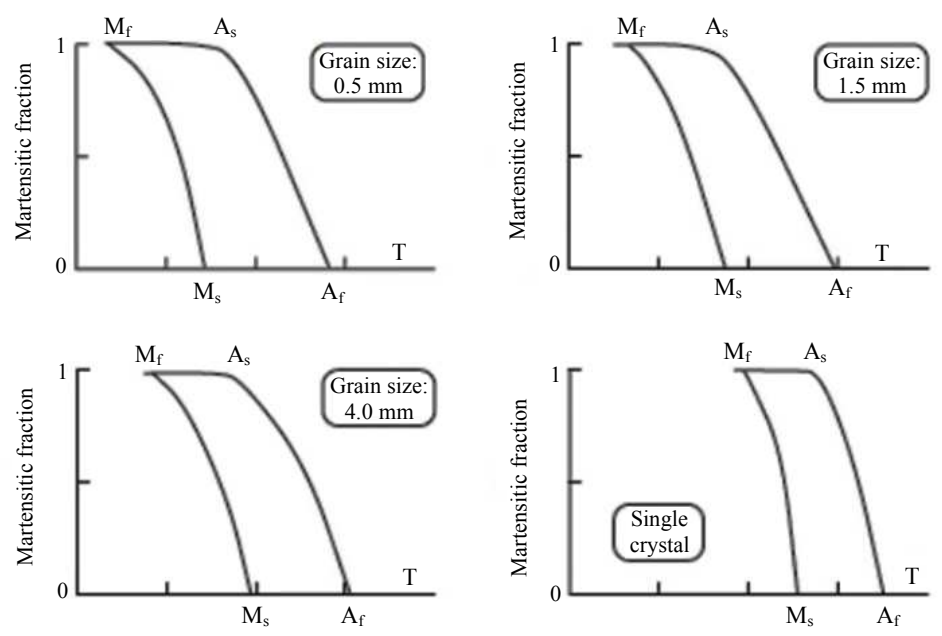

Fig. 33: Grain size and transition temperature

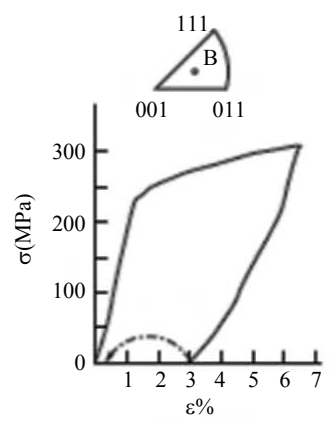

(a)

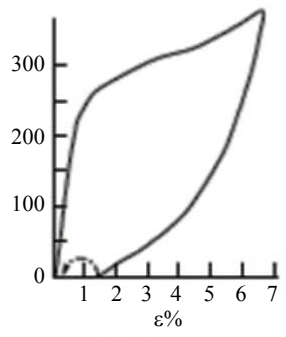

(b)

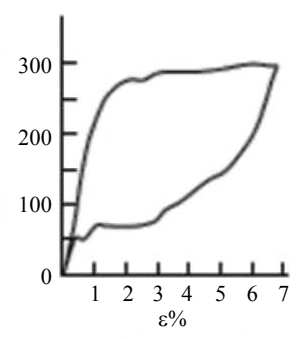

(c)

Fig. 34: Grain size effect on superelastic behavior (a) single crystal (b) $1 \mathrm{~mm}$ (c) $50 \mu \mathrm{m}$ 


\section{Case Study Of NI-TI Programming}

In order to better understand in practice SMA behavior, Shape Memory Effect and how to get good results to program preset macroscopic shapes for martensitic and austenitic phases, an experimental study for the training of Nitinol wires have been carried out.

The aim has been to program at beginning one-way effect, where for one-way effect we mean the SMAs ability to remember and resume the macroscopic shape associated with austenitic phase when heated up to Af temperature and later two-way effect, where for two-way effect, instead, we mean the first ability described (to remember austenitic macroscopic shape) added to the capability to recover also the macroscopic shape associated with martensitic phase when cooled up to Mf temperature.

In particular, Nitinol wires with a diameter of 0.75 $\mathrm{mm}$, with Af temperature of $85^{\circ} \mathrm{C}$ and As a temperature of $44^{\circ} \mathrm{C}$, have been used. Regarding fixtures, instead, a steel plate perforated with round holes and screws to mold and clamp the wires have been utilized.

For heat treatments needed, instead, an oven with temperature control (for annealing) and beckers with cold water (for quenching) have been used.

For one-way programming the procedure has been the following:
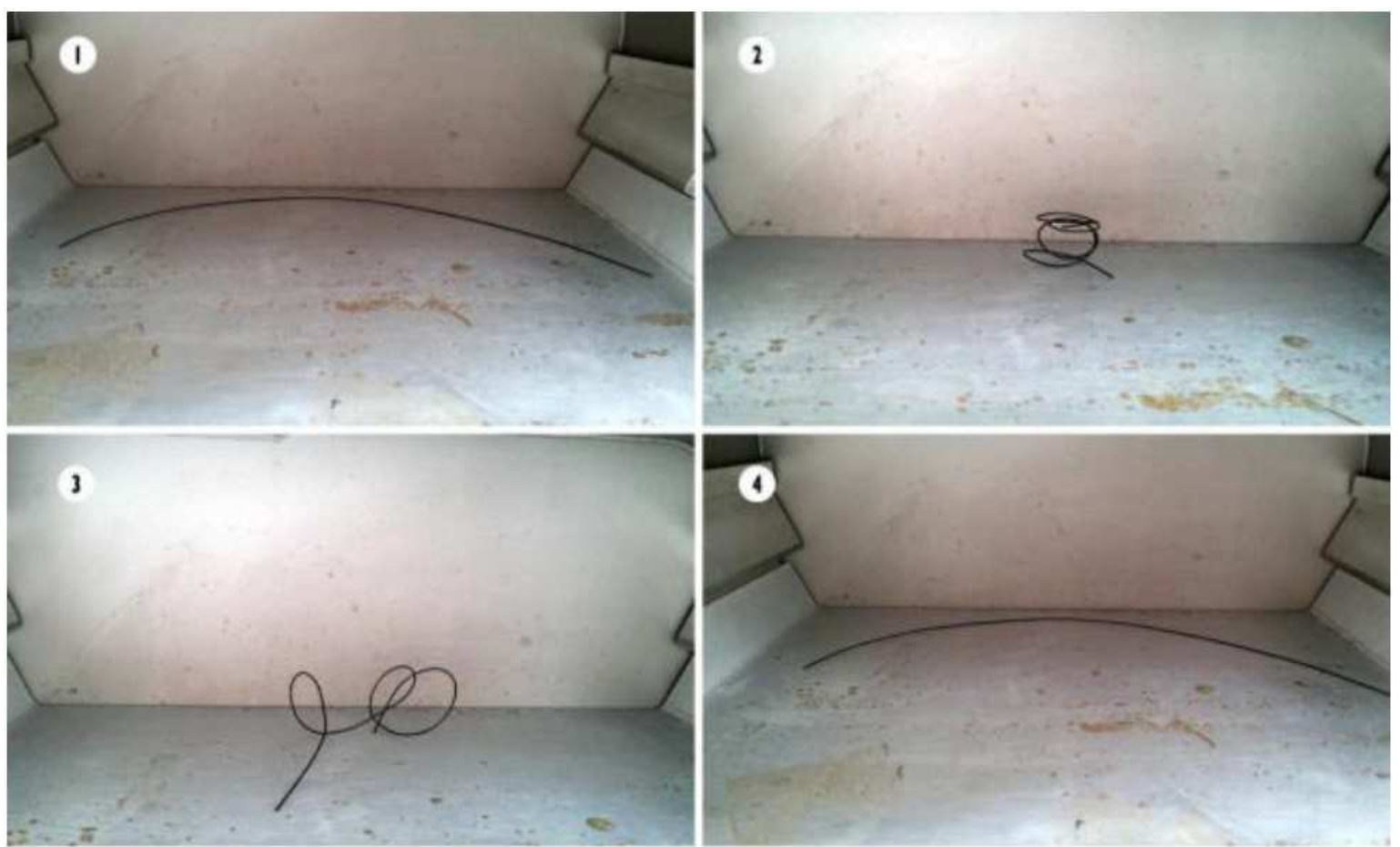

Fig. 35: Nitinol wire trained to have a one-way effect. The wire after a mechanical strain (2) recovers its austenitic shape upon heating (4) 


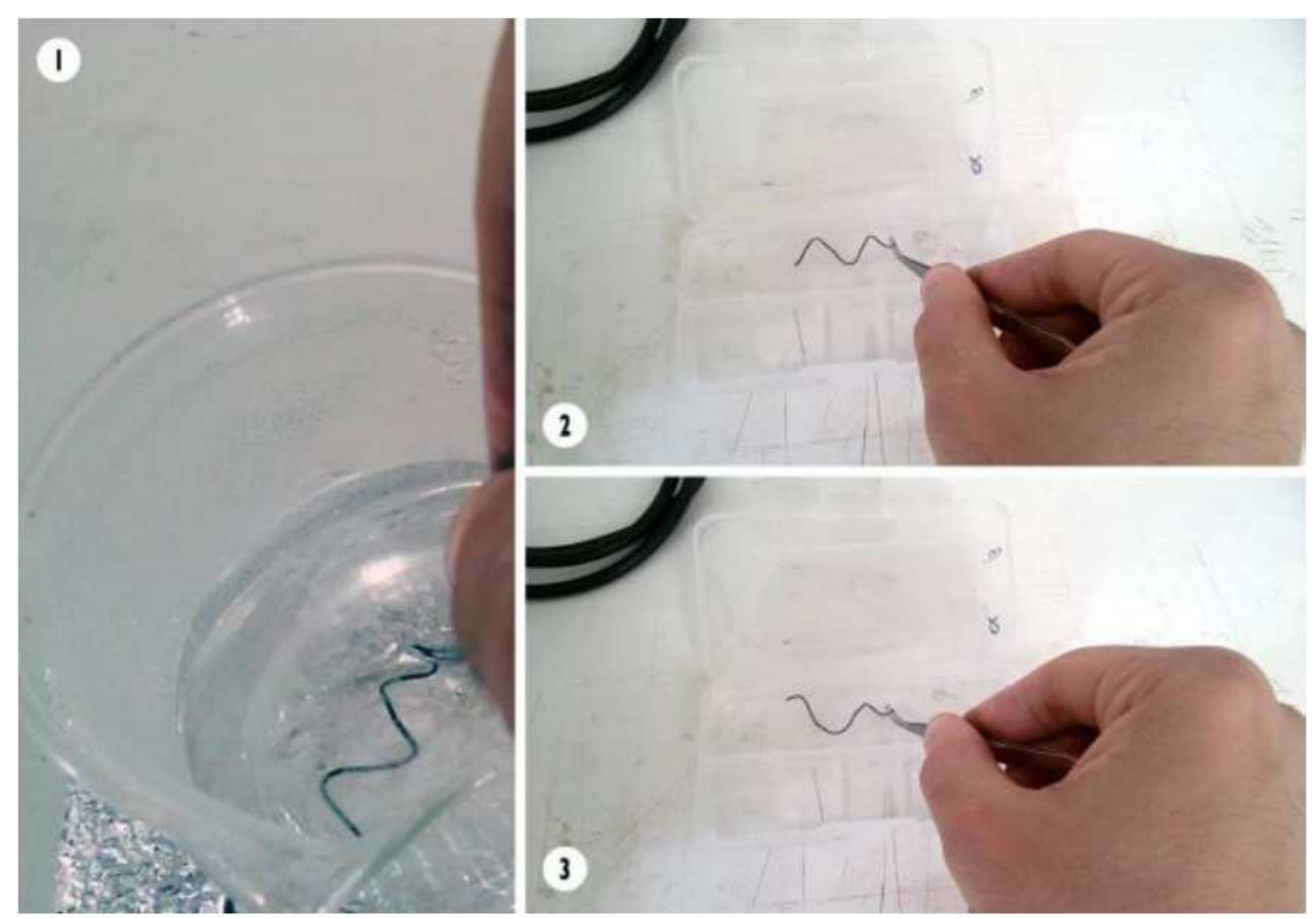

Fig. 36: Nitinol wire trained to have a two-way effect. The wire upon heating "remember" its austenitic shape (1) and upon cooling recovers its martensitic shape $(2,3)$

\section{Development of Industrial Applications}

According to one of the aims of the thesis to develop an industrial application and, in particular, a smart and adaptive shadow system that properly uses and exploits the advanced properties of SMAs, many kinds of design hypothesis have been considered and tested.

The goal has been to design an active shadow system that could be used for the thermal comfort of urban or indoor environments, able to valorize the unique property of SMAs to change their shape depending on the temperature (SME). Without the need to use expensive and complex mechanical system composed of many parts to assemble and characterized by higher cost of energy required for its functioning and its manufacturing.

In particular, the challenge for the application has been to develop a living and weather-responsive system, able to ensure the best thermal condition for any meteorological situation. To have a control on the system functioning, very important parameters to consider have been transition temperatures and forces generated by SMAs, thicknesses, weights, the structure of a system, materials used and their mechanical behavior.

An effort to design shapes and structures with a low aesthetic impact and a good integration with natural environment was made, too. In fact, for the system, the choice has been to take inspiration by nature, especially for its capacitance to be adaptive and to evolve in response to external stimuli, but also for its aspect characterized by organic and not linear shapes.

A significant source of inspiration has been the sensitive mimosa (mimosa pudica). A plant characterized by leaves that fold when touched. The principles that govern the plant behavior are still being investigated, but the most accepted hypothesis is that small mechanoreceptor cells on the underside of leaves respond to mechanical stimuli creating an electrical impulse propagation that results in leaves folding. Since plants do not have muscles, the movement occurs through hydraulic forces (flow of water), (Fig. 37).

For the smart shadow system developed the stimulus is the heat and not mechanical, but sensitive mimosa has been an important reference to developing an adaptive behavior, able to change in response to different external conditions.

Basically, the concept of the smart shadow system is to work as a shield for the sun rays when the weather is hot, increasing its size and providing bigger shadows, to not shield the sun rays when the weather is not hot, keeping its smallest size configuration. 

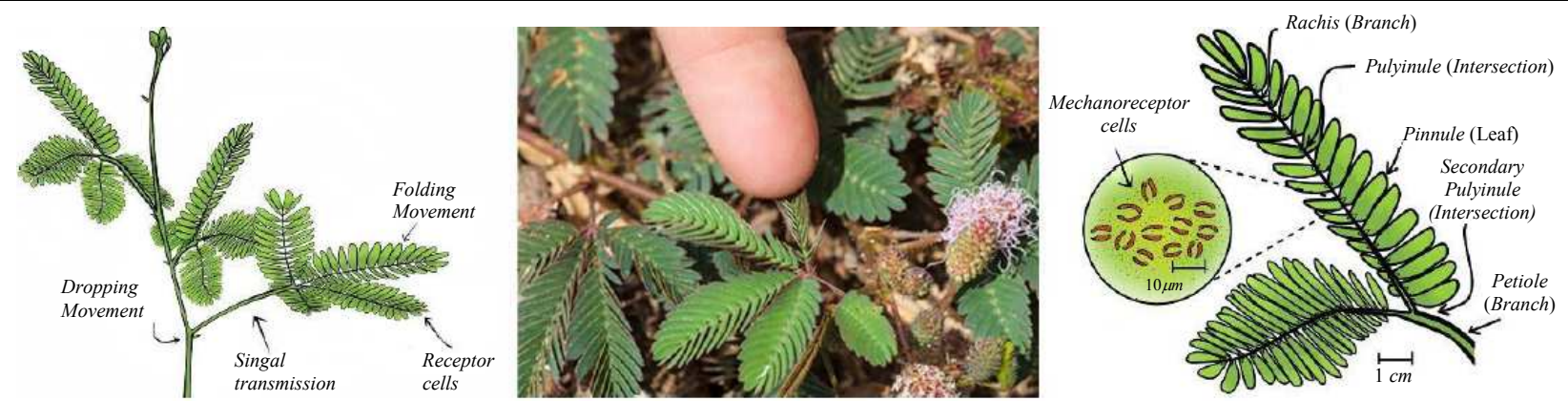

Fig. 37: Sensitive Mimosa. A plant characterized by different responses to touch. With a light touch, the leaves fold together along the rib. With a strong touch, they will fold and the branch will drop where the main branch (petiole) joins the stem.

The use of SMAs gives the possibility to have and remember preset shapes for different temperatures and obtain smart modules that don't need human input or external devices control to react to weather changes.

The main characterizing aspect of the smart shadow system is its programmed ability to be a living and selfsufficient organism.

\section{Design of Application}

In order to develop a system with the features mentioned in the previous paragraph, different solutions and design hypothesis have been considered and tested.

All the design choices and evolutions have been aimed to build a system where the use of SMA becomes an advantage and not a useless and unproductive effort, with a valorization of its advanced properties and the exploitation of its potentialities.

To get the expected results and in order to better know the thermo-mechanical behavior of SMA, many laboratory experimentations on SMA programming, strain capacity and forces generated have been carried out.

In particular Nitinol wires with a diameter of 0.75 $\mathrm{mm}$ and a Af temperature of $85^{\circ} \mathrm{C}$ have been programmed and used to test the two main design hypothesis developed, in both cases a module with the shape of a leaf and the capability to open when the weather is hot (shielding the sun rays) and close when the weather is cold (allowing to the sun rays the environment heating). In fact, the module can have two configurations, the closed or bent one when the Nitinol wire is in its martensitic range of temperature and the opened one when the wire is in its austenitic range of temperature. The advantage of this design option is to have one part, where the Nitinol wires are embedded in a rubber (silicone or polyurethane, for example).

In this case, at the beginning of manufacturing process, the wires are fixed inside the mold and only after this step the rubber is cast. The flexibility of the rubber gives the possibility to the module to strain and bend according to the programmed shapes of Nitinol wires used. Obviously, the process is reversible and both configurations (opened and closed) depend just on temperature. To obtain this behavior is only needed to use Nitinol wires programmed to have two-way Shape Memory Effect.

For this design, the solution is very important to have a deep control of parameters like geometry, thickness and weight of the rubber part, diameter, forces generated and transformation temperatures of SMA wires. To obtain the most proper functioning for this design solution the optimization of all these parameters is absolutely necessary.

For the second design option, another solution has been developed. In this case, there is the assembly of two parts, one manufactured with additive technologies, like Fused Deposition Modeling (FDM), to exploit the net shape capability of Additive Manufacturing (AM) and build several parts in one, without the use of any kind of external joints. In fact, in this case, in one part there is a hinge joint (it is in the middle and gives the possibility to the part to close and open) and a lever system that is assembled to SMA wires that changing their shapes allow to the leaf to take opened and closed configurations.

With this solution, the forces needed to change the shape of the module are lower and it is easier to programme in detail and with a good precision the shape for both configurations. On the other hand structure and geometry of the module are more complex to optimize and manufacture and there is the need to assemble different parts (Fig. 38).

A high control on parameters like diameter, forces generated and transformation temperatures of SMA wires is also in this case needed.

For the temperature control of SMA wires different heating methods have been considered:

- By passing an electrical current through the wire. This method is only applicable where a small diameter SMA wire is used, otherwise the electrical resistance is too small provide enough heating

- By passing an electrical current through a high resistance wire wrapped around SMA wire. In this case, the electrical wire needs to be electrically 
insulated, but the insulator should have a good thermal conductivity to let the heat flow the SMA wire

- by exposing the SMA wire to thermal radiation. An SMA wire exposed to the light of the sun can heat up to a temperature of $150^{\circ} \mathrm{C}$ or where it doesn't happen a system for a high concentration of solar light could be used. In this case, the system becomes selfsufficient, but the control on shape changes is lower than with a low voltage electrical activation (Fig 39)

\section{CAD Models Development}

CAD models have been the ground to virtually and physically test the two design options and every solution adopted for their development (Fig. 40).

As a solid modeler, in order to obtain information on weights, structures, to know their effects on functionality and get useful data to optimize the smart module, SolidWorks software has been used.

Both design options described in the previous paragraph have been developed through the use of CAD models. In one case, where the Nitinol wires are embedded in a rubber that gives the possibility to the module to strain and bend according to the programmed shapes of Nitinol wires used, basically, the 3D models have been utilized to simulate mechanical behavior of the composite module (rubber and SMA), to test system functioning and SMA integration within the module. In addition, $\mathrm{CAD}$ models have been necessary as a digital file to manufacture molds by $\mathrm{CNC}$ milling, where to cast liquid rubber, to obtain results for every evolutionary stage of application and physically test the part built-up (Fig. 40).

In the second case, for the design option wherein one part there is a hinge joint and a lever system that is assembled to SMA wires that changing their shapes allow to the leaf module to take opened and closed configurations, essentially the virtual 3D model has been fundamental for the additive manufacturing process of the smart shadow system, by which digital 3D design data, after a virtual slicing, are used to build up the component in layers by depositing materials (Fig. 41).
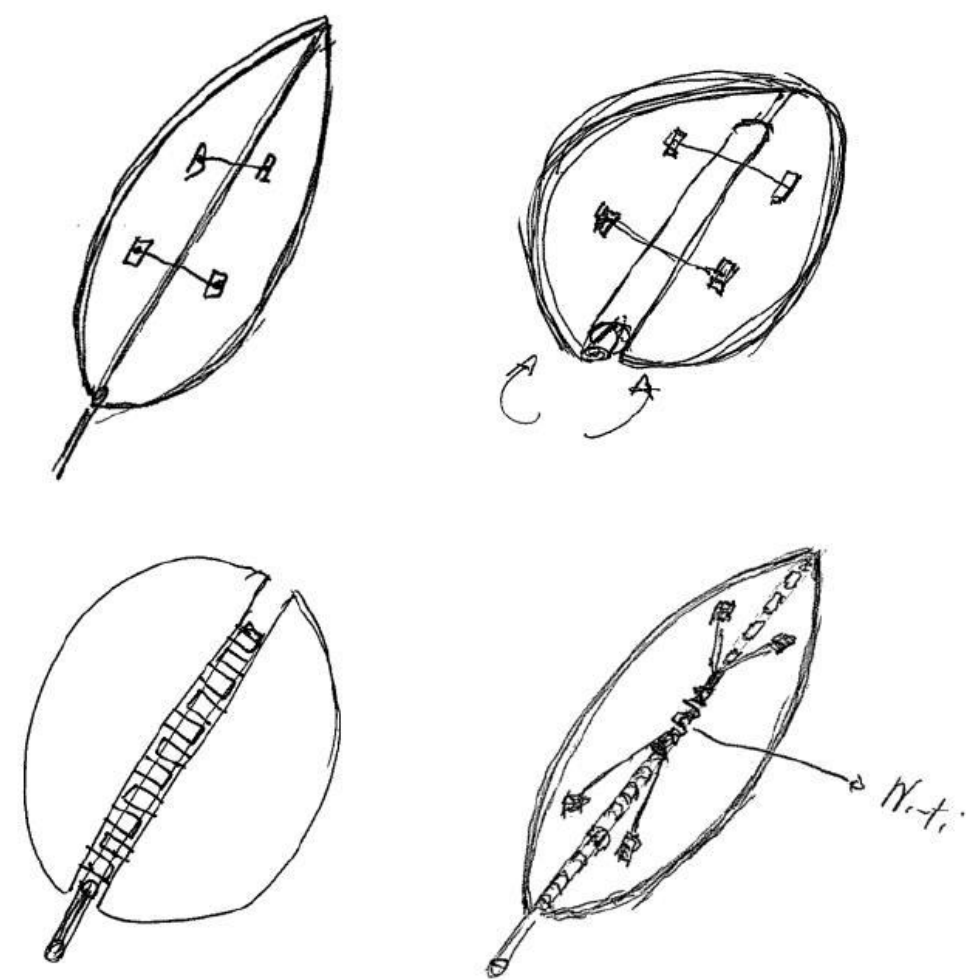

Fig. 38: Sketches of application
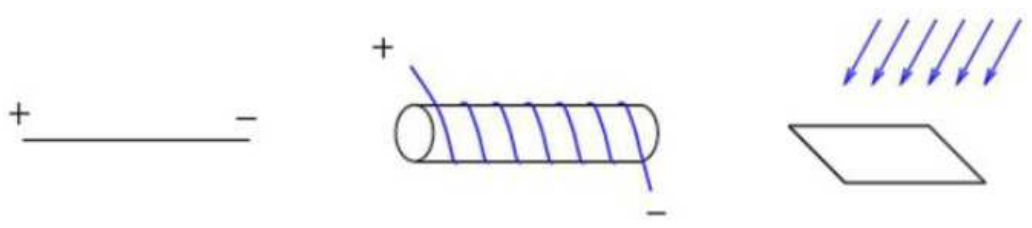

Fig. 39: Heating methods. (a) passing a current through; (b) external heating by conductive wire; (c) thermal radiation. 


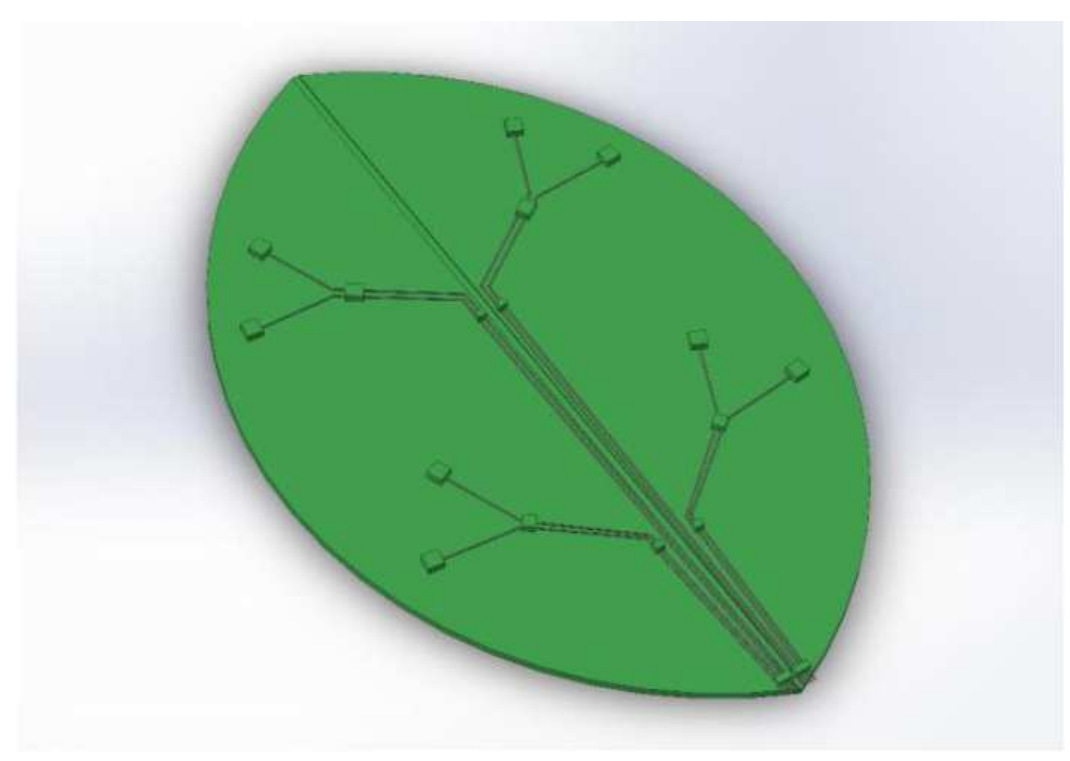

Fig. 40: Design option with SMA wires and silicone rubber

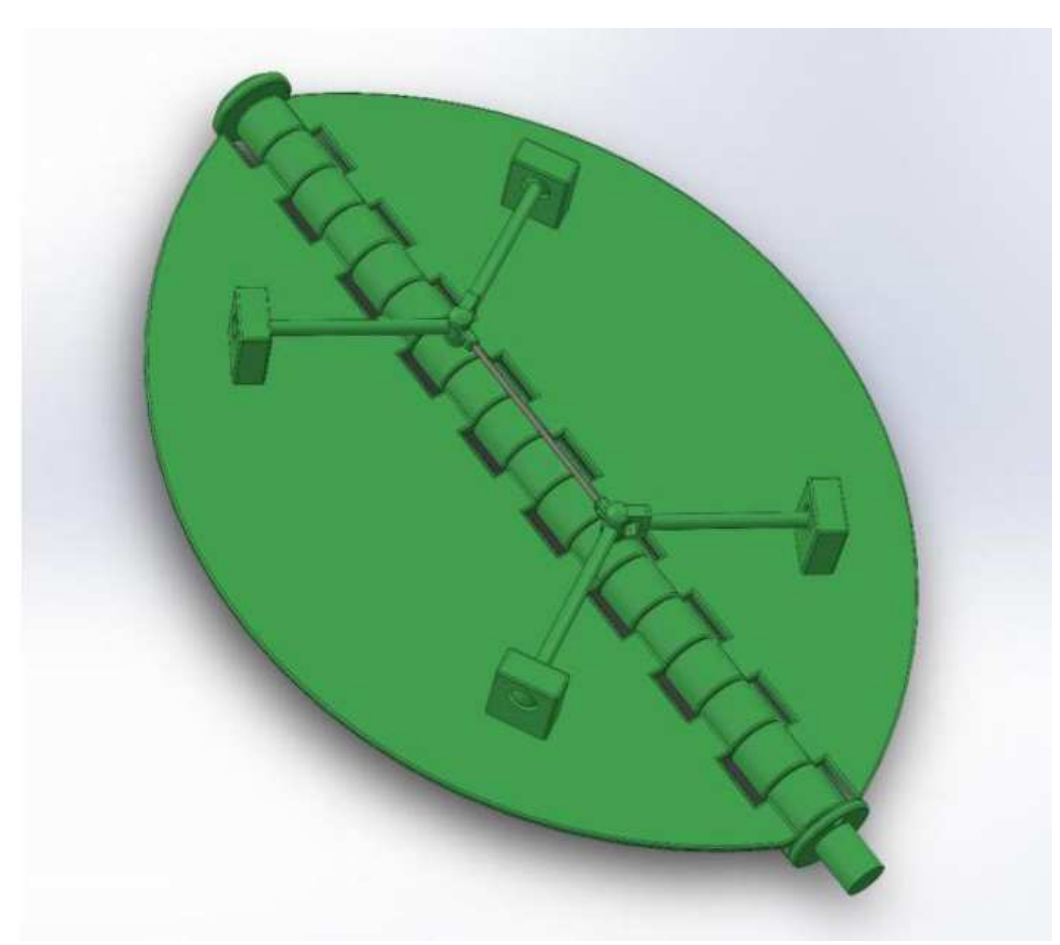

Fig. 41: Design option with 3D printed part assembled to SMA wire

In general, CAD software has been for the design development a flexible tool to immediately make modifications where needed, for design analysis, to increase creativity and productivity along the design process and to improve design quality.

In particular, for both design options CAD models have been the way to evaluate design choices, not only to show or prototype the final design but to develop it in term of functioning optimization, selection and use of material and process technology, size and structure of geometries and environment integration.

Moreover, CAD modeling has been a considerable instrument to simulate and better understand forces needed for a proper functioning of the smart shadow system, to predict its behavior, to have a support for a correct choice of SMA wires (selecting wires with a diameter suitable to produce a force high enough to open and close the smart leaf), to decide wires positioning and quantity. 


\section{Simulations}

Simulations tools have been very important to virtually test the system behavior, to predict the interaction between rubber part and SMA wires, with a particular focus on the loads needed to bend a fixed shape and thickness of rubber.

In particular, to test the design option where SMA wires are embedded in a rubber the add-in of SolidWorks named "SolidWorks Simulations" has been used. The add-in provides core simulation tools to test a design, eliminating the redundant tasks required with traditional analysis tools.

Specifically, the simulations aimed to have a support for the choice of the most suitable diameter of SMA wires to use and decide their quantity and positioning, have been performed with the SolidWorks simulation option named "static".

For every 3D model analyzed materials and their mechanical properties have been defined and then applied loads. As materials a silicone rubber has been utilized, where properties have an elastic modulus, Poisson ration, shear modulus, yield and tensile strength have been set. For the loads has been used, as a reference, a technical data sheet provided by "Dinalloy, Inc." for some flexinol wires, where forces generated by wires with different diameters are indicated. Flexinol is an SMA where the main constituents of alloyed are Nickel and Titanium (Fig. 42).

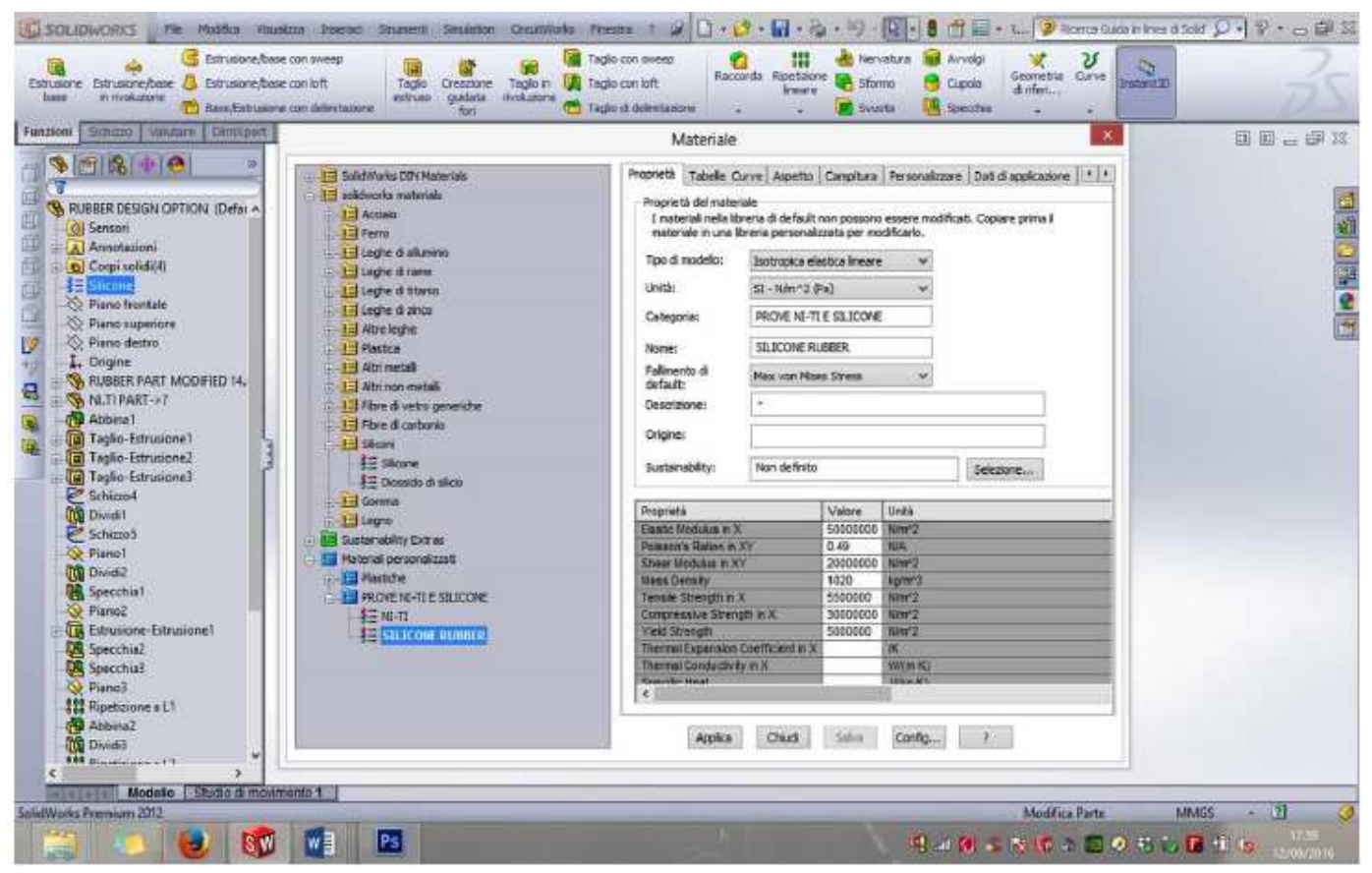

Fig. 42: Materials properties defined for silicone rubber

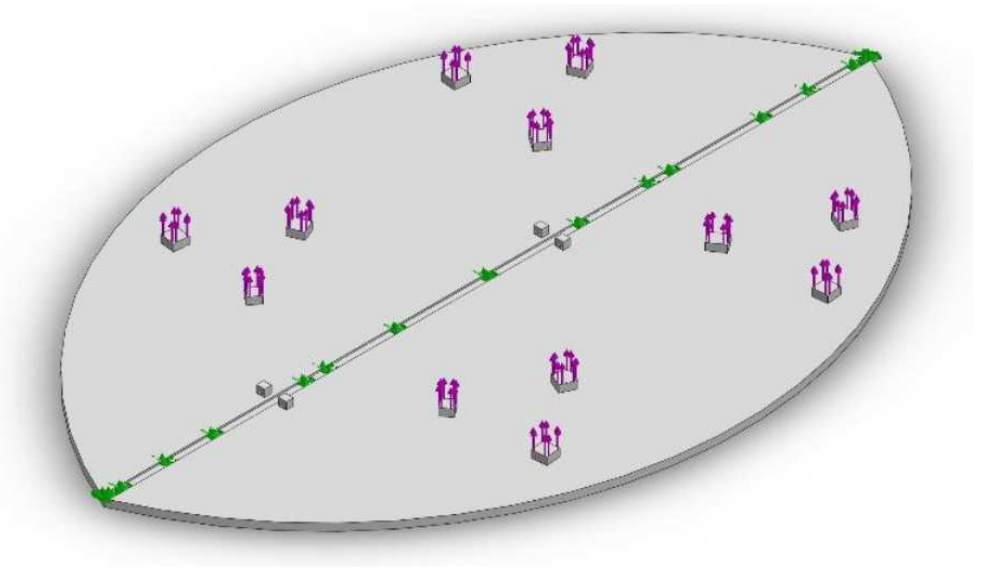

Fig. 43: Definition of loads and constraints positioning 
Many virtual simulations with different diameters for SMA wires and therefore different applied forces have been performed. All the test have been aimed to roughly know the system behavior and study range and distribution of forces required for a proper functioning of the smart shadow system (Fig. 43).

The results of simulations show that solutions with low thickness wires, but high distribution have a better performance of bending and thus of functioning. Moreover, the use of wires with a lower diameter gives advantages regarding SMA activation, in fact, heating and cooling both for thermal radiation or electrical current activated systems is faster and easier.

The simulations, in fact, demonstrate that for the design option where, for SMA wires distribution, there is a sort of reproduction of the typical veins that characterize the skeleton of the leaves, there is an optimization of smart shadow system functioning (Fig. 44-46).

For the second design option, wherein one part there is a hinge joint and a lever system assembled to SMA wires, in order to avoid interferences during the system working, motion analysis by SolidWorks have been performed (Fig. 47).

\section{Prototyping Experimentations and Possible Applications of Smart Module}

For the development of industrial application based on the use of SMAs and, in particular, on their SME ability, some prototyping experiments aimed to practically test design options and solution have been carried out.

For prototyping experiments, basically, the Nitinol wires, studied with the thermal analysis discussed in the third chapter, with a diameter of $0.75 \mathrm{~mm}$ and an Af temperature of $85^{\circ} \mathrm{C}$ have been programmed and used to test the two main design hypothesis developed.
For the first one, where the Nitinol wires are embedded in a silicone rubber, at the beginning of prototyping process, the wires are fixed inside the mold and only after this step the rubber is cast. The flexibility of the rubber gives the possibility to the part to strain and bend according to the preset shapes (programmed to have two-way Shape Memory Effect) of Nitinol wires used. CAD models, in this case, have been necessary as a digital file to manufacture molds by CNC milling or additive technology.

For this design solution, a silicone mold was used and, in order to avoid the polymer match between silicone of mold and silicone of casted part, a demolding agent (PVA, Polyvinyl Alcohol) has been used. Some prototyping experiments for the above-described design option are reported below (Fig. 48-49).

For the second design option, another prototyping experience has been developed. In this case, there is the assembly of two parts, one manufactured with Fused Deposition Modeling (FDM) additive technology, in order to exploit the net shape capability of AM.

In fact, in this case, in one part there is a hinge joint (it is in the middle and gives the possibility to the part to close and open) and a lever system that is assembled to an SMA wire that changing its shape allows to the leaf to take opened and closed configurations.

In this case, the virtual $3 \mathrm{D}$ model has been fundamental for the additive manufacturing process of the part, by which digital 3D design data, after a virtual slicing, are used to build up the component in layers by depositing materials.

Some prototyping experiments for this design option are reported below (Fig. 50).

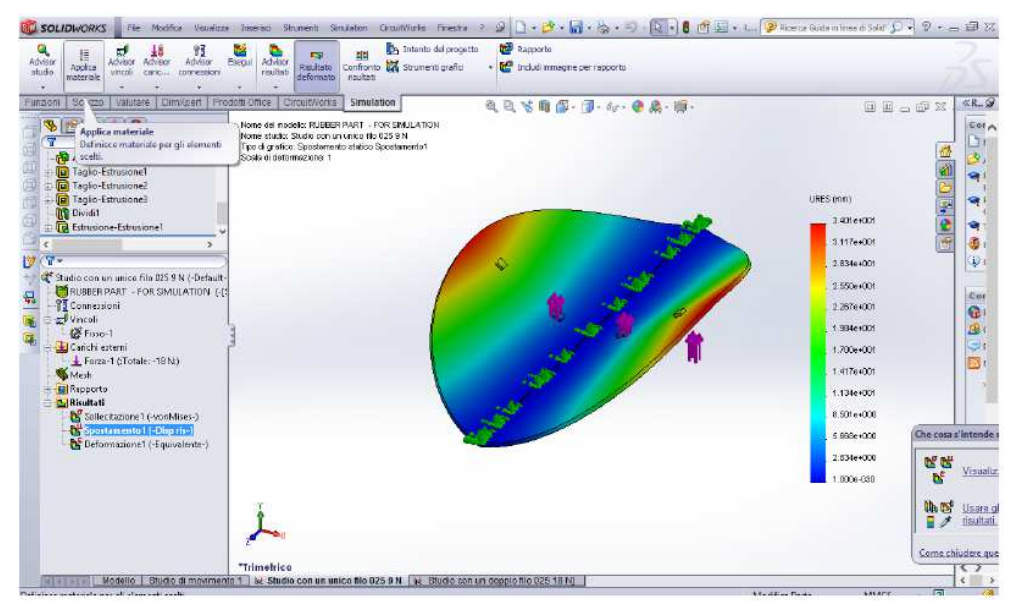

Fig. 44: Simulation, wire diameter $-0.25 \mathrm{~mm}$; number of wires -2 ; load applied $-9 \mathrm{~N}$ for side; maximum displacement $-34.0 \mathrm{~mm}$ 


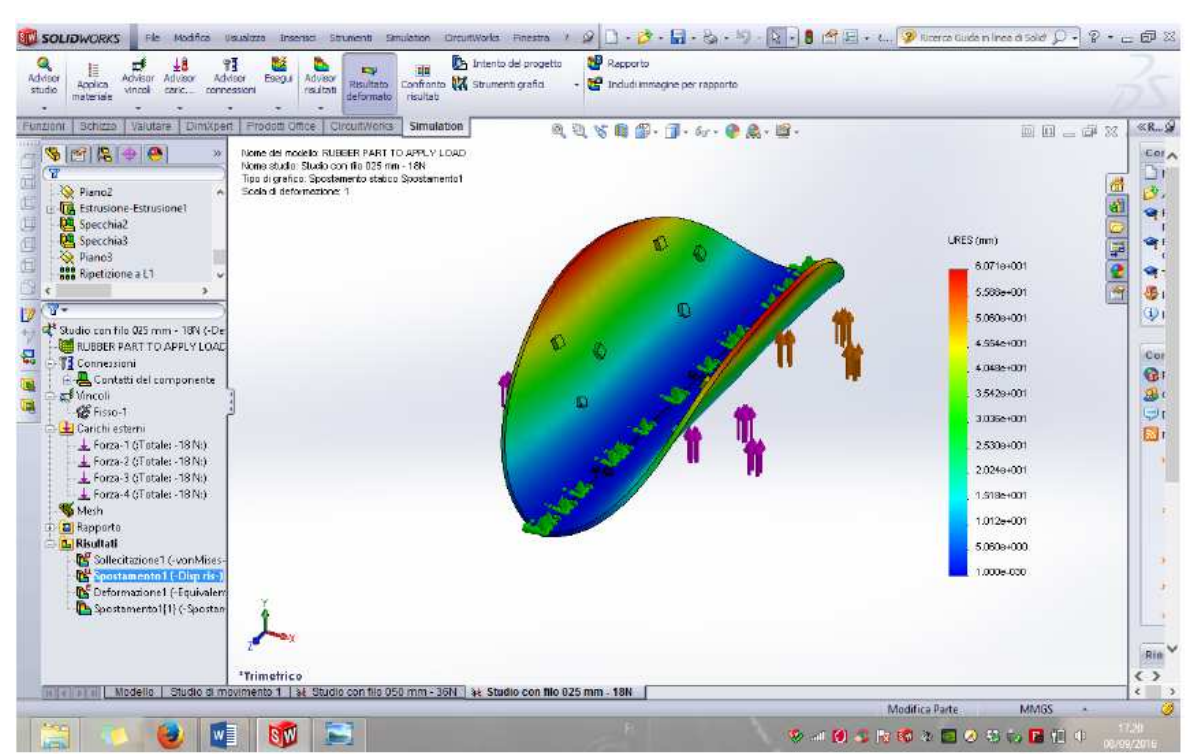

Fig. 45: Simulation, wire diameter - $0.25 \mathrm{~mm}$; number of wires -8 ; load applied - 36N for side; maximum displacement $-60.7 \mathrm{~mm}$

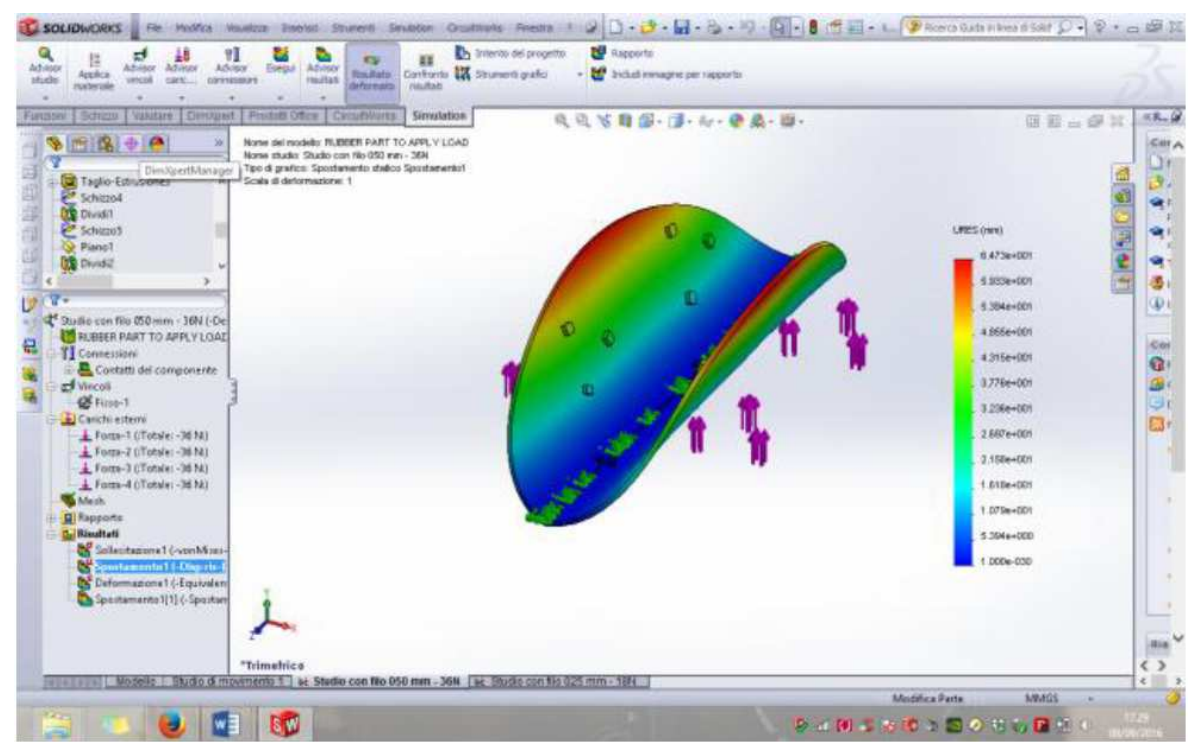

Fig. 46: Simulation, wire diameter - $0.50 \mathrm{~mm}$; number of wires -8 ; load applied - $72 \mathrm{~N}$ for side; maximum displacement $-64.7 \mathrm{~mm}$
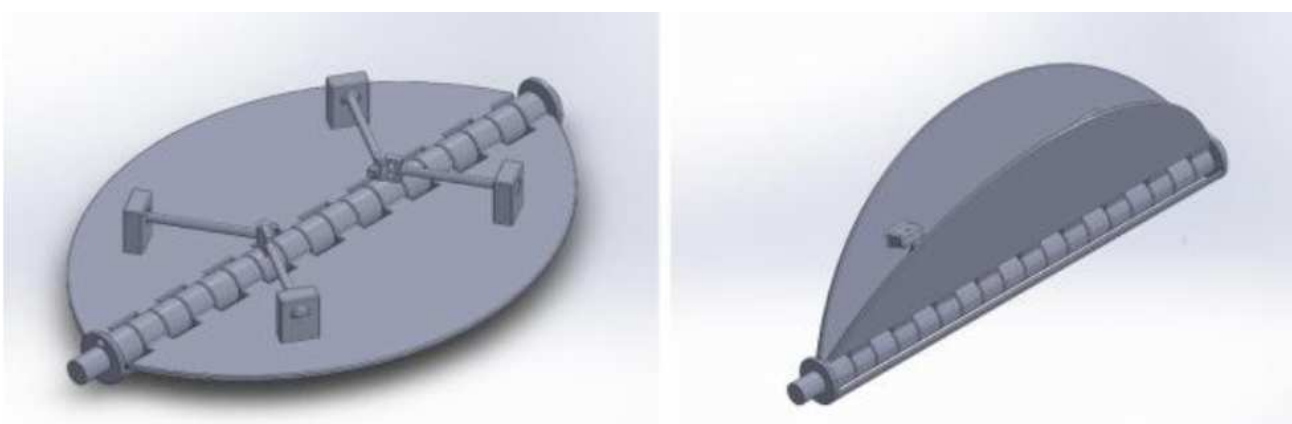

Fig. 47: Motion study performed for design option with 3D part assembled to SMA wire 

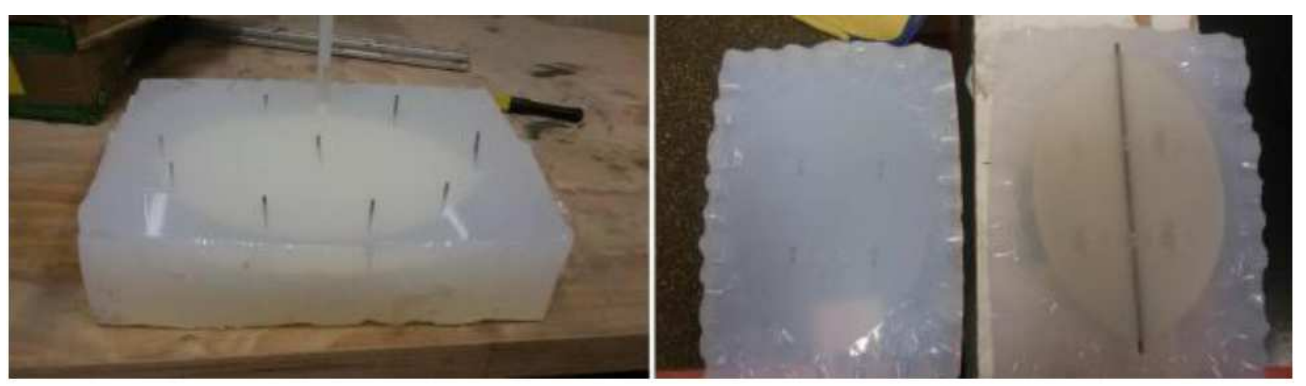

Fig. 48: A mold used for first design option experimented. Materials used: A mold of silicone, PVA demoulding agent, liquid silicone to cast

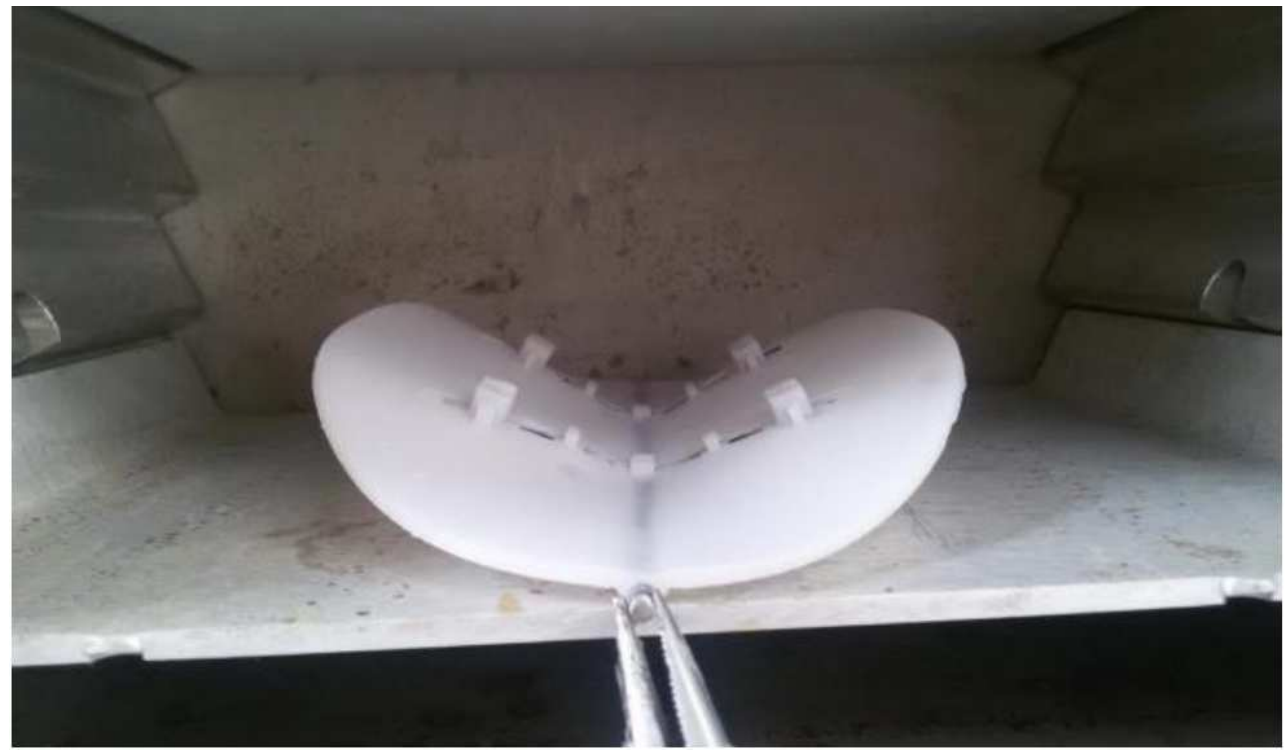

Fig. 49: Leaf module with 2 Nitinol wires $(0.75 \mathrm{~mm})$ embedded in silicone rubber. Heating up to Af $\left(85^{\circ} \mathrm{C}\right)$ the module bends. In this case only two wires are used, with a higher number and distribution the bending behavior can be increased
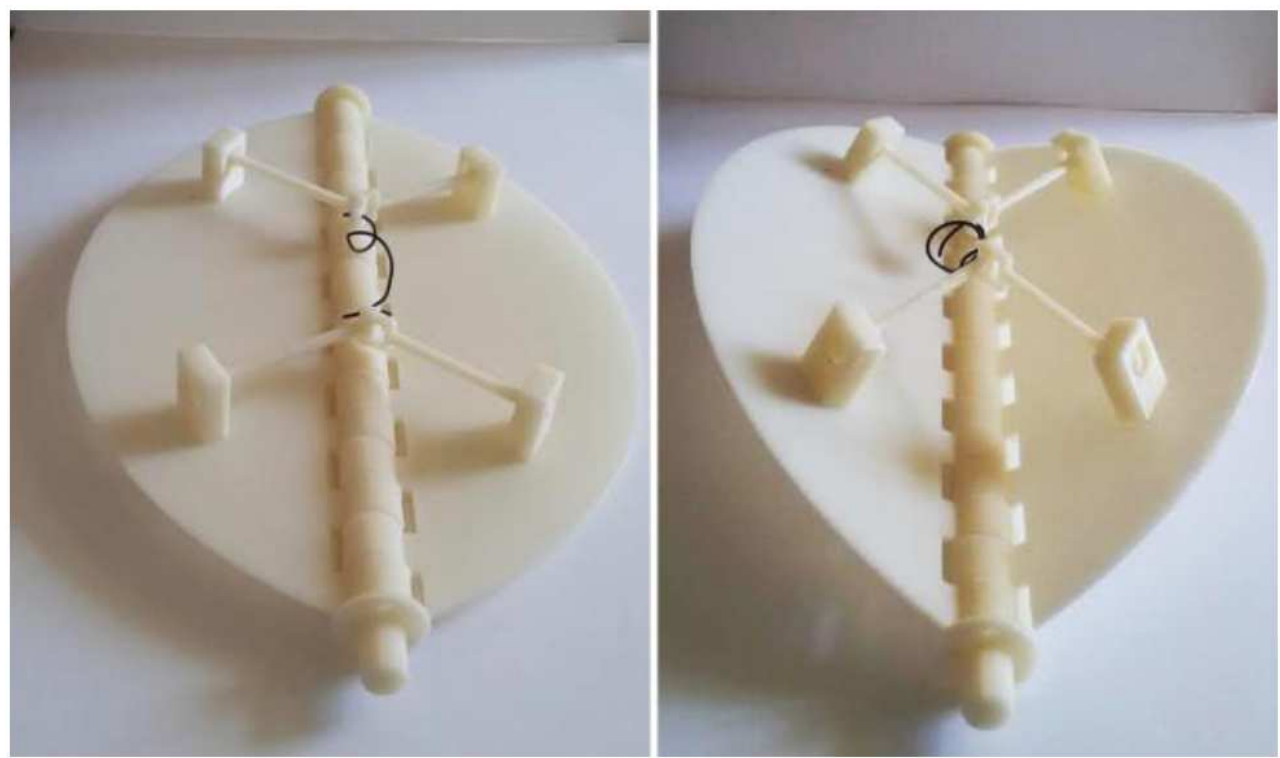

Fig. 50: Second design option with one spring of Nitinol assembled to a $3 \mathrm{D}$ printed part. The spring, increasing and decreasing its size, opens and closes the module 
Although the presented prototyping experience is still to implement and needs a further development, an integrated approach, by comparing the data collected with DSC thermal analysis, SolidWorks simulations of system behavior and prototyping experience, has been adopted in order get support during the design development.

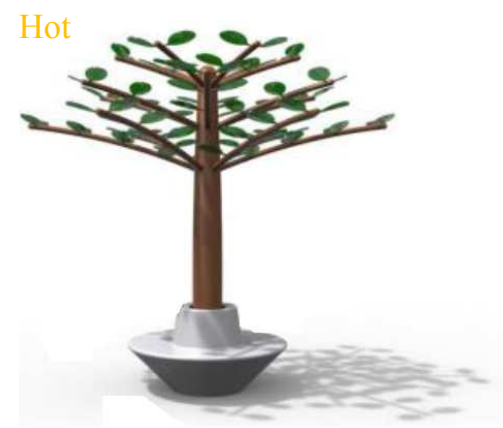

The information collected and the research activities carried out will be the ground for future developments.

Some potential application for the designed smart module, for urban or house window shielding, are shown below (Fig. 51-54).

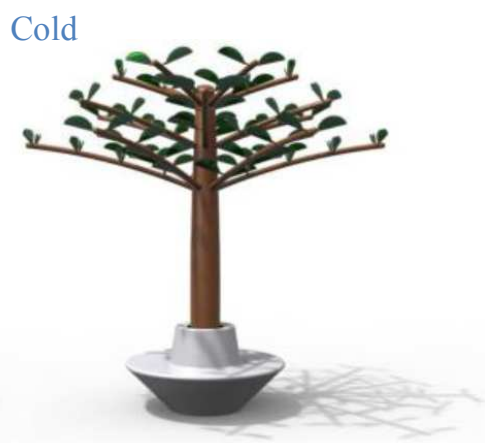

Fig. 51: Trees using Smart Shadow Leaves. On the left opened configuration, on the right closed configuration

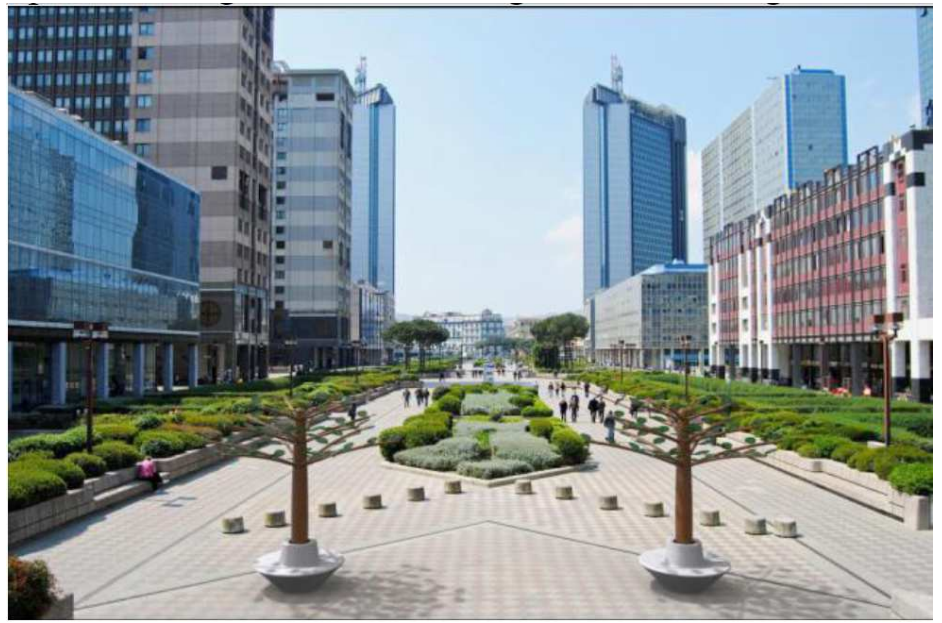

Fig. 52: Example of urban application of Smart Shade Trees

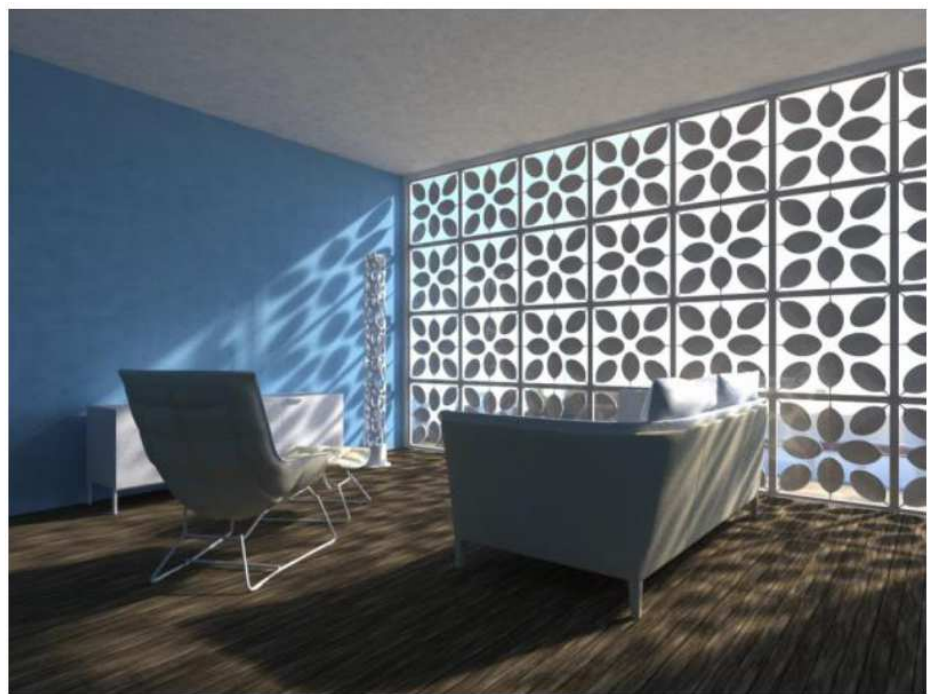

Fig. 53: Example of application of Smart Shadow Leaves for glass windows. Closed configuration (warm weather) 


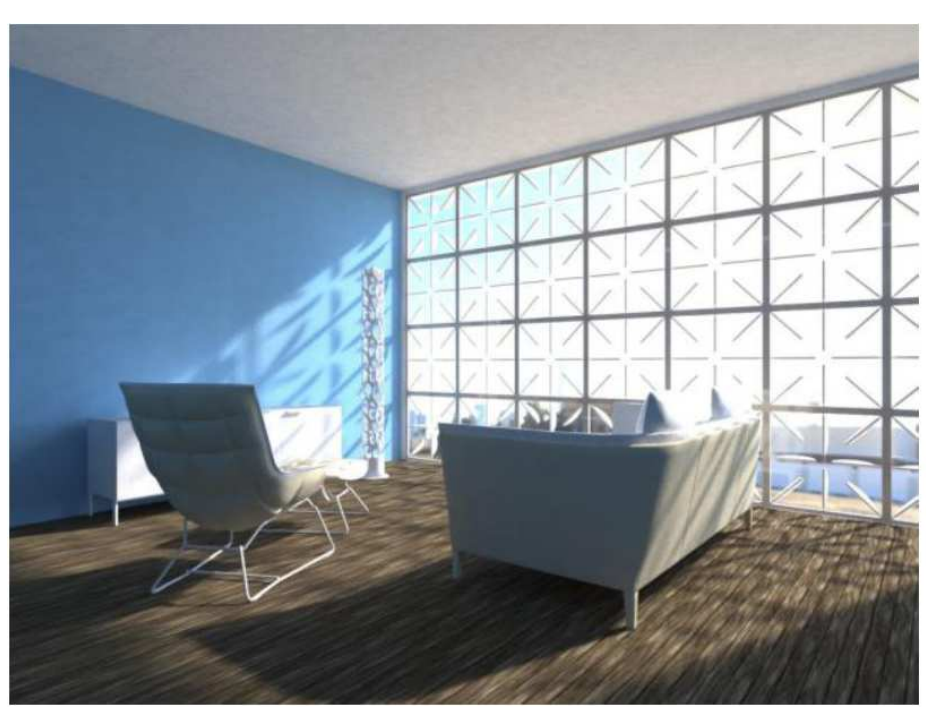

Fig. 54: Example of application of Smart Shadow Leaves for glass windows. Opened configuration (cold weather)

\section{Future Perspectives for Use of SMAs in Industrial Design Applications}

Considering the topics discussed in the previous paragraphs, the specific focus on industrial design applications and their evolution, study and experimentation of Shape Memory Alloys and the case study of a Smart Shadow System development, future outlooks for industrial design applications have been elaborated.

As described in the preceding paragraphs, nowadays SMAs are mainly used as a wire for thermal or electrical actuators. More advanced approaches, instead, to use SMAs, not only to open and close simple mechanisms or switch on and off a system, can be possible through a smart and combined use of material and advanced manufacturing technologies.

Three main way to get smarter applications of SMAs, exploring new and more complex solutions but with higher potentialities, have been identified.

One hypothesis regards smart composite materials containing thin Shape Memory Alloy wires. Tools for designing such materials are still far from being available, but simulation tools and an approach similar to that experimented for the paragraph entitled "simulation" of this thesis can help to roughly predict the behavior of a smart composite to develop. The major aspects to consider for the design of a Smart Composite with SMA wires embedded are the following:

- SMA wire selection and characterization

- Host material selection

- Development of manufacturing process for the production of composites with programmed SMA wires

- Analysis and modeling of the action of the SMA wires in the composite
- The contribution of the SMA-host material interface

The success of an SMA composite depends on the selection of a proper matrix and SMA wire combination. A good knowledge of the thermomechanical SMAbehaviour is fundamental to assist the selection process. The use of a thin well-adherent oxide surface layer on the SMA wires can provide the best adhesion and thus stress transfer. The SMA composite curing procedure, as well as the material fixing, have a great importance.

The use of programmed SMA wires to embed inside the matrix can be recommended in order to have an easy

training of wires and an easy handling for SMA composite manufacturing (often made by polymer casting process). Due to the possible presence of quite elevated temperature during SMA wires activation, it is of crucial importance that the $\mathrm{Tg}$ (glass transition) of the matrix is as high as possible and that the resin is fully cured. The temperature window in which an SMA composite can be used safely must be defined. Otherwise, composite degradation can appear during its utilization. The wire positioning, instead, should not have a strong influence (Fig. 55).

Another solution identified is to design novel materials or systems combining the use of SMAs with advanced technologies like Additive Manufacturing (AM).

Additive manufacturing, in fact, with its layer-bylayer fabrication approach allows the user, in contrast to traditional manufacturing techniques where there is the only access to the external surfaces of the part, to work on the entire volume of the part throughout the build process. This allows for the embedding of functional components and actuators to enable the fabrication of complex systems in a single process. 

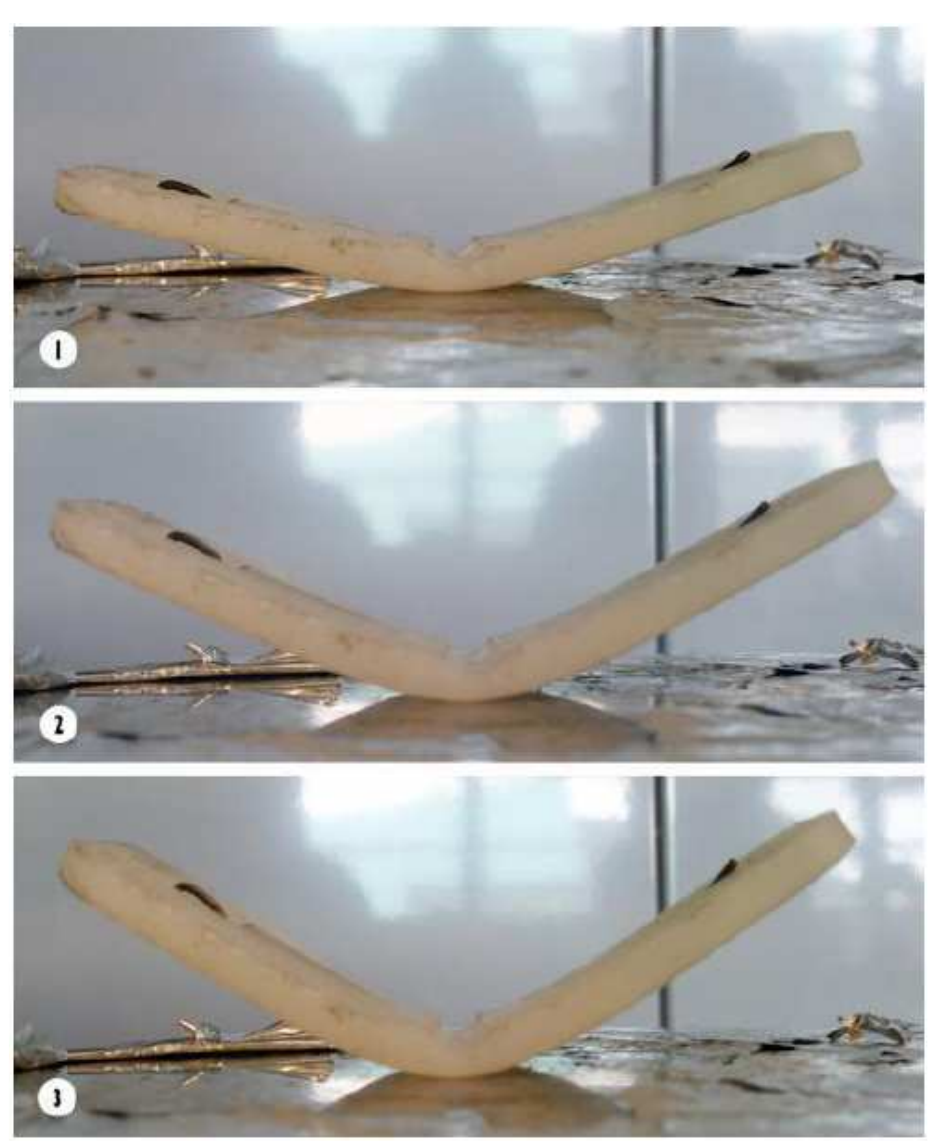

Fig. 55: Smart composite manufactured and experimented during the Smart Shadow System development. Nitinol wire embedded in silicone rubber. Heating up from (1) to (3)

A significant method for creating actuated joints via embedding SMAs with PolyJet additive technology, for instance, has been developed by N. A. Meisel, A, M. Elliot and C. B. Williams of Dream Lab (Virginia Tech, VA, USA). In particular, they have demonstrated embedding with PolyJet technology for actuation of a multi-material assembly and proposed a set of unified rules. PolyJet is a material jetting technique that utilizes drop-on-demand inkjet printing to selectively deposit droplets of photopolymer directly onto a build platform. Once a layer of droplets is deposited via inkjet print heads and a roller evens out the layer surface, two UV lights pass over the printed layer multiple times to cure the photopolymer. With PolyJet is also possible to use flexible and elastomeric materials and not only stiff materials. This is a condition that in some cases can be useful for embedded actuators.

Basically, the method proposed to embed foreign actuating components within PolyJet printed parts is composed of the following steps:

- Design guide channels or cavities to accommodate the SMA wire

- Design the fixation points to fix the ends of the SMA
- If necessary, design a shape converter (it is embedded with SMA) to ensure a level printing surface on top of the embedded object

- Pause the build and remove support material from the channels

- Secure the SMA to the designed fixation points, using UV-curable adhesive, if needed

- Place the shape converter (it is necessary to avoid the creation of support for the cavity where the wire is accommodated) on top of the embedded component, ensuring that its surface is flush with the printed part

- Resume the build

Some case studies for the application of this method have been reported (Fig. 56-57).

Another future perspective identified is the direct Additive Manufacturing of SMAs powders. Additive Manufacturing can allow, in fact, to build more complex parts than with the conventional manufacturing process existing for SMAs and to overcome the traditional shapes (wires, springs, plate sheets, tubes, etc.) that we find for these materials. 

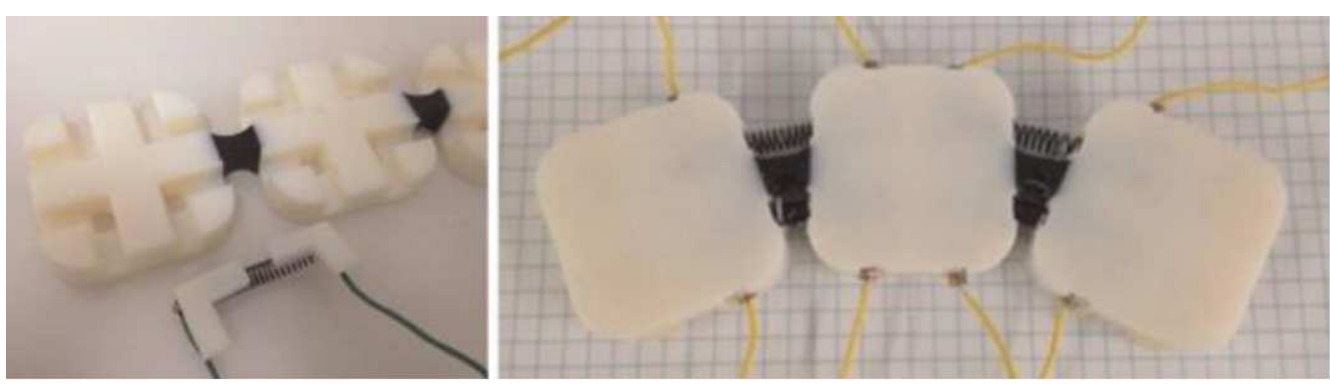

Fig. 56: Actuated joints(spring actuation) via embedding SMAs with PolyJet additive technology. Courtesy of Dream Lab, OH, USA
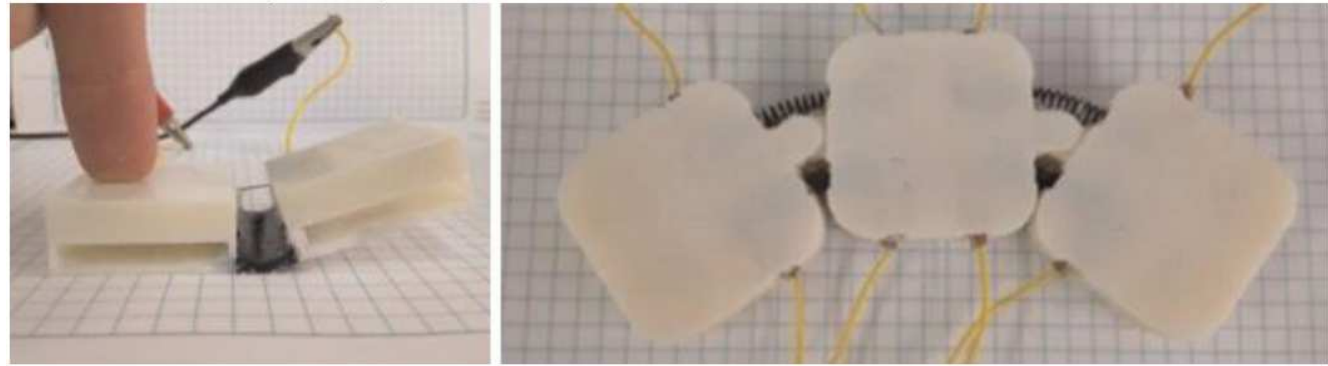

Fig. 57: Actuated joints(straight wire actuation on the left and pin joint use on the right) via embedding SMAs with PolyJet additive technology. Courtesy of Dream Lab, OH, USA

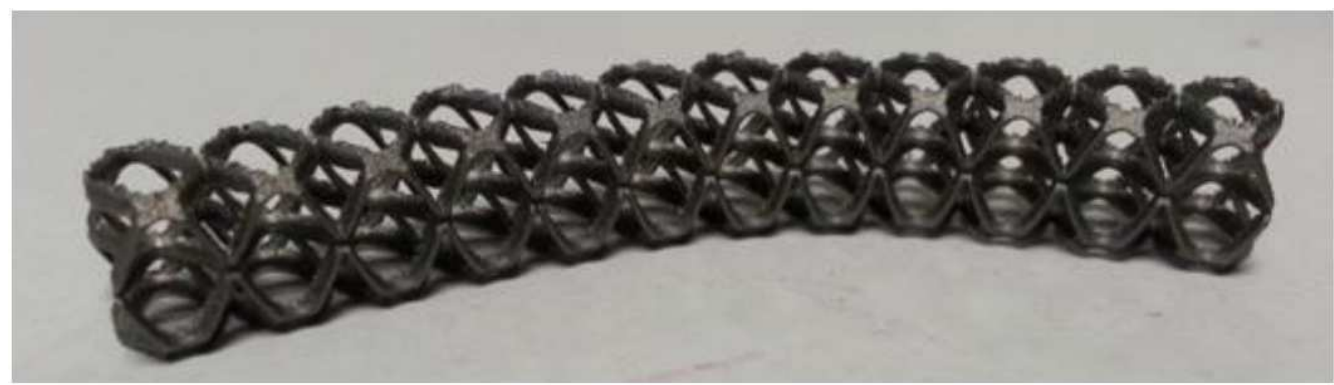

Fig. 58: Ni-Ti alloy manufactured with Selective Laser Melting technology. Courtesy of Dynamic and Smart Systems Lab (Toledo University, OH, USA)

Additive Manufacturing obviously offers a greater freedom of design and shape and can provide promising alternatives to conventional manufacturing processes. On the other hand, a careful control of process parameters is of great importance. In fact, for example, Nitinol transformation temperatures are dependent on and are extremely sensitive to, the relative concentrations of nickel and titanium. Alloys differing by one weight percent of $\mathrm{Ni}$ (or $\mathrm{Ti}$ ) concentration can have transformation temperatures that differ by $80 \mathrm{~K}$.

Therefore a low control on process parameters can affect also the functional properties of SMAs like shape memory and pseudoelasticity.

As claimed also by M. Andani, C. Haberland, J. Walker and M. Elahinia of Dynamic and Smart Systems Lab (Toledo University, OH, USA), that experimented the Selective Laser Melting (SLM) technology for Ni-Ti powders, it is crucial to adjust the process parameter setup in a way that dense material can be processed but the impurity pickup is kept to a minimum and the transformation temperatures are affected as little as possible. They show that SLM NiTi exhibits distinct functional properties like shape memory and pseudoelasticity which compares favorably with the properties of conventionally processed NiTi.

In general, many kinds of Additive Manufacturing technologies can experiment for SMA parts in order to enhance and enlarge the industrial applications range and build smarter and more complex systems. The challenge with these technologies will be to have a deep process control and keep the functional properties of SMAs like shape memory and pseudoelasticity (Fig. 58). Nowadays, the weak point for Additive Manufacturing of SMA parts, that needs to be studied and improved, is 
not too much related to structural properties such as density, impurity content and mechanical behavior, but to Shape Memory Effect and superelasticity (Arghavani et al., 2011; Auricchio, 2009; Auricchio et al., 2009; Darijani and Naghdabadi, 2010; Frick et al., 2005; Hohne et al., 2003; Haberland et al., 2014; Schrooten et al., 2002; Machado and Savi, 2003; Mustafa et al., 2015; Nicholas et al., 2014; Otsuka and Wayman, 1998; SchmidtMende and Reiss, 1991; Wayman and Duerig, 1988).

\section{Conclusion}

A shape memory alloy (also known as smart metal, metal memory, memory alloy, muscle wire, smart alloy) is an alloy that "remembers" its original shape and when it deforms, it returns to the preform when is heated. This material is an easy and solid alternative to conventional drive devices, such as hydraulic, pneumatic and engine systems. The form of memory alloy has applications in industries including automotive, aerospace, biomedical and robotics. The two main types of memory alloys are copper-aluminum-nickel and nickel-titanium alloys (NiTi), but SMAs can also be made with zinc, copper, gold and iron alloys. Although iron and copper based SMAs such as Fe- $\mathrm{Mn}-\mathrm{Si}, \mathrm{Cu}-\mathrm{Zn}-\mathrm{Al}$ and $\mathrm{Cu}-\mathrm{Al}-\mathrm{Ni}$ are commercially available and cheaper than NiTi, NiTi-based SMAs are preferred for most applications due to stability, thermo-mechanical performance. SMA can exist in two different phases, with three different crystalline structures (eg martensite twinned, martensite detwinned and austenite and six possible transformations.

The research presented provides an overview of the existing relationship between Smart Materials and Industrial Design. Commonly the use of Smart Materials is widespread for advanced fields of application like aeronautics, military and biomedical, for example. It happens sometimes because of high costs associated with these materials or their manufacturability, sometimes because of a lack of a suitable method and approach to carrying out technology transfer and use of Smart Materials for Industrial Design field, where the demand for product smarter, more active and adaptive is progressively higher.

In general, the work presented provides, using case studies, an example of a method to manage technology transfer of Smart Materials, adopting an approach where concurrently different aspects that go from material science to process technology, simulations tools and creativity are considered.

In particular, instead, if we focus on material studied and case study developed, it is possible to notice that, although the Smart Shadow System is not completely engineered and other evolutionary steps for it are possible, the experience related to its development suggested future outlooks for SMA use in industrial design applications.
In fact, three main way to get smarter applications, exploring new and more complex solutions but with higher potentialities, have been identified.

The first is related to the design smart composite materials containing thin Shape Memory Alloy wires. In this case simulation tools and an approach similar to that experimented for the paragraph entitled "simulation" of the thesis can help to roughly predict the behavior of a smart composite that embeds SMAs in a polymeric matrix.

The major aspects to consider to design Smart Composite incorporating SMAs are the following:

- SMA selection and characterization

- Host material selection

- Development of a proper manufacturing process

- Analysis and modeling of the action of the SMA in the composite

- A contribution of the SMA-host material interface

Moreover, due to the possible presence of quite elevated temperature during SMA activation, it is absolutely important that the Tg (glass transition) of the matrix is as high as possible to withstand the temperature needed for SMA activation.

The second solution identified is, instead, to design novel materials or systems combining the use of SMAs with advanced technologies like AM (Additive Manufacturing). In particular, this option allows embedding functional components inside 3D manufactured parts providing the possibility to build complex systems in a single process.

A significant method experimented, as discussed in the previous chapter, has been developed by N. A. Meisel, A, M. Elliot and C. B. Williams of Dream Lab (Virginia Tech, VA, USA).

Finally, the last opportunity identified is the direct Additive Manufacturing of SMAs powders. Additive Manufacturing, in fact, can allow to build more complex parts than with the conventional manufacturing process existing for SMAs and to overcome the traditional shapes (wires, springs, plate sheets, tubes, etc.) that we find for these materials on market. Additive Manufacturing obviously can provide promising alternatives to conventional manufacturing processes, but new developments to obtain a higher control on concentrations of the metals alloyed in SMAs are necessary. In fact, a low control can affect functional properties like SME and pseudoelasticity, thus the challenge for the success of this solution will be to improve the control of process parameters.

\section{Acknowledgement}

The Authors acknowledge Liquid Metals Technologies Inc, Ca USA that kindly supplies the 
samples for the characterization and Dream Laboratory (Virginia Tech, VA, USA).

\section{Funding Information}

This research has been funded by Italian Ministry of University and Research project FIRB Future in Research 2008, project RBFR08T83J.

\section{Author's Contributions}

All the authors contributed equally to prepare, develop and carry out this manuscript.

\section{Ethics}

This article is original and contains unpublished material. Authors declare that are not ethical issues and no conflict of interest that may arise after the publication of this manuscript.

\section{References}

Arghavani, J., F. Auricchio, R. Naghdabadi and A. Reali, 2011. An improved, fully symmetric, finitestrain phenomenological constitutive model for shape memory alloys. Finite Elements Anal. Design, 47: 166-174. DOI: 10.1016/j.finel.2010.09.001

Auricchio, F., 2009. Shape memory alloys - applications, micromechanics, macromodelling and numerical simulatios, University of California, Berkeley.

Auricchio, F., A. Reali and U. Stefanelli, 2009. A macroscopic $1 \mathrm{~d}$ model for shape memory alloys including asymmetric behaviors and transformationdependent elastic properties. Comput. Methods Applied Mechan. Eng. 198: 1631-1637.

Aversa, R., F.I.T. Petrescu, R.V. Petrescu, and A. Apicella, 2016a. Biomimetic FEA bone modeling for customized hybrid biological prostheses development. Am. J. Applied Sci., 13: 1060-1067. DOI: 10.3844/ajassp.2016.1060.1067

Aversa, R., F.I.T. Petrescu, R.V. Petrescu and A. Apicella, 2016b. Biofidel FEA modeling of customized hybrid biological hip joint prostheses, Part I: Biomechanical behavior of implanted femur. Am. J. Biochem. Biotechnol., 12: 270-276. DOI: 10.3844/ajbbsp.2016.270.276

Aversa, R., F.I.T. Petrescu, R.V.V. Petrescu, and A. Apicella, 2016c. Biomimetic finite element analysis bone modeling for customized hybrid biological prostheses development. Am. J. Applied Sci., 13: 1060-1067. DOI: 10.3844/ajassp.2016.1060.1067

Aversa, R., D. Parcesepe, R.V. Petrescu, G. Chen and F.I.T. Petrescu et al., 2016d. Glassy amorphous metal injection molded induced morphological defects. Am. J. Applied Sci., 13: 1476-1482. DOI: 10.3844/ajassp.2016.1476.1482
Aversa, R., R.V. Petrescu, F.I.T. Petrescu and A. Apicella, 2016e. Smart-factory: Optimization and process control of composite centrifuged pipes. Am. J. Applied Sci., 13: 1330-1341. DOI: 10.3844/ajassp.2016.1330.1341

Aversa, R., F. Tamburrino, R.V. Petrescu, F.I.T. Petrescu and M. Artur et al., $2016 \mathrm{f}$. Biomechanically inspired shape memory effect machines driven by muscle like acting NiTi alloys. Am. J. Applied Sci., 13: 1264-1271. DOI: 10.3844/ajassp.2016.1264.1271

Aversa, R., F.I.T. Petrescu, R.V.V. Petrescu, and A. Apicella, 2016g. Flexible stem trabecular prostheses. Am. J. Eng. Applied Sci., 9: 1213-1221. DOI: 10.3844/ajeassp.2016.1213.1221

Aversa, R., R.V.V. Petrescu, A. Antonio and F.I.T. Petrescu, 2016h. Physiologic human fluids and swelling behavior of hydrophilic biocompatible hybrid ceramo-polymeric materials. Am. J. Eng. Applied Sci., 9: 962-972. DOI: 10.3844/ajeassp.2016.962.972

Aversa, R., R. Sorrentino and A. Apicella, 2016i. Biomechanically active ceramic-polymeric hybrid scaffolds for tissue engineering. Proceedings of the International Conference on Biological Sciences and Technology, (BST' 16), Atlantis Press, pp: 308-318.

Aversa, R., R.V.V. Petrescu A. Apicella and F.I.T. Petrescu, 2017a. Nano-diamond hybrid materials for structural biomedical application. Am. J. Biochem. Biotechnol., 13: 34-41.

Aversa, R., D. Parcesepe, R.V. Petrescu, F. Berto and G. Chen et al., 2017b. Processability of bulk metallic glasses. Am. J. Applied Sci., 14: 294-301. DOI: 10.3844/ajassp.2017.294.301

Aversa, R., R.V. Petrescu, A. Apicella and F.I.T. Petrescu, 2017c. Modern transportation and photovoltaic energy for urban ecotourism. Transylvanian Rev. Administrat. Sci., 13: 5-20. DOI: 10.24193/tras.SI2017.1

Aversa, R., RV. Petrescu, F.I.T. Petrescu and A. Apicella, 2018. Nanodiamond for structural biomimetic scaffolds. MSCE, 6: 6-17. DOI: $10.4236 / \mathrm{msce} .2018 .64002$

Biewener, A.A. and T.J. Roberts, 2000. Muscle and tendon contributions to force, work and elastic energy savings: A comparative perspective. Exerc. Sport Sci. Rev., 28: 99-107.

Darijani, H. and R. Naghdabadi, 2010. Constitutive modeling of solids at finite deformation using a second-order stress-strain relation. Int. J. Eng. Sci., 48: 223-236.

Duerig, T.W., 1990. Engineering Aspects of Shape Memory Alloys. 1st Edn., Butterworth-Heinemann, London, England. 
Frick, C.P., A.M. Ortega, J. Tyber, A.El.M. Maksound and H.J. Maier et al., 2005. Thermal processing of polycrystalline NiTi shape memory alloys. Mater. Sci. Eng. A, 405: 34-49.

DOI: $10.1016 /$ j.msea.2005.05.102

Haberland, C., M.W. Elahinia, J.M.H. Meier and J. Frenzel, 2014. On the development of high quality NiTi shape memory and pseudoelastic parts by additive manufacturing. Smart Mater. Structures.

Hanlon, J.E., S.R. Butler and R.J. Wasilewski, 1967. Effect of martensitic transformation on the electrical and magnetic properties of NiTi. Trans. Metallurgical Society AIME, 239: 1323-1327.

Harrison, J.D. and D.E. Hodgson, 1975. Use of TiNi in Mechanical and Electrical Connectors. In: Shape Memory Effects in Alloys, Perkins, J. (Ed.), Plenum Press, N.Y.

Hohne, G.W.H., W. Hemminger and H.J. Flammersheim, 2003. Differential Scanning Calorimetry: An Introduction for Practitioners. 2nd Ed., Springer-Verlag, Berlin.

Huang, X., G.J. Ackland and K.M. Rabe, 2003. Crystal structures and shape-memory behaviour of NiTi. Nature Mater., 2: 307-311: DOI: 10.1038/nmat884

Kauffman, G. and I. Mayo, 1993. Memory metal. Chem. Matters, 381: 1-2.

Knowles, K.M. and D.A. Smith, 1981. The crystallography of the martensitic transformation in equiatomic nickeltitanium. Acta Metall., 29: 101-110.

DOI: 10.1016/0001-6160(81)90091-2

Kus, K. and T. Breczko, 2010. DSC-investigations of the effect of annealing temperature on the phase transformation behaviour in $\mathrm{Ni}-\mathrm{Ti}$ shape memory alloy. Mater. Phys. Mechan., 9: 75-83

Lahoz, R. and J.A. Puértolas, 2004. Training and twoway shape memory in NiTi alloys: influence on thermal parameters. J. Alloys Compounds.

Lindstedt, S., 2016. Skeletal muscle tissue in movement and health: Positives and negatives. J. Experi. Biol., 219: 183-188.

Machado, L. and M. Savi, 2003. Medical applications of shape memory alloys. Brazilian J. Med. Biol. Res., 36: 683-691.

Matsumoto, O., S. Miyazaki, K. Otsuka and H. Tamura, 1987. Crystallography of martensitic transformation in $\mathrm{Ti} \cdot \mathrm{Ni}$ single crystals. Acta Metallurgica, 35: 2137-2144. DOI: 10.1016/0001-6160(87)90042-3

Meisel, N.A., A.M. Elliott and C.B. Williams, 2014. A procedure for creating actuated joints via embedding shape memory alloys in PolyJet 3D printing. J. Intelligent Mate. Syst. Structures. DOI: $10.1177 / 1045389 X 14544144$

Melton, K.N. and O. Mercier, 1980. The mechanical properties of NiTi-based shape memory alloys. Acta Metallurgica, 29: 393-398.

DOI: 10.1016/0001-6160(81)90165-6
Mirsayar, M.M., V.A. Joneidi, R.V. Petrescu, F.I.T. Petrescu and F. Berto, 2017. Extended MTSN criterion for fracture analysis of soda lime glass. Eng. Fracture Mechan., 178: 50-59.

DOI: $10.1016 /$ j.engfracmech.2017.04.018

Miyazaki, S., S. Kimura, K. Otsuka and Y. Suzuki, 1984. The habit plane and transformation strains associated with the martensitic transformation in TiNi single crystals. Scripta Metall., 18: 883-888. DOI: 10.1016/0036-9748(84)90254-0

Mustafa, O.G., M.Z. Bilira and B.H. Gürcümb, 2015. Shape-memory applications in textile design. Proc. Soc. Behav. Sci., 195: 2160-2169.

Naresh, C., P.S.C. Bose and C.S.P. Rao, 2016, Shape memory alloys: A state of art review. IOP Conf. Mater. Sci. Eng., 149: 1-14.

Nicholas, A.M., A.M. Elliott and C.B. Williams, 2014. A procedure for creating actuated joints via embedding shape memory alloys in PolyJet 3D printing. J. Intelligent Mater. Syst. Structures. DOI: $10.1177 / 1045389 X 14544144$

Nikolaev, V.I., S.A. Pul'nev, G.A. Malygin, V.V. Shpeizman and S.P. Nikanorov, 2008. Generation and relaxation of reactive stresses in a $\mathrm{Cu}-\mathrm{Al}-\mathrm{Ni}$ shape memory alloy upon cyclic temperature variation in the range $293-800$ K. Phys. Solid State, 50: 2170-2174. DOI: 10.1134/S1063783408110279

Otsuka, K., T. Sawamura and K. Shimizu, 1971. Crystal structure and internal defects of equiatomic TiNi martensite. Phys. Stat. Solid, 5: 457-470.

Otsuka, K. and X. Ren, 1999. Recent developments in the research of shape memory alloys. Intermetallics, 7: 511-528. DOI: 10.1016/S0966-9795(98)00070-3

Otsuka, K. and C.M. Wayman, 1998. Shape Memory Materials. 1st Edn., Cambridge University Press, Cambridge.

Otsuka, K., C.M. Wayman, K. Nakay, H. Sakamoto and K. Shimizu, 1976. Superelasticity effects and stressinduced martensitic transformations in $\mathrm{CuAlNi}$ alloys. Acta Metallurgica, 24: 207-226.

Petrescu, FIT., E. Buzea, L. Nănuţ, M. Neacşa and C. Nan, 2015. The role of antioxidants in slowing aging of skin in a human, analele univers. Craiova Biol. Horticultura Tehnol. Prel. Prod. Agric. Ing. Med., 20: 567-574.

Petrescu, R.V., R. Aversa, A. Apicella, S. Li and G. Chen et al., 2016a. Something about electron dimension. Am. J. Applied Sci., 13: 1272-1276.

Petrescu, R.V., R. Aversa, A. Apicella, F. Berto and S. Li et al., 2016b. Ecosphere protection through green energy. Am. J. Applied Sci., 13: 1027-1032.

Petrescu, F.I.T., A. Apicella, RV. Petrescu, S.P Kozaitis and R.B. Bucinell et al., 2016c. Environmental protection through nuclear energy. Am. J. Applied Sci., 13: 941-946. 
Petrescu, F.I.T. and J.K. Calautit, 2016a. About nano fusion and dynamic fusion. Am. J. Applied Sci., 13: 261-266.

Petrescu, F.I.T. and J.K. Calautit, 2016b. About the light dimensions. Am. J. Applied Sci., 13: 321-325.

Pittaccio, S., L. Garavaglia, C. Ceriotti and F. Passaretti, 2015. Applications of shape memory alloys for neurology and neuromuscular rehabilitation. J. Funct. Biomater., 6: 328-344. DOI: $10.3390 / \mathrm{jfb} 6020328$

Priadko, A.I., V.I. Nikolaev, S.A. Pulnev, S.I. Stepanov and A.V. Rogov et al., 2017. Shape memory $\mathrm{Cu}-$ Al-Ni single crystals for application in rotary actuators. Mater. Phys. Mechan., 32: 83-87.

Schmidt-Mende, P. and H.G. Reiss, 1991. Design of actuating elements made of shape memory alloys. J. Phys. IV, 1: 175-180.

Schrooten, J., V. Michaud, J. Parthenios, G.C. Psarras and C. Galiotis et al., 2002. Progress on composites with embedded shape memory alloywires. Mater. Trans., 43: 961-973.

Shaw, J.A., C.B. Churchill and M.A. Iadicola, 2008. Tips and tricks for characterizing shape memory alloy wire: Part 1 - differential scanning calorimetry and basic phenomena. Society Experi. Mechan. DOI: $10.1111 / \mathrm{j} .1747-1567.2008 .00410 . \mathrm{x}$

Šittner, P., L. Heller, C.C Pilch, A. Thiery and D. Favier, 2014. Young's modulus of austenite and martensite phases in superelastic NiTi wires. J. Mater. Eng. Performance, 23: 2303-2314. DOI: $10.1007 / \mathrm{s} 11665-014-0976-\mathrm{X}$

Sofla, A.Y.N., D.M. Elzey and H.N.G. Wadley, 2008. Two-way antagonistic shape actuation based on the one-way shape memory effect. J. Intelligent Mater. Syst. Structures, 19: 1017-1027.

Tamburrino, F., 2016. Advanced manufacturing for novel materials in industrial design applications, development of a smart and adaptive shadow system using SMAs. Ph.D. Thesis, Italy.
Van Humbeeck, J., 2010. Introduction to shape memory alloys. Proceedings of the School and Symposium on Smart Structural Systems Technologies (SST' 10), Porto, Portugal, pp: 3-23.

Velázquez, R. and E.E. Pissaloux, 2012, Modelling and temperature control of shape memory alloys with fast electrical heating. Int. J. Mechan. Control.

Viscuso, S. and S. Pittaccio, 2012. Design and implementation of a portable a magnetic shape memory rotary actuator. J. Intell. Mater. Syst. Struct., 24: 454-472.

Wayman, C.M. and T.W. Duerig, 1988. An Introduction to Martensite and Shape Memory. In: Engineering Aspects of Shape Memory Alloys, Duerig, T.W. (Ed.), Butterworth-Heinemann, pp; 3-20.

Xiangyang, H., J. Graeme, Ackland and K.M. Rabe, 2003. Crystal structures and shape-memory behaviour of NiTi. Nature Mater., 2: 307-311. DOI: $10.1038 /$ nmat884

Yang, J.H. and C.M. Wayman, 1992. Self-accomodation and shape memory mechanism of $\varepsilon$-martensite-I. Experimental observations. Mater. Characterizat., 28: 23-35.

Yang, H.Z., X.G. Duan and H. Deng, 2013. A study on the force distribution for artificial antagonistic muscles. Mechan. Mater., 278-280: 105-110.

Ziólkowski, A., 2012. On analysis of DSC curves for characterization of intrinsic properties of NiTi shape memory alloys. Proceedings of the 12th International Symposium on Physics of Materials, Sept. 4-8, Prague.

\section{Source of Figures}

Tamburrino, 2016. 